Centre for Atmospheric Sciences Indian Institute of Technology Delhi New Delhi, India

\title{
Climate Change and Disease Simulation
}

\section{Somnath Jha}

\section{Presented as Guest Lecture in:}

Central Advanced Faculty Training (CAFT) Programme

Indian Council of Agricultural Research (ICAR)

(CAFT programme by Ministry of Agriculture, Govt. of India)

Venue: Division of Plant Pathology, I.A.R.I.

New Delhi 12, India

Dated: October 31 ${ }^{\text {st }}, 2011$ 


\section{Introduction}

- Presently working in Asia Risk Centre, RMS Risk Management Solutions India, Noida, ڤั India (period from Aug,2011-present)

年 RMSI Pvt Ltd., Noida, India (period from Oct, 2010- Jul,2011)

PhD in Atmospheric Sciences, Indian Institute of Technology Delhi, New Delhi (period from 2005-thesis submission process is going on)

Post Graduate in Agricultural Physics in Indian Agricultural Research Institute (I.A.R.I.), New Delhi, India (period from 2003-2005)

Lectures delivered here are the part of the jobs done in various phases of Career in

- Centre for Atmospheric Sciences, Indian Institute of Technology Delhi

- Asia Risk Centre, RMS Risk Management Solutions India

- RMSI Pvt Ltd 

of Nature of Works in

Asia Risk Centre, My Present Affiliation 


\section{Asia Risk Centre - Mission}

- Models and schemes for risk catastrophe risk mitigation the Bottom of the Pyramid (BOP)

- Natural and man-made catastrophe

- Impact of Climate Changes on their life, health and livelihood.

Work with all the stake holders in the risk transfer eco space (impacted populations, governments, insurers/reinsurers, brokers and financial markets)

- Catalyst for all the stake holders to develop solutions and help them implement such solutions for the protection of civil societies.

- Solutions based on a solid business proposition and not based on philanthropy or Corporate Social responsibility (CSR) concepts.

- "Solving the problem and challenge at hand" also benefit from implementing the developed solutions. 


\section{Asia Risk Centre - Vision}

- Global leader in helping risk mitigation and management challenges in Asia

- Agriculture risk,

- Food safety and micro-insurance domains through global insurance/reinsurance strategies and modern risk management tools

- Risk mitigation strategies that also impact on sovereign risk and global food supply/demand landscape

- Thought leader in these domains to governments, insurers, reinsurers, brokers and those who are at risk 


\section{Asia Risk Centre - Affiliate of RMS}

- Capability and capacity for most robust solutions

- ARC operations - three campuses

- California - solutions architecture

- Singapore - pan Asian business development

- India - model and software development 


\section{ARC - Crop Insurance Risk, India, China, Mozambique}

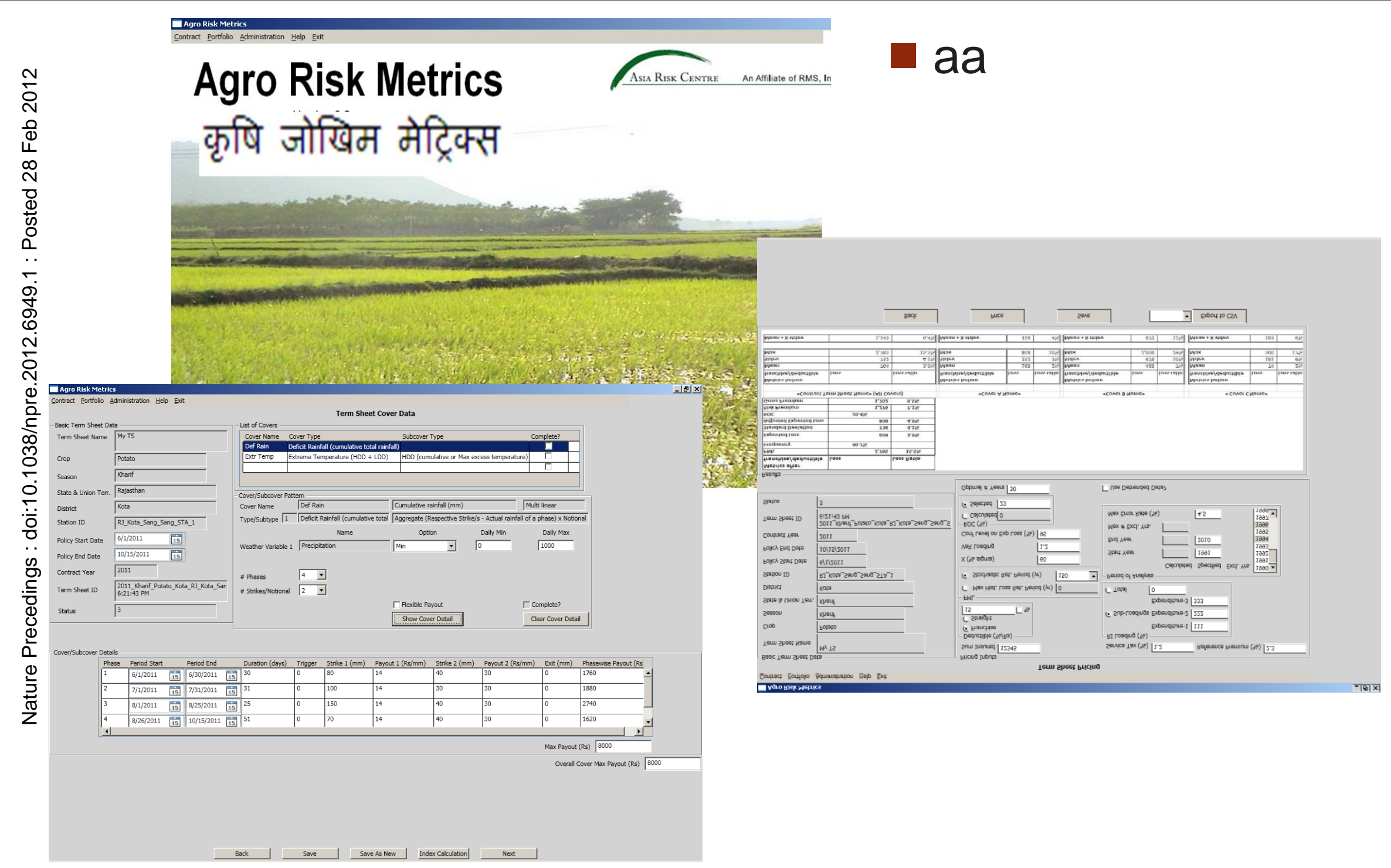




\section{Contents}

- Part1: Few Climate Change Impacts and Factors

- Part2: Description of State-of-the-science Climate Simulation Tools

- Part3: Introductory description of Regional climate model (i.e. Dynamic Downscaling)

- Part4: Disease Simulation

- Regional Climate Model Coupled Mango Powdery Mildew Simulation

- Pandemic Dengue Simulation under future climate scenario 


\section{Part One}

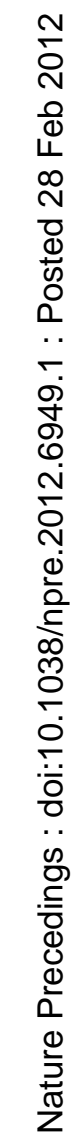

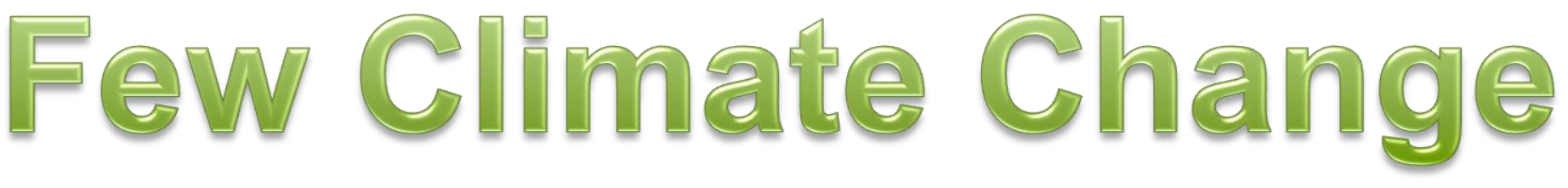

Impacts \& Factors

Acknowledgement: My works cited in this part have been accomplished during my research in Indian Institute of Technology Delhi in

collaboration with Indian Agricultural Research Institute, New Delhi 


\section{Earth : The Only Planet with Life}

Mars

Thin atmosphere

(Almost all $\mathrm{CO}_{2}$ in ground)

Average temperature : $-\mathbf{5 0} 0^{\circ} \mathrm{C}$

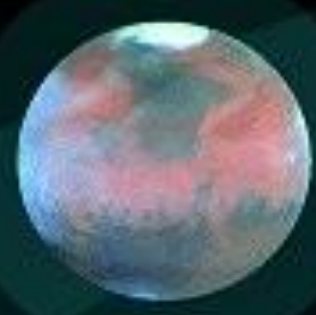

GRID (Q)

Arendal tît:

GAAPHIC BEGION FHUPPE REXUCEMCZ

\section{Planets and atmospheres}

Earth

$0,03 \%$ of $\mathrm{CO}_{2}$ in the atmosphere

Average temperature : $+15^{\circ} \mathrm{C}$
Venus

Thick atmosphere

containing $96 \%$ of $\mathrm{CO}_{2}$

Average temperature : $+420^{\circ} \mathrm{C}$ 


\section{Global Climate Change}

$\Delta \mathrm{T}$ over the 20th century............ $+0.6 \pm 0.2^{\circ} \mathrm{C}$

Rate of $\Delta T$ increase since $1950 \ldots . .$. $+0.17^{\circ} \mathrm{C} /$ decade

Sea level rise over 20th century..... $+0.1-0.2$ m

Change in precipitation............ $\quad+0.5-$ $1 \% / d e c a d e$

Extreme events..................... $\quad+2-4 \%$ ..........IPCC (2001) 


\section{Climate Change Prediction Uncertainty}

Major Causes are

- Anthropogenic Activity (Deforestation mainly)

- Unpredicting Teleconnection Pattern (EI Nino \& Southern Oscillation (ENSO) activity, Indian Ocean Dipole etc) 


\section{Role of SST: El Nino \& Southern Oscillation}

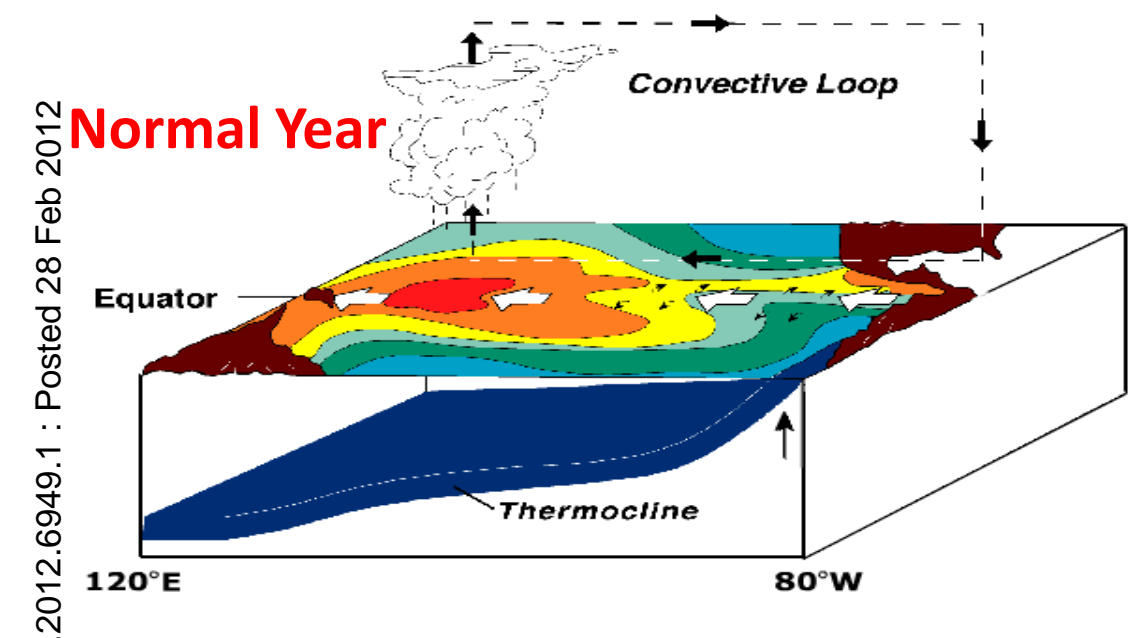

- El Nino \& Southern Oscillation (ENSO)

- Various Southern Oscillation Indices; SOI, SOI-EQ, Nino3 etc

El Nino Year

La Nina

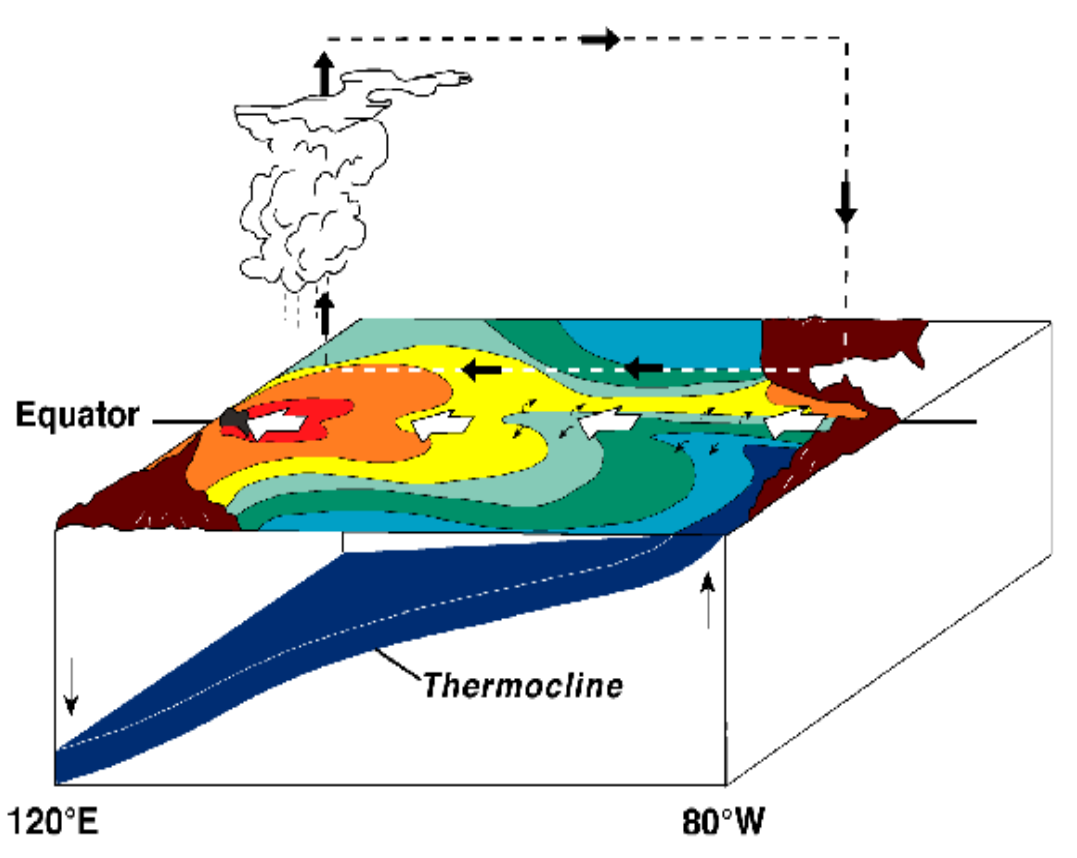




\section{Effect of High ENSO Index on Global Precipitation Pattern}

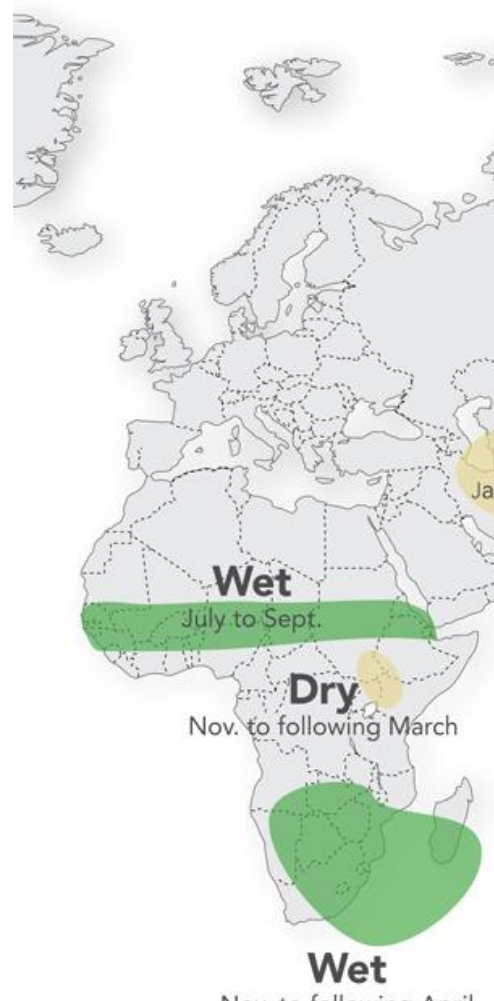

Nov. to following April
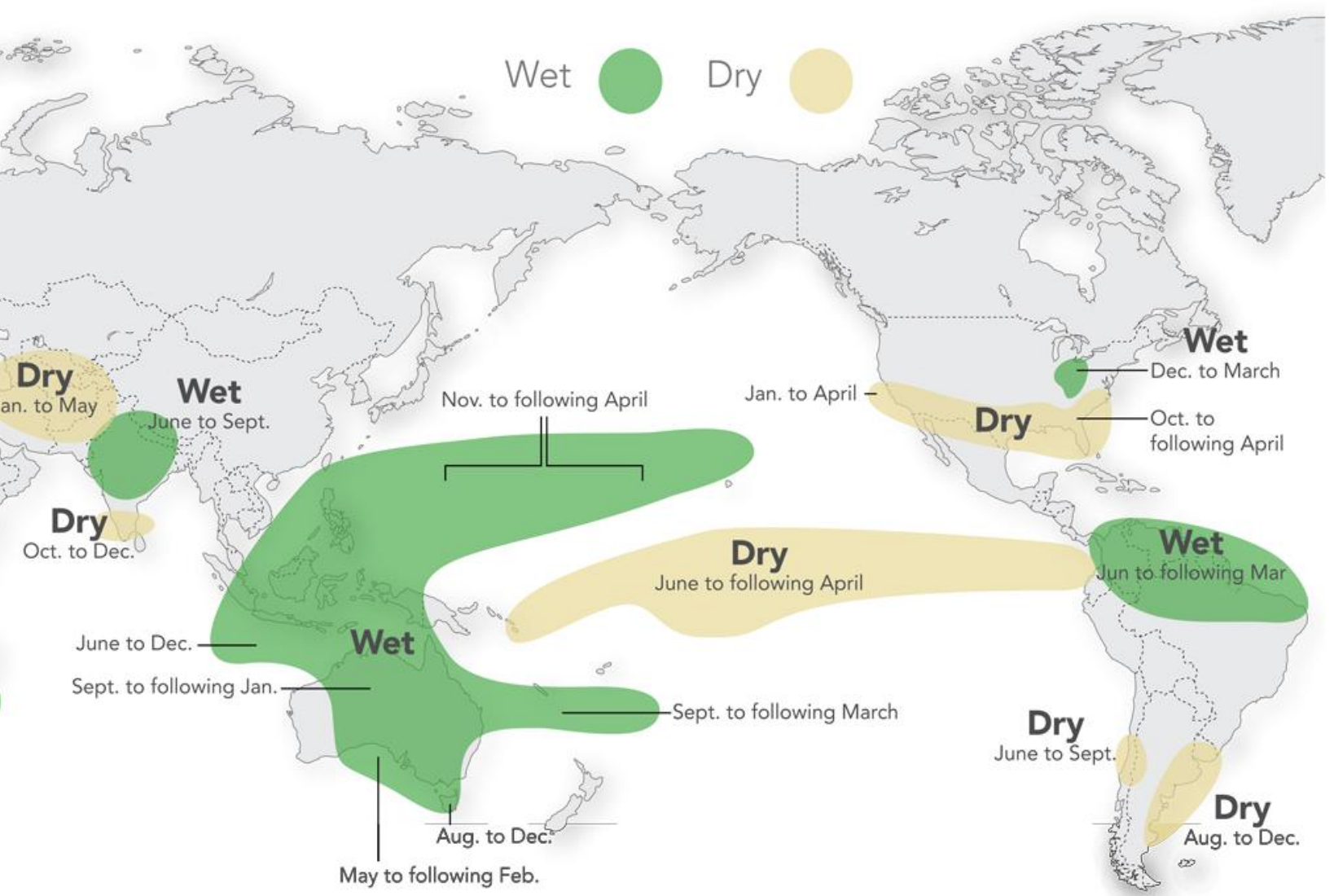

Source:

Ropelewski \& Halpert, 1989 


\section{Role of SST \& Wind: Indian Ocean Dipole}

0
0
0

Positive Dipole Mode

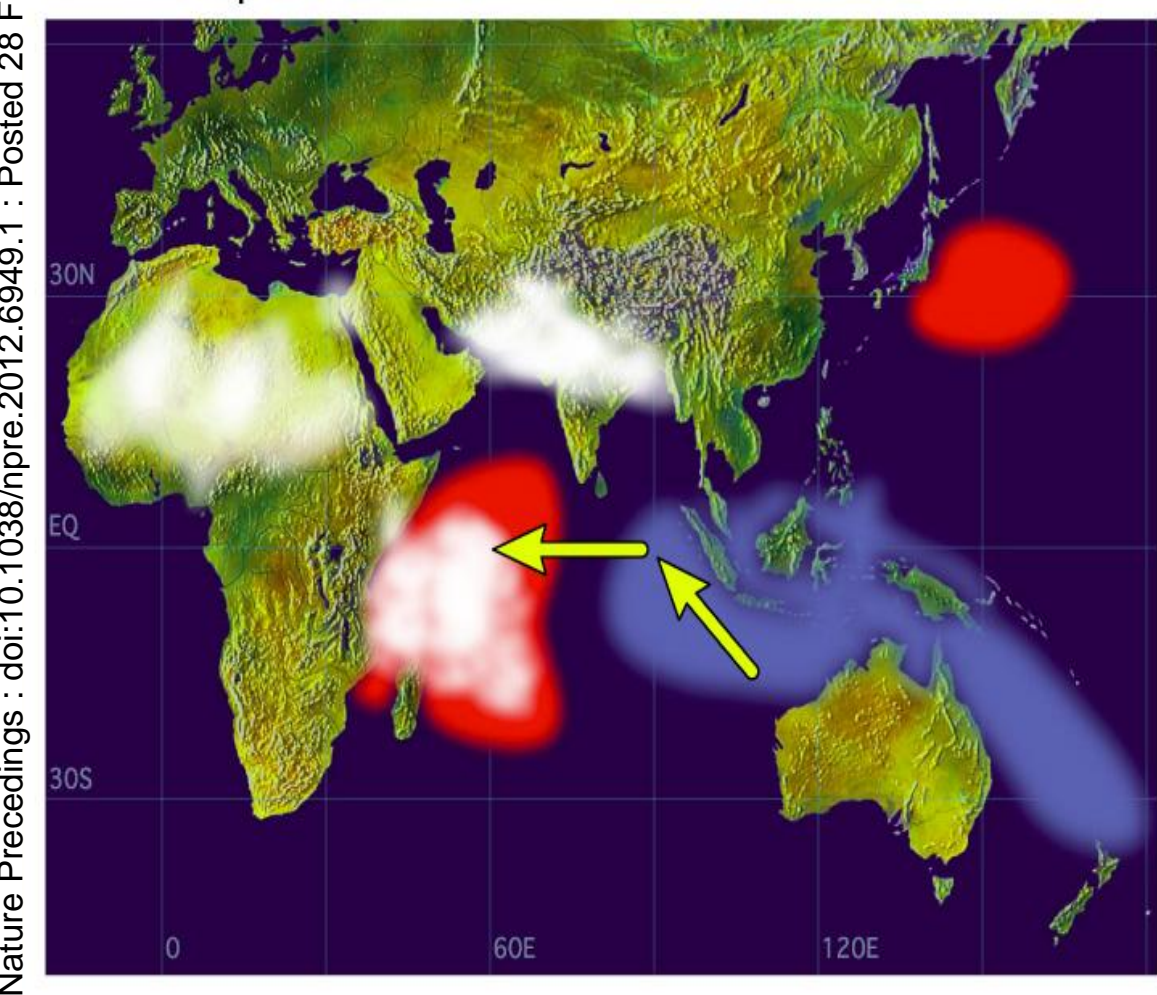

Negative Dipole Mode

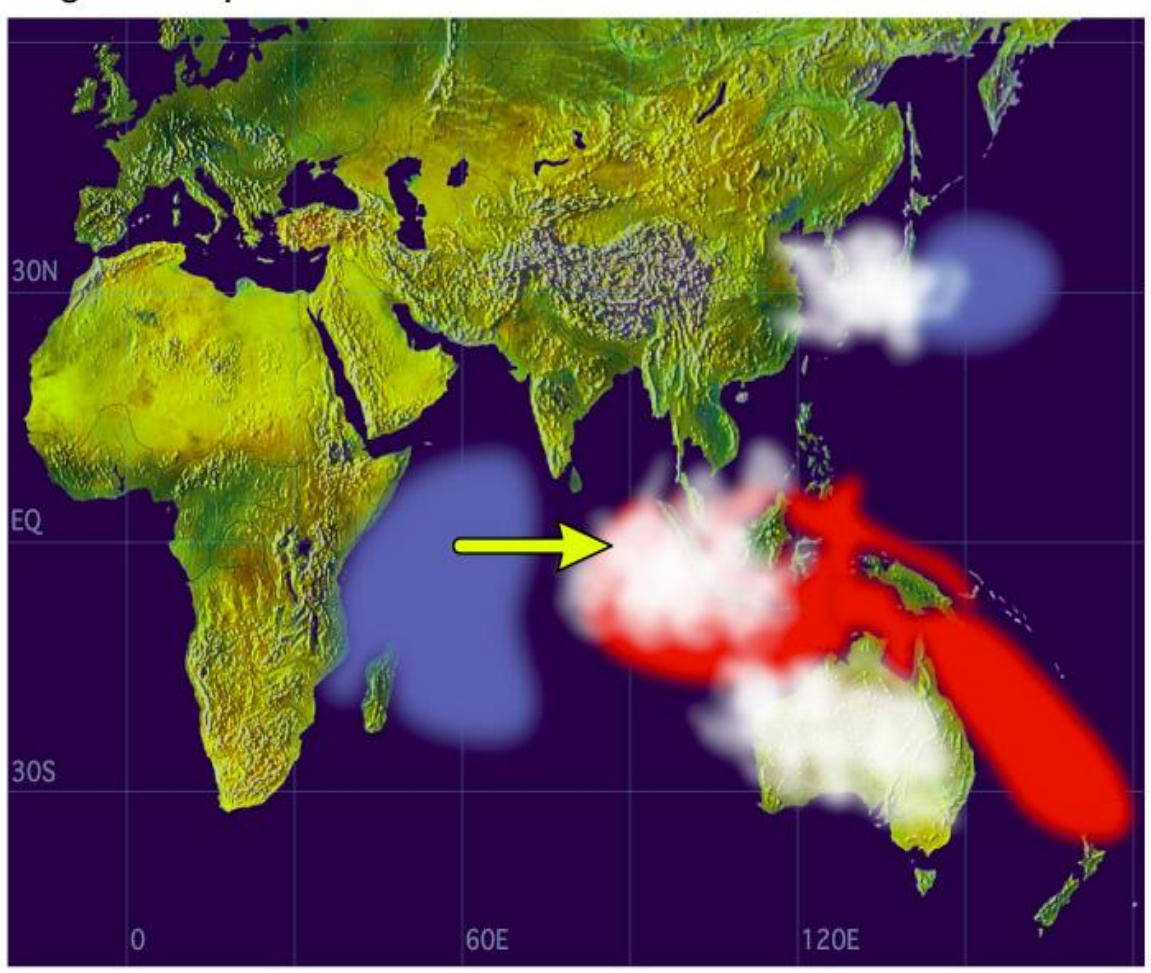




\section{Role of Wind:Trajectories during the Dry}

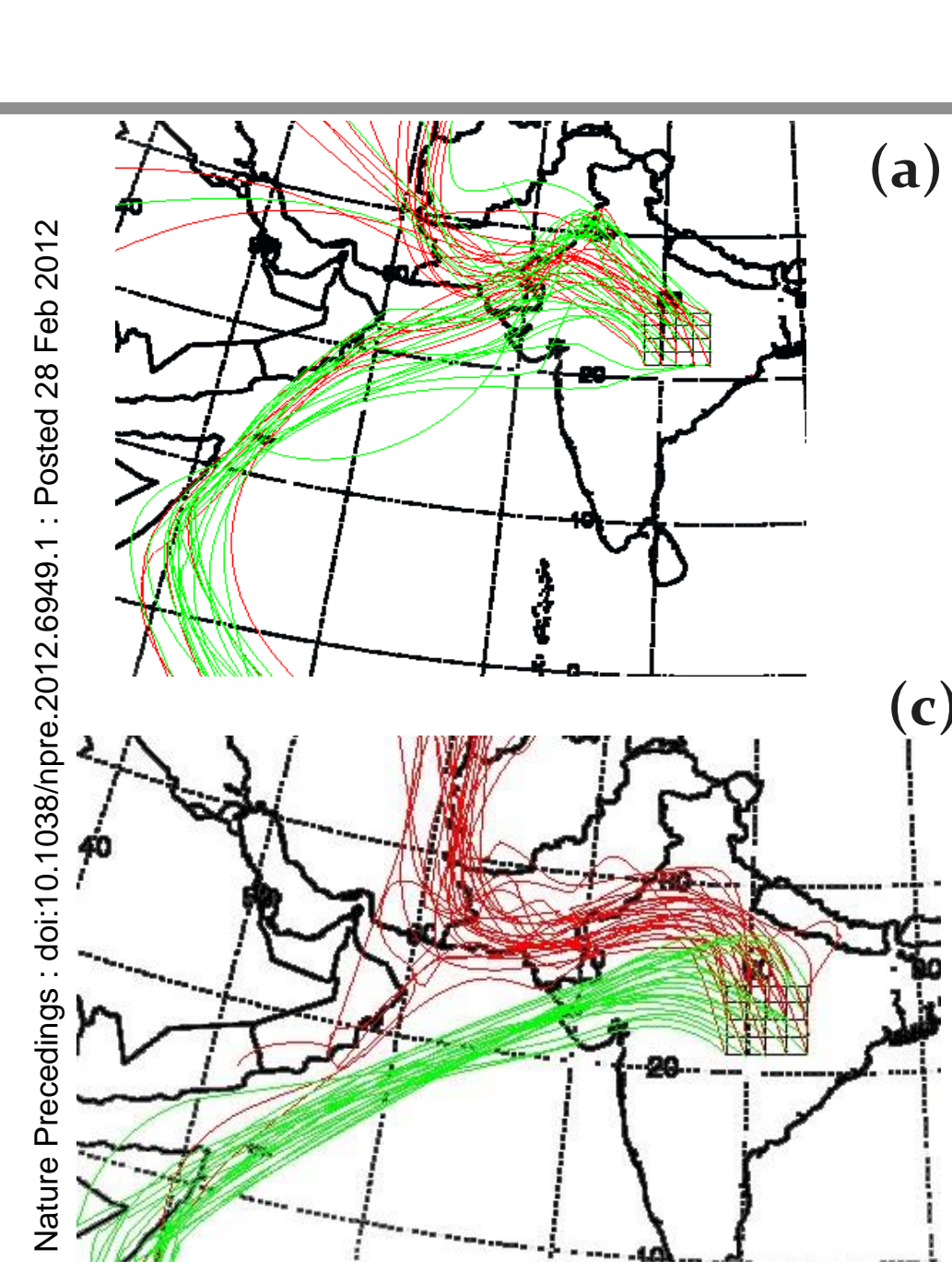

Spells.

a)

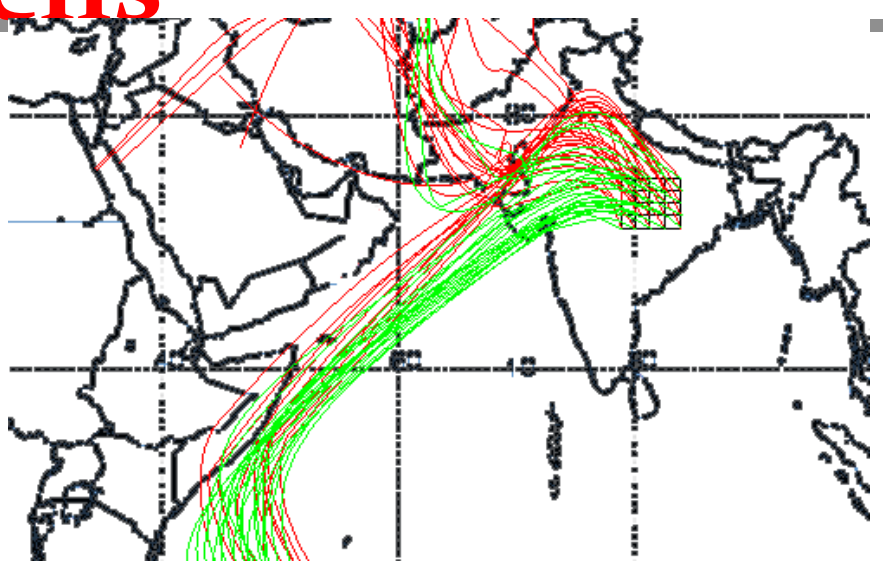

(b)

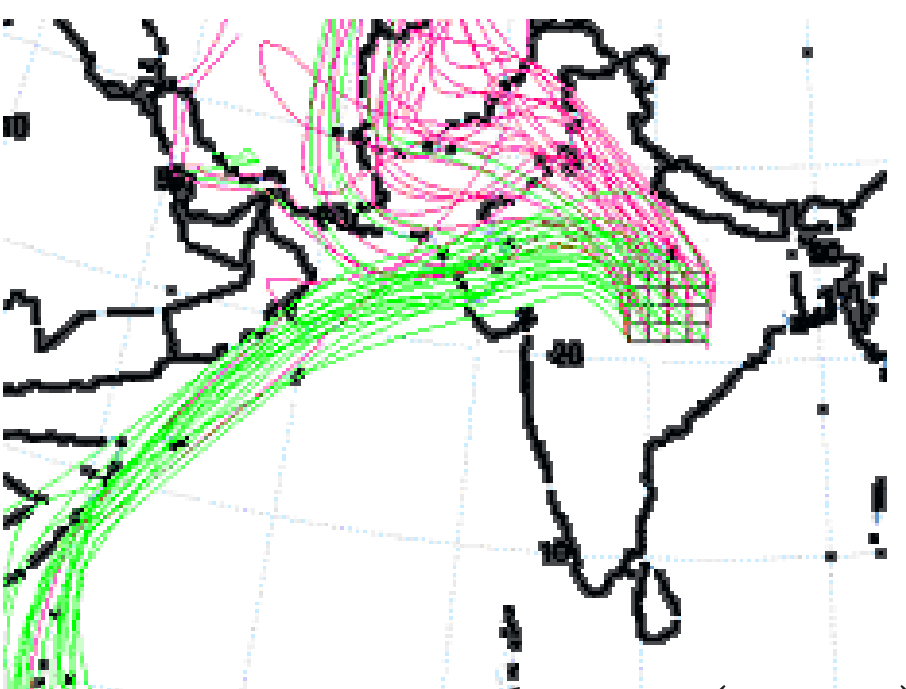

(d)

10 day back trajectories from Central India terminating at the 850 (green) and 700 (red), for the dry spells of the Indian summer monsoon. (a) 18 June 20o9; 14 August 2005; (c) 16 July 2002; (d) 30 August 2001;

Source: Book "An Introduction to Numerical Weather Prediction Techniques" by T.N. Krishnamurti \& L. (-2011 Asia Risk Eetrô
Bounouater 13) 
Source: Book "An Introduction to Numerical Weather Prediction Techniques" by T.N. Krishnamurti \& L. Bounoua (Chapter 13)

Role of Wind: Trajectories during the Wet Spells

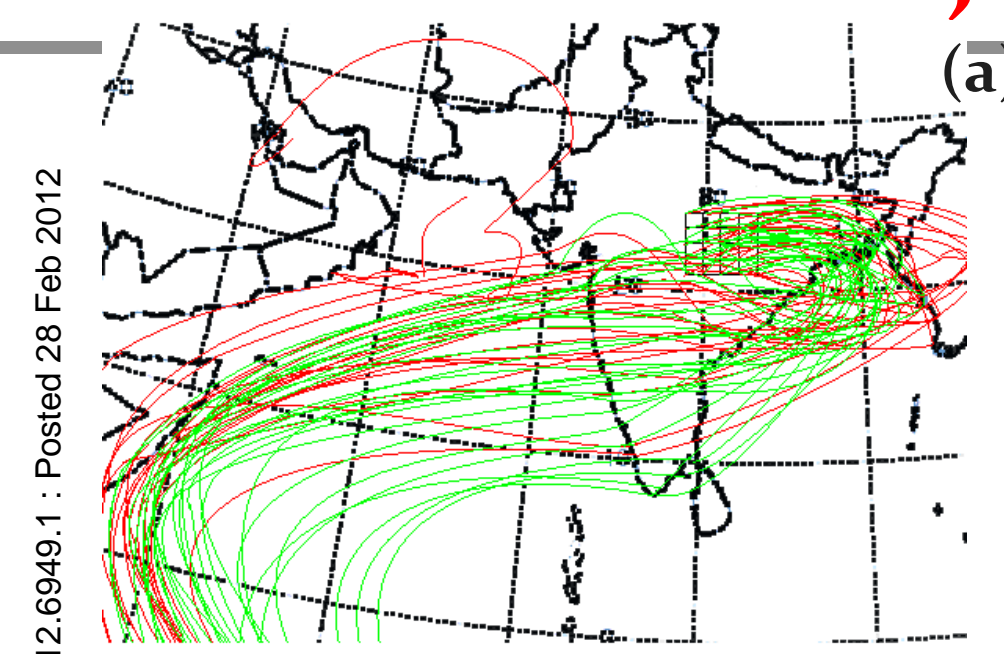

(a)

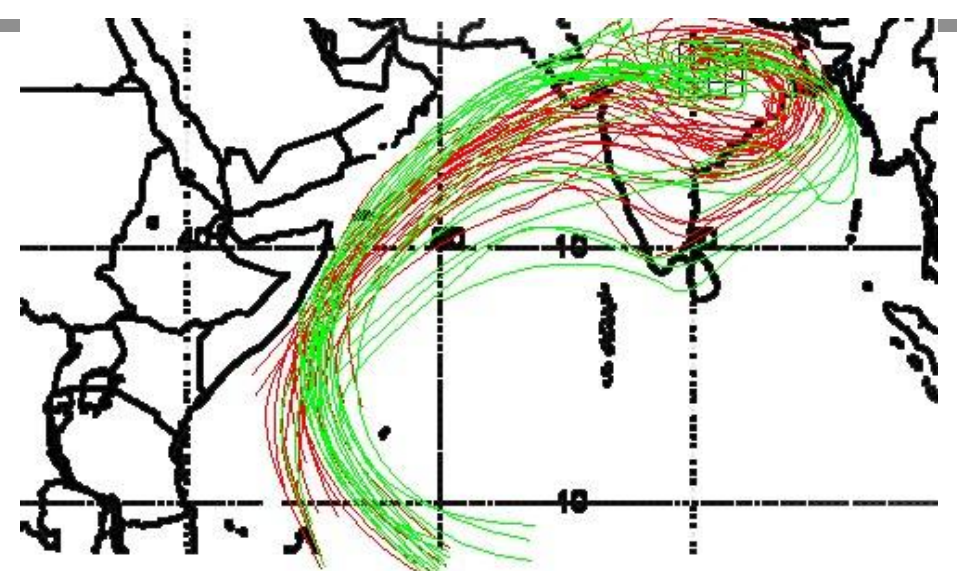

(c)

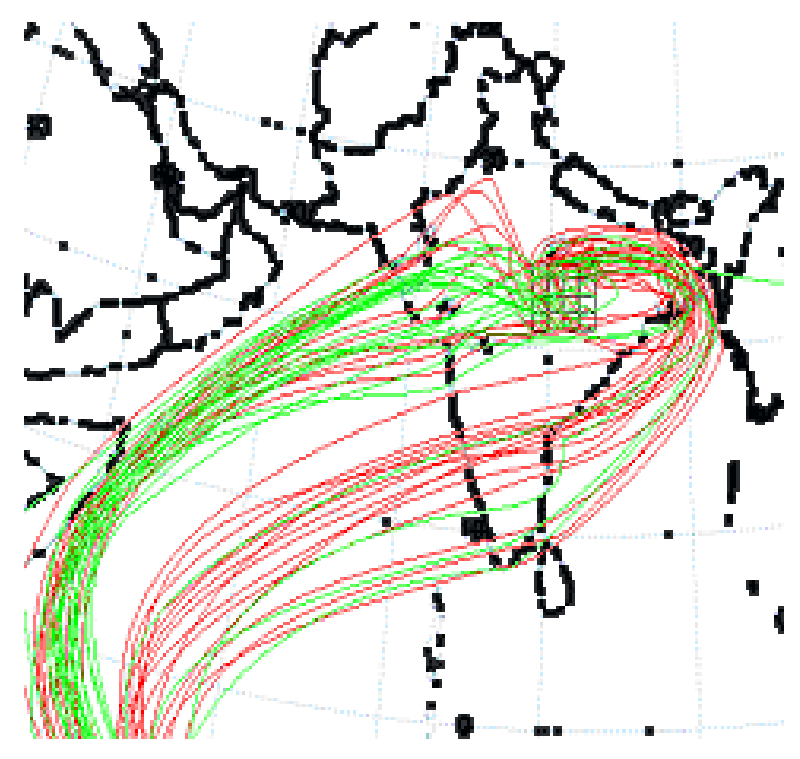

(d)

10 day back trajectories from Central India terminating at the 850 (green) and 700 (red), for the wet spells of the Indian summer monsoon. (a) 14 July 2009; (b) of 2Aưguistentroo5; (c) 31 August 2002; (d) 12 July 2001 


\section{Climate Change \& Agriculture}

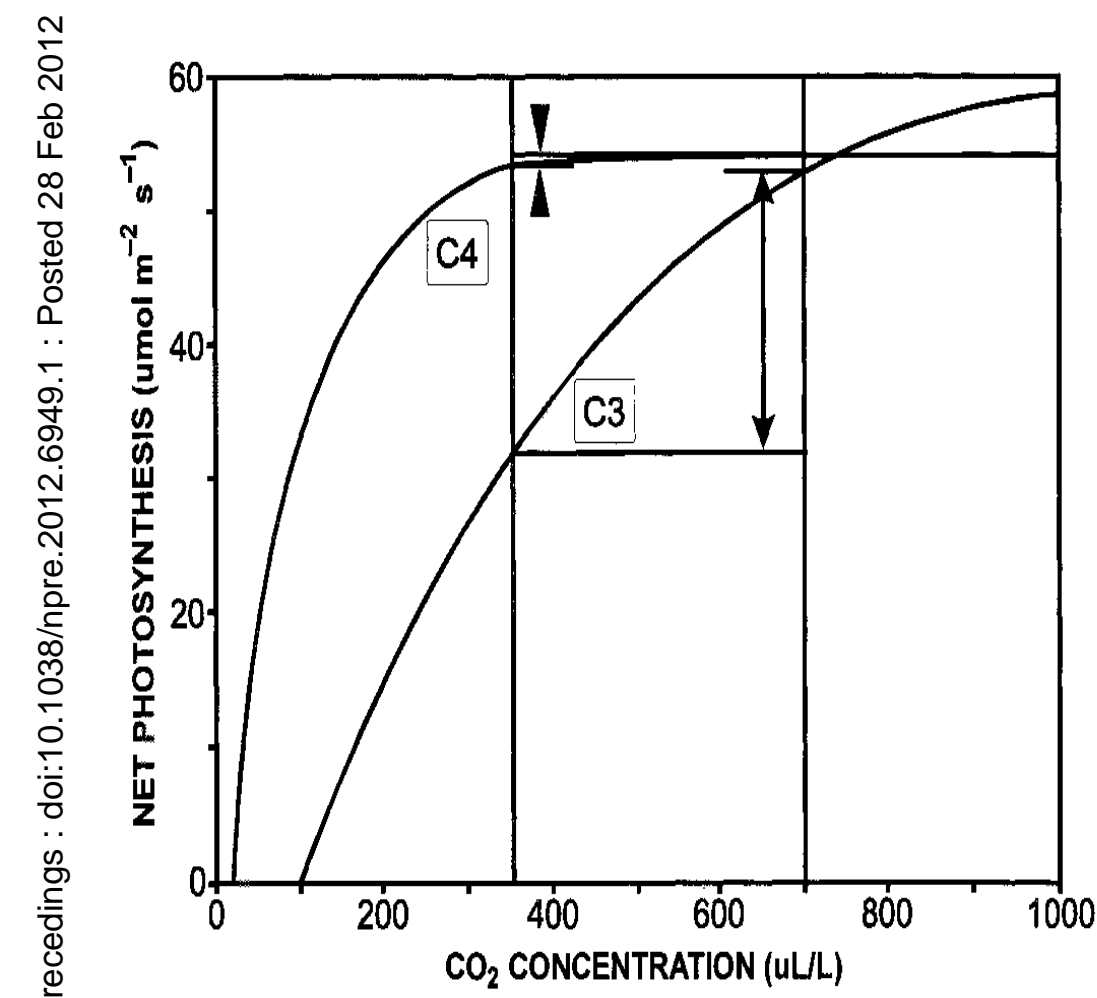

Current growth duration and decrease of post-anthesis (PoA) and total growth duration (Total: emergence to maturity) of widely used cultivars of rice, maize and wheat due to increase in average temperature

\begin{tabular}{|c|c|c|c|c|c|c|c|}
\hline \multirow[t]{2}{*}{ Crop, Cultivar } & \multicolumn{2}{|c|}{$\begin{array}{l}\text { Post-anthesis and } \\
\text { total growth } \\
\text { duration (days) } \\
\end{array}$} & \multirow{2}{*}{$\begin{array}{c}\text { Season } \\
\text { avg. } \\
\text { temp. } \\
\left({ }^{\circ} \mathrm{C}\right)\end{array}$} & \multirow[b]{2}{*}{$\left({ }^{\circ} \mathrm{C}\right)$} & \multicolumn{2}{|c|}{$\begin{array}{c}\text { Corr. decro } \\
\text { in PoA and } \\
\text { Total (\%) }\end{array}$} & \multirow[t]{2}{*}{$\begin{array}{l}\text { Areas representative } \\
\text { of temp. range }\end{array}$} \\
\hline & PoA & Total & & & PoA & Total & \\
\hline \multirow{4}{*}{$\begin{array}{l}\text { Subtropical } \\
\text { (spring) } \\
\text { wheat }\end{array}$} & 40 & 150 & $10 / 19$ & 0.0 & & & \multirow[t]{4}{*}{ Syria and Israel } \\
\hline & 38 & 138 & $11 / 20$ & +1.0 & -5 & -8 & \\
\hline & 36 & 128 & $12 / 2$ & +2.0 & -10 & -15 & \\
\hline & 33 & 111 & $14 / 23$ & +4.0 & -18 & -26 & \\
\hline \multirow{4}{*}{$\begin{array}{l}\text { Temperate } \\
\text { (spring) } \\
\text { wheat }\end{array}$} & 63 & 273 & $5 / 15$ & 0.0 & & & \multirow{4}{*}{$\begin{array}{l}\mathrm{N} \text { therlands, } \\
\mathrm{N} \text { Germany }\end{array}$} \\
\hline & 59 & 234 & $6 / 17$ & +1.0 & -6 & -14 & \\
\hline & 54 & 194 & $7 / 8$ & +2.0 & -14 & -29 & \\
\hline & 50 & 167 & $9 / 20$ & +4.0 & -21 & -39 & \\
\hline \multirow{4}{*}{$\begin{array}{l}\text { Trop. Maize } \\
\text { med.learly; }\end{array}$} & 58 & 113 & 230 & 0.0 & & & \multirow{4}{*}{$\begin{array}{l}\text { Su ssaharan Africa, } \\
(80-1300 \mathrm{~m} \\
\text { al tude) }\end{array}$} \\
\hline & 55 & 106 & 240 & +1.0 & -5 & -6 & \\
\hline & 50 & 97 & 25.5 & +2.5 & -14 & -14 & \\
\hline & 46 & 89 & 27. & +4.0 & -21 & -21 & \\
\hline \multirow{4}{*}{$\begin{array}{l}\text { Subtropical } \\
\text { rice }\end{array}$} & 59 & 139 & 21. & 0.0 & & & \multirow[t]{4}{*}{ Sputhem France } \\
\hline & 52 & 125 & 22.0 & 1.0 & -12 & -10 & \\
\hline & 46 & 110 & 23.5 & 2.5 & -22 & -21 & \\
\hline & 42 & 100 & 25.0 & 4.0 & -29 & -28 & \\
\hline \multirow[t]{4}{*}{ Tropical rice } & 42 & 95 & 27.0 & 0.0 & & & \multirow[t]{4}{*}{ Thailand } \\
\hline & 39 & 90 & 28.0 & 1.0 & -7 & & \\
\hline & 36 & 83 & 29.5 & & -14 & & \\
\hline & 33 & 77 & 31.0 & & -21 & 19 & \\
\hline
\end{tabular}

Calculations based on pre- and post-anthesis temperature requirements from: Van Keulen and Seligman, 1987; Supit et al., 1994; Rötter, 1993; Penning de Vries et al., 1989; Penning de Vries, 1993. 
Available online at: http://precedings.nature.com/documents/5899/version/1

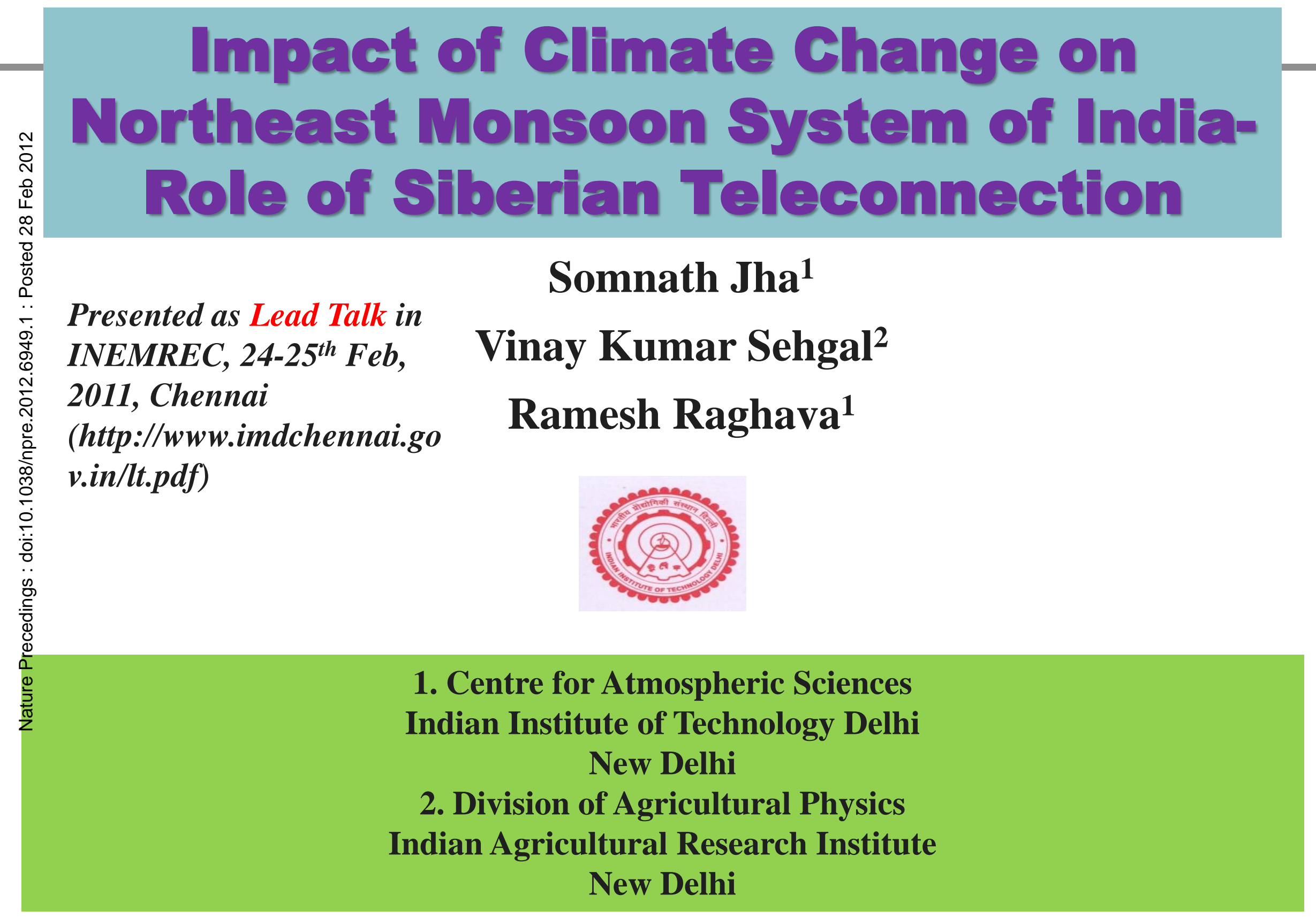




\section{Principal Axis of Monsoon}

No

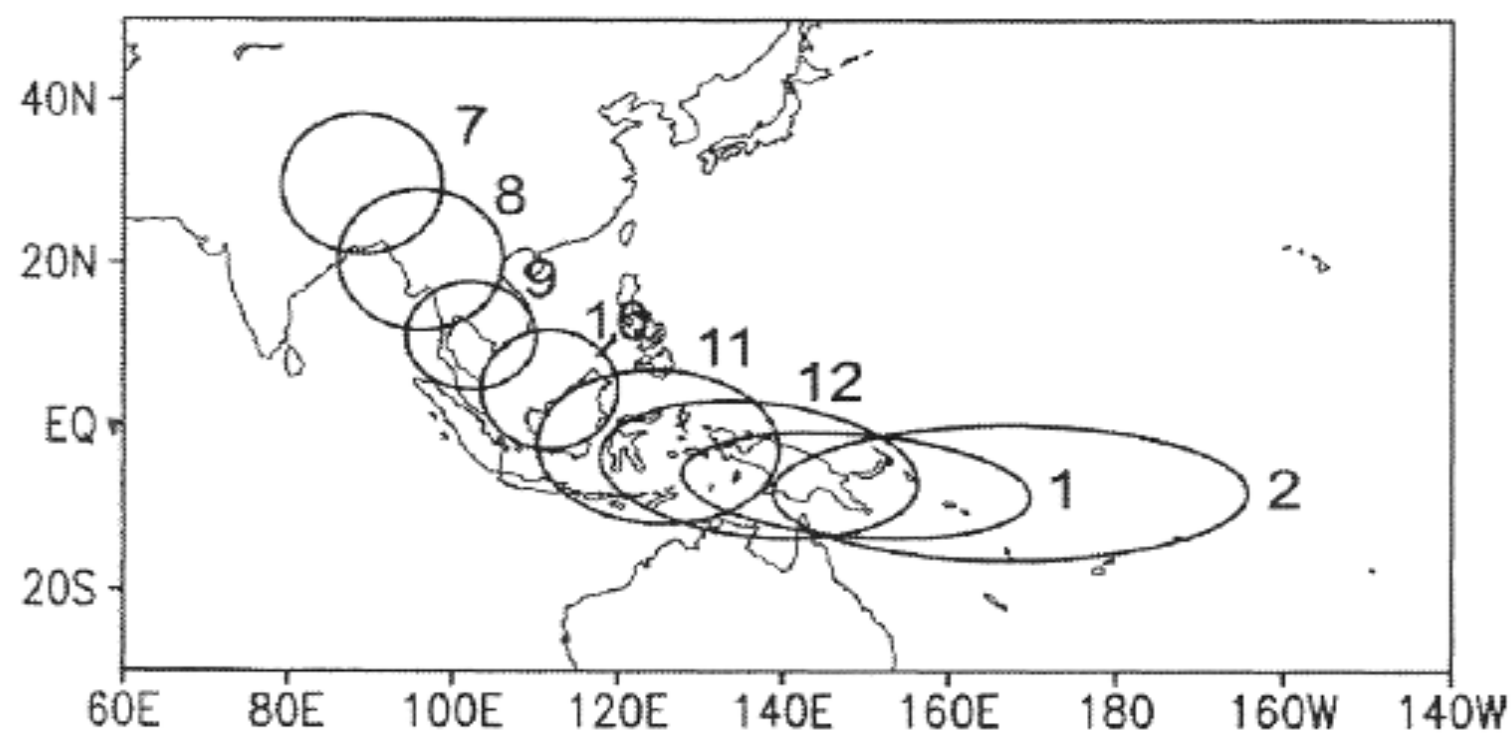

- Differential Heating is responsible for divergent vertical circulation with ascending lobes at Q1 (heat source) \& descending lobes over Q2 (moisture sink)

Seasonal propagation of Heat Source (Q1) associated with heavy Monsoonal precipitation between July \& February. The line described by the heat source locations in different months forms the principal axis of the Asian Monsoon 


\section{NEM Precipitation \&Temperature Trend}

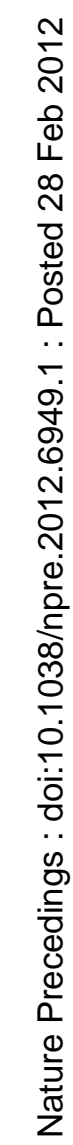
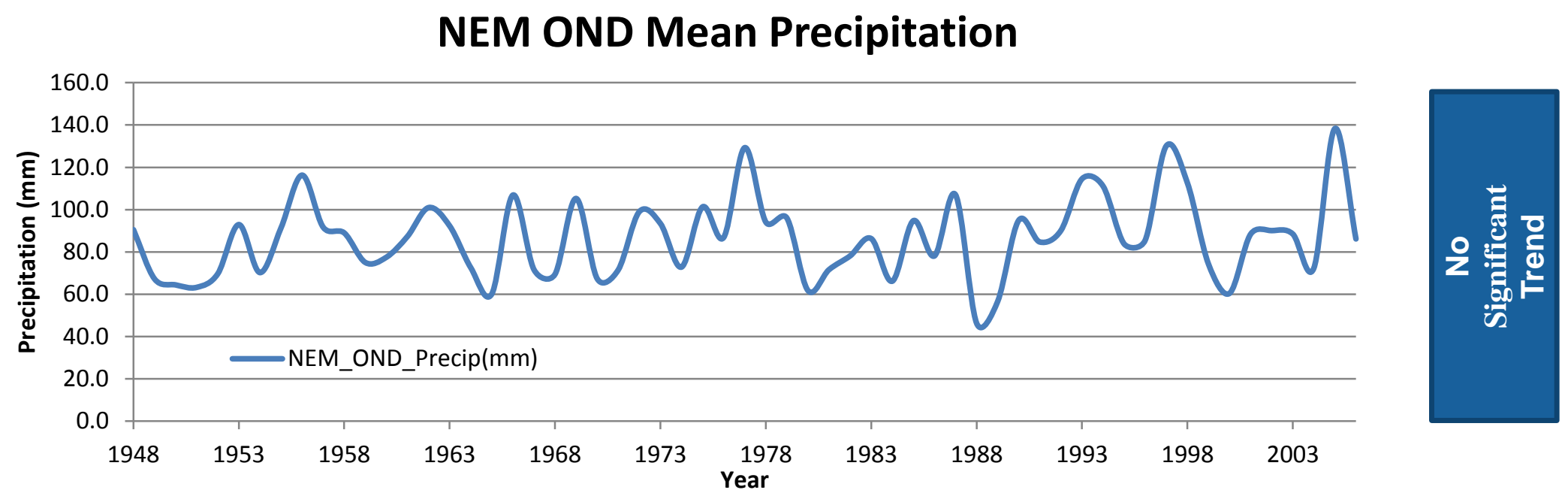

\section{NEM OND Temperature}
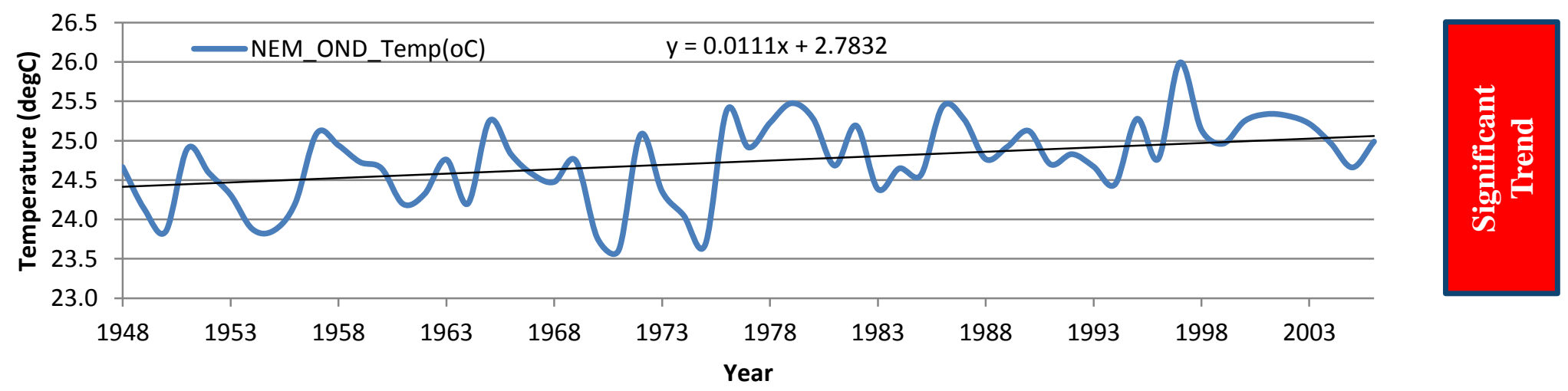


\section{Serial Correlation between NEM Precipitation and ENSO \& IOD Indices}

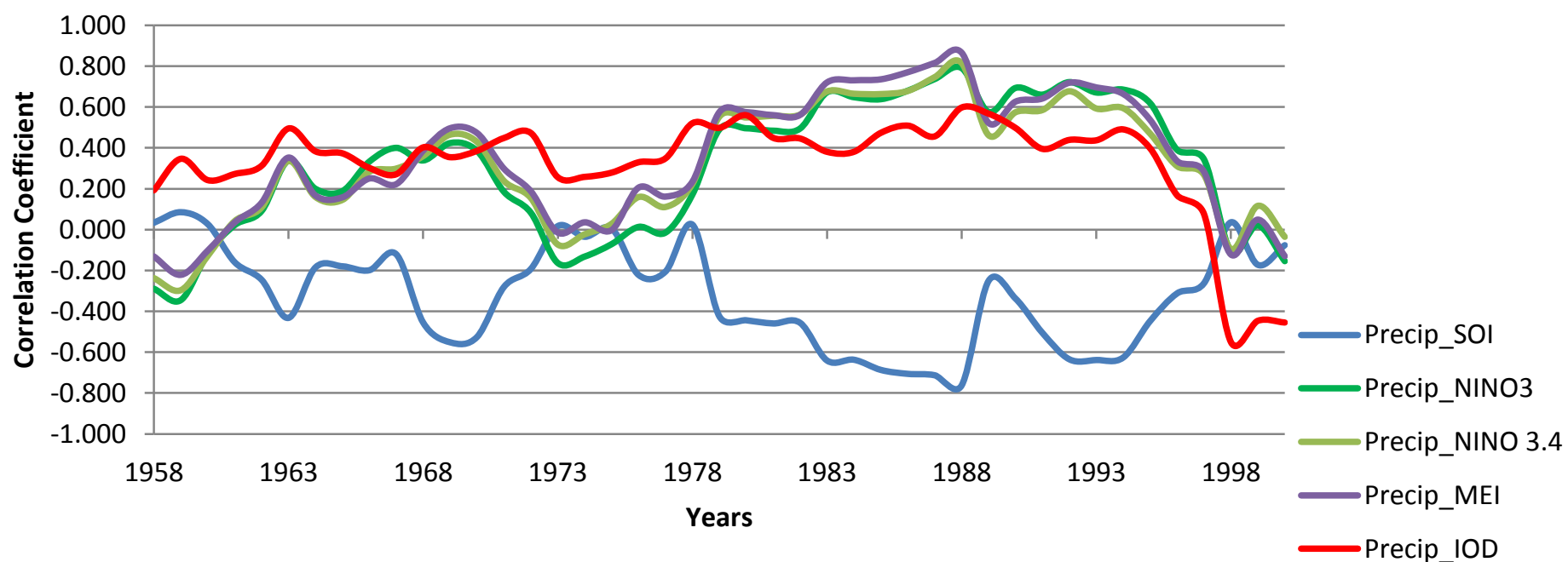

-Serial (10 year running window) correlation reveals that correlation of ENSO indices \& DMI with NEM precipitation has increased between the period 1975-1998 and decreased at 1996

- Serial correlation of DMI \& NEM precipitation remains less than that of ENSO \& NEM precipitation during the period 19781996 whereas this relation is opposite during the period 1970-1978 


\section{Snow Extent for Oct.,Nov.,\& Dec. for 1978-2007}

AdGIF UNREGISTERED - www.gif-animator.com Extent Anomalies

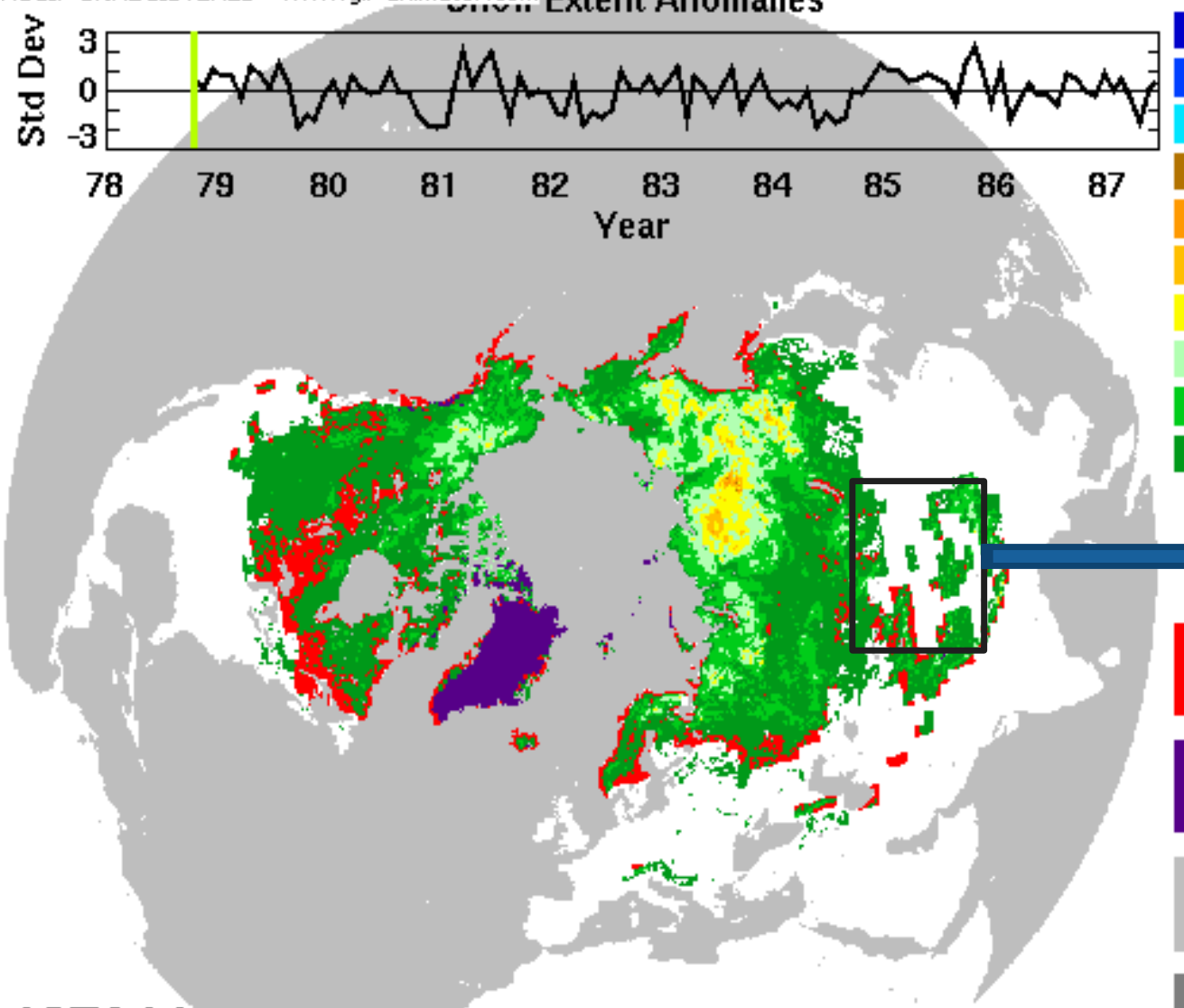

197811

Visible + Passive Microwave Blended Snow Cover $\mathrm{Y} Y \mathrm{YMM}=197811$ BP_VIS: Microwave SWE + visible snow for 2 or more weeks Source:
http://nsidc.org/data/docs/daac/nsidc0271_ease_grid_Swe_climatology/browse/viewer.
$\underline{\text { html }}$

(Armstrong, R. L., M. J. Brodzik, K. Knowles, and M. Savoie. 2007. Global monthly EASE-Grid snow water equivalent climatology. Boulder, CO: National Snow and Ice

\section{Visible}

$2+$ wks

Ice

Sheet

Ocean

No TBs 


\section{Spatio-temporal Trends of Standardized Precipitation Index for Meteorological Drought Analysis across Agroclimatic Zones of India}

Somnath Jha 1, Vinay K Sehgal 2, R.C. Raghava 1

1 Centre for Atmospheric Sciences, IIT, Delhi

2 Division of Agricultural Physics Indian Agricultural Research Institute

New Delhi- 110012 INDIA 


\section{SPI TREND FOR JJAS}

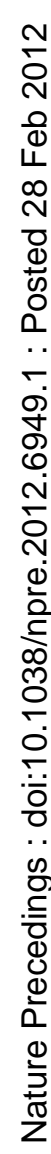

\begin{tabular}{|l|c|c|c|c|c|c|}
\hline ACZ & $\begin{array}{c}\text { Tau corr. } \\
\text { Coeff. }\end{array}$ & S value & Z value & P value & Intercept & Slope \\
\hline ACZ4 & -0.367 & -565 & -3.986 & 0.000 & 42.708 & -0.0216 \\
\hline ACZ5 & -0.264 & -406 & -2.862 & 0.004 & 39.075 & -0.0197 \\
\hline ACZ7 & -0.188 & -290 & -2.043 & 0.041 & 25.387 & -0.0129 \\
\hline ACZ8 & -0.226 & -348 & -2.452 & 0.014 & 27.300 & -0.0138 \\
\hline
\end{tabular}

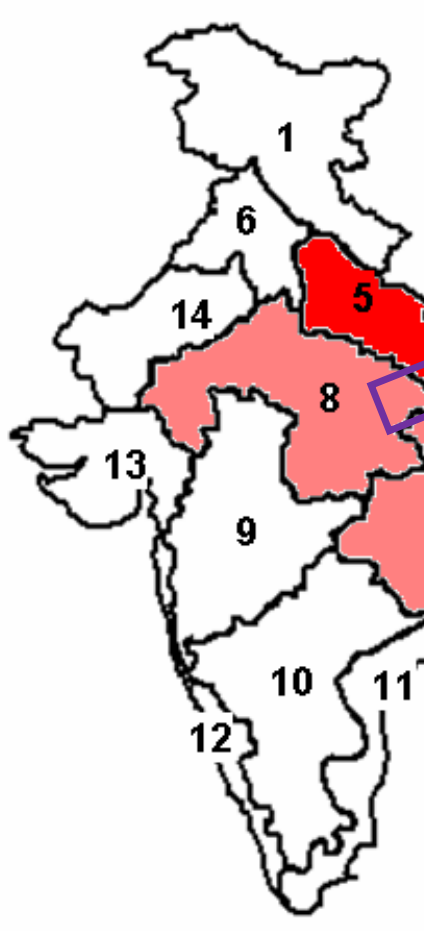

Significantly Drying ACZs of India 


\section{Climate Change: Crop Duration \& Shift in Peak Vegetative Stage}

$\sim$

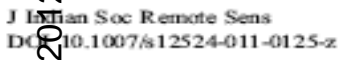

\section{Ro요 \\ ㄴ}

Dẽ्

Tiques Series NOAA-AVHRR NDVI Data

Tign

Vifny Kumar Sehgal * Surabhi Jain.

Pramod Kumar Aggarwal - Somnath Jha

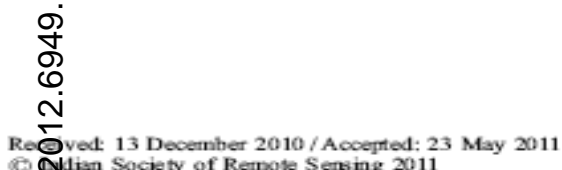
phology metrics and productivity of crops grown, at Sisaggregated level in Indo-Gangetic Plains of Indra (IGP), which are helpful in understanding the impet of climatic, ecological and socio-economic driyers. The NOAA-AVHRR NDVI PAL dataset fro용 1981 to 2001 was stacked as per the crop year and subjected to Savitzky-Golay filtering. For crop pixols, maximum and minimum values of normalpixols, maximum and minimum values of normalof currence and total duration of kharif (Juneof
Octorrence and total duration of kharif (Junewe of derived for each crop year and later subjected

๑

$\mathrm{V}$ Sehgal (민)

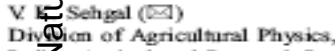

Ind $Z_{\text {. Agricultural Research Institute, }}$

Pusa Campus,

Now Delhi 110012 , India

e:mail visehgal@gmail.or

S. hin. P K. A aganwal

S. Lin - P K. Aggarwal
Division of Environrnemtal Sciences,

Indian Agricultural Research Institute

New Delhi 110012, India

S. Tha

Centre for Atmospheric Sciences,

Indian Instifute of 'Tochno.
New Delhi 110016, India

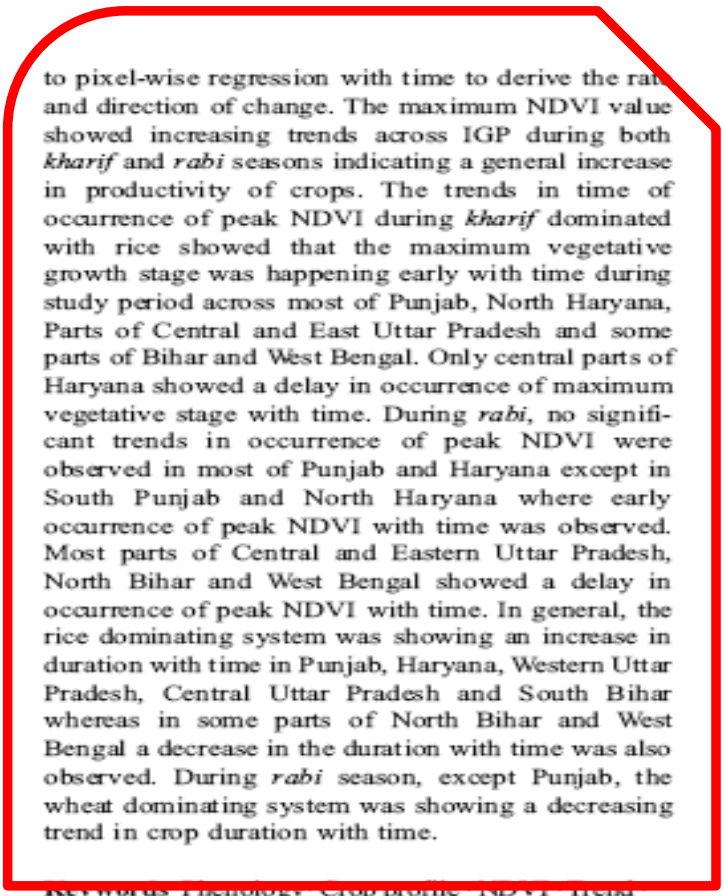

Time series - Indo-gangetic plains

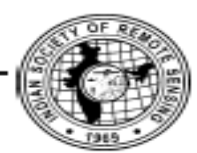

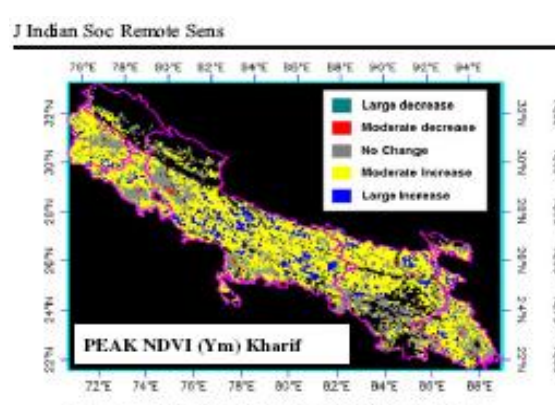
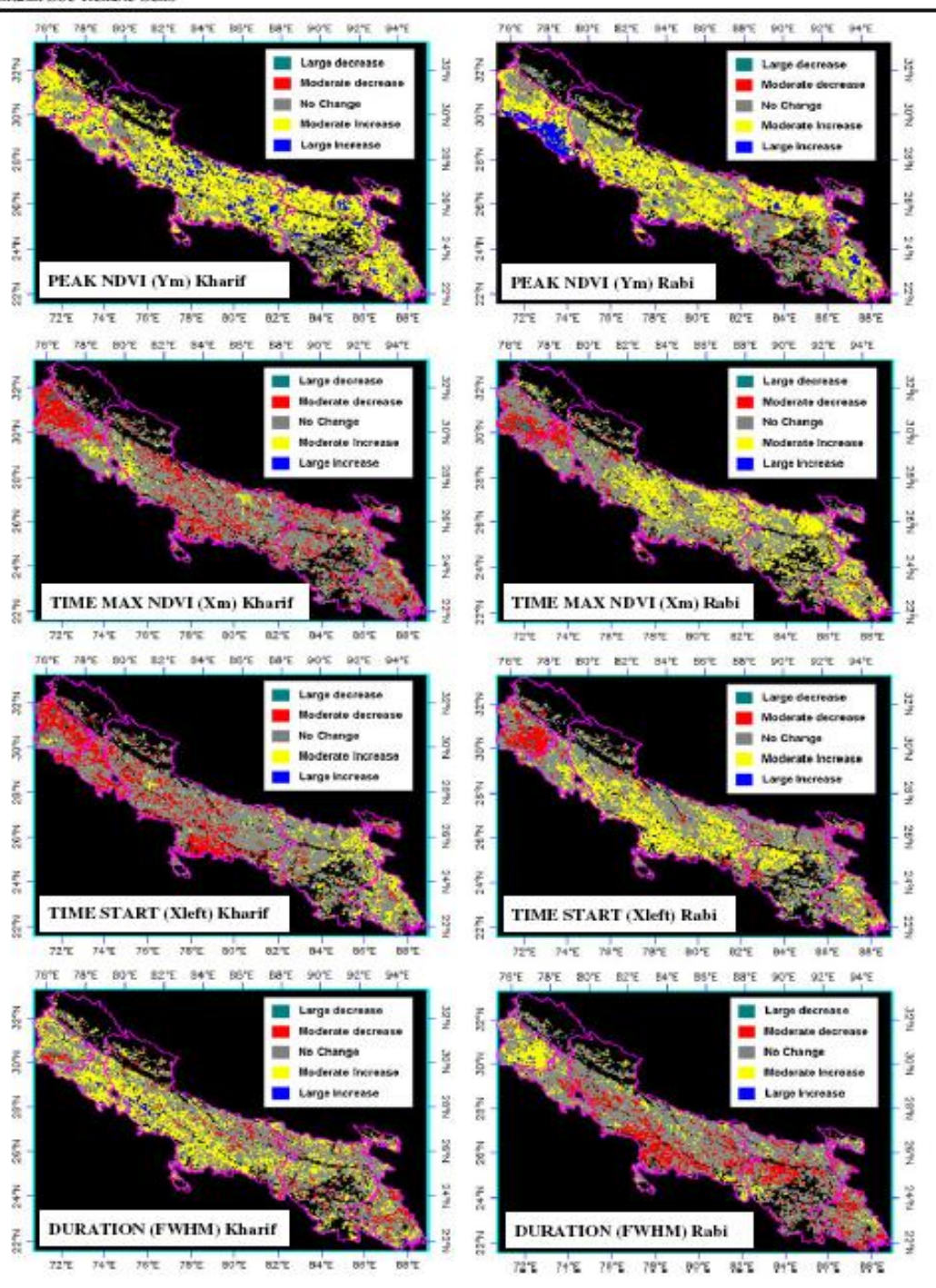

Q Springer 


\section{Therefore}

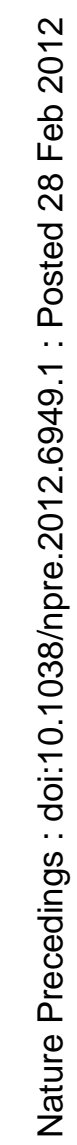

- Local weather variability are not captured due to our inability to comprehend the Global Teleconnection

- Uncertainty in weather or climate prediction is our gap to understand this Macro to Micro Integration of SpatioTemporal climatic Wave 


\section{Therefore Climate Change is ALSO}

,

A slow bur gr|aిmal change îs going on Sillently 证 虬造

bîosphere of earth.

NO『 nerely the change in

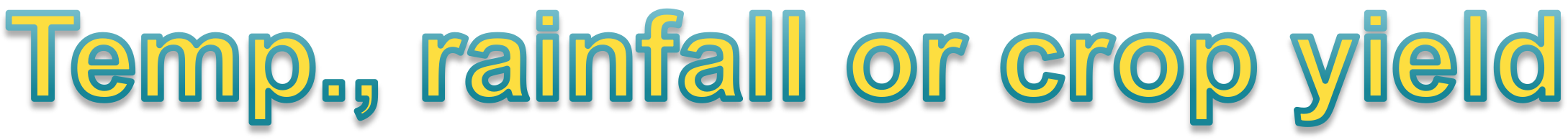




\section{Part Two}

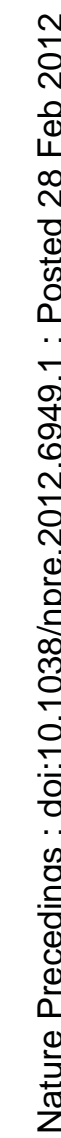

\section{Description of}

State-of-the-science

Climate Simulation Tools 
- Climate Models

- General Circulation Models

- Regional Climate Models

- Weather Forecast Models

- Climate Diagnostic Study based new code insertion 
- Earth heat surplus zone : $40^{\circ} \mathrm{N}$ to $40^{\circ} \mathrm{S}$ Latitude

- Earth heat deficit zone : $40^{\circ}$ to $90^{\circ}$ (both hemisphere)

- General Circulation of Fluids over Earth : Equilibrate the temperature inequlibrium by

(a) Atmospheric Circulation(80\%)

(b) Oceanic Circulation(20\%)

- Numerical prediction Model for paleoclimate prediction or Future climate prediction or Present Realtime high accuracy global prediction SIMULATE THIS GENERAL CIRCULATION OF EARTH as GENERAL CIRCULATION MODEL (4Dimension), popularly known as GCM

- GCM is of three types:

(a) Atmospheric GCM (AGCM)

(b) Oceanic GCM(OGCM)

(c) Coupled A-OGCM

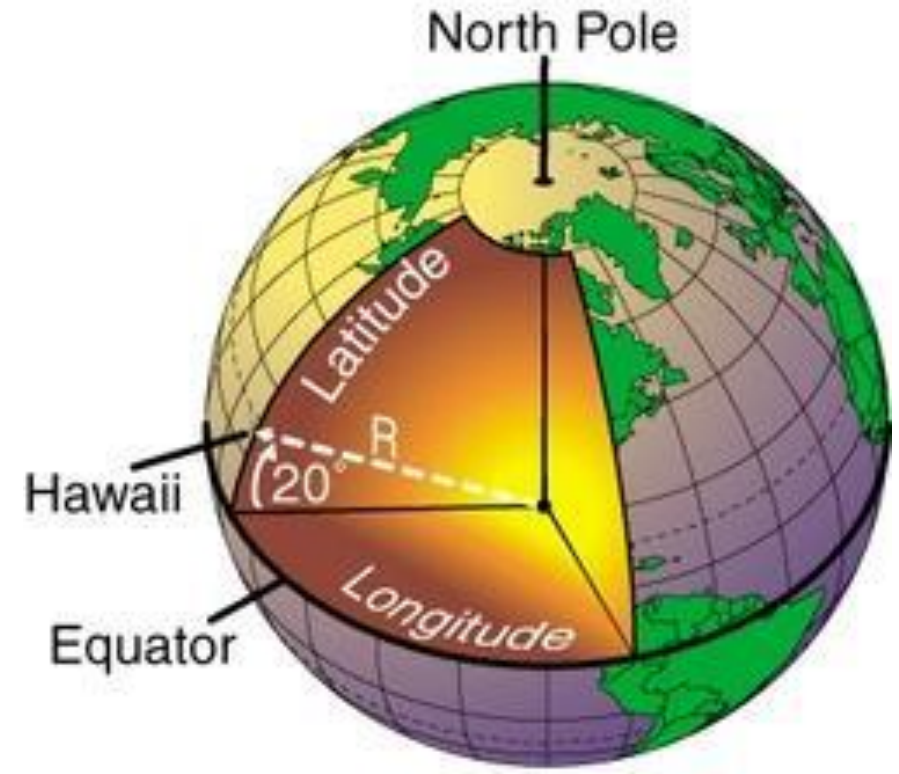




\section{Differential heating of the Earth}

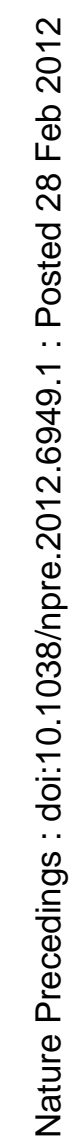

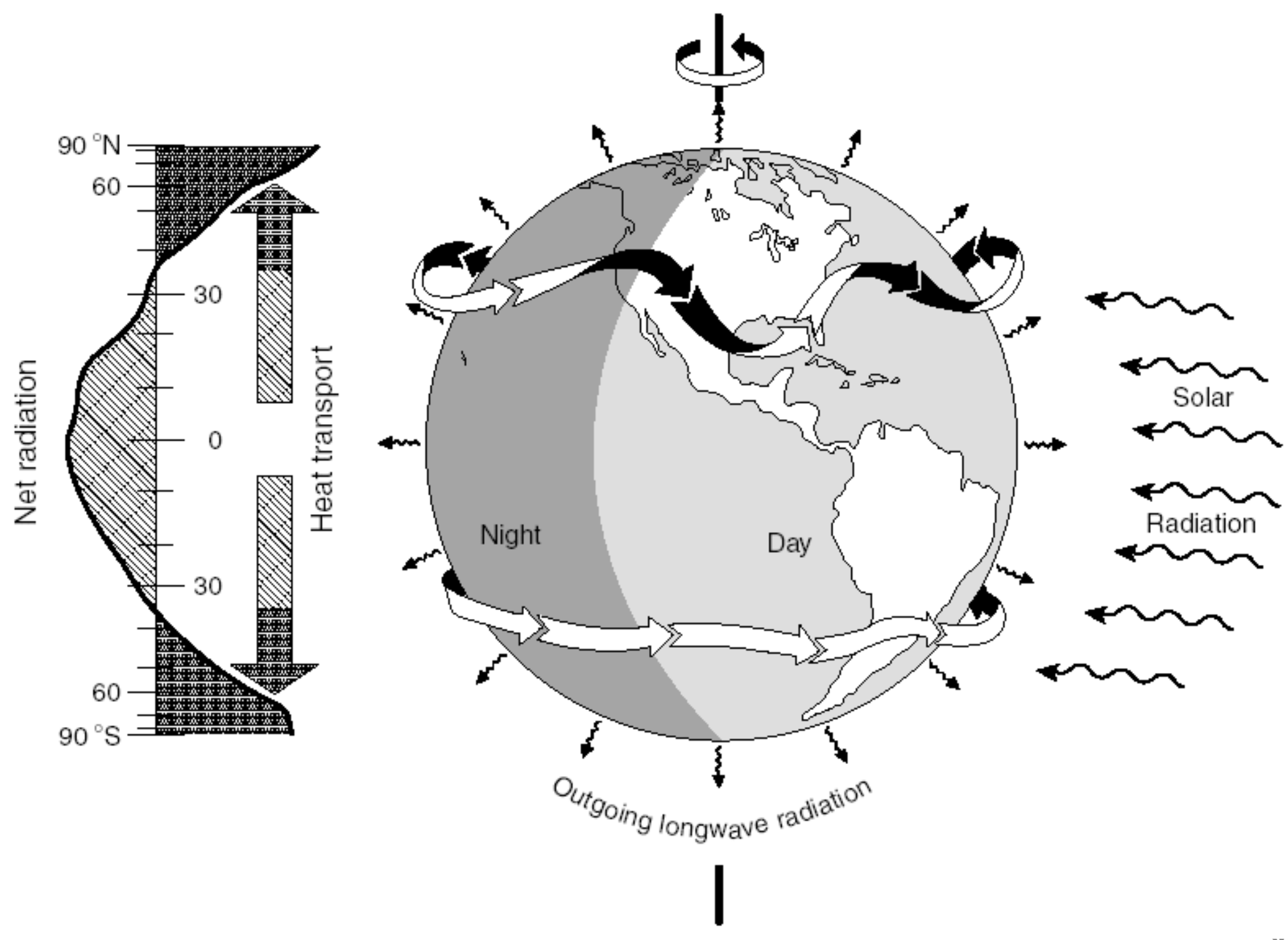




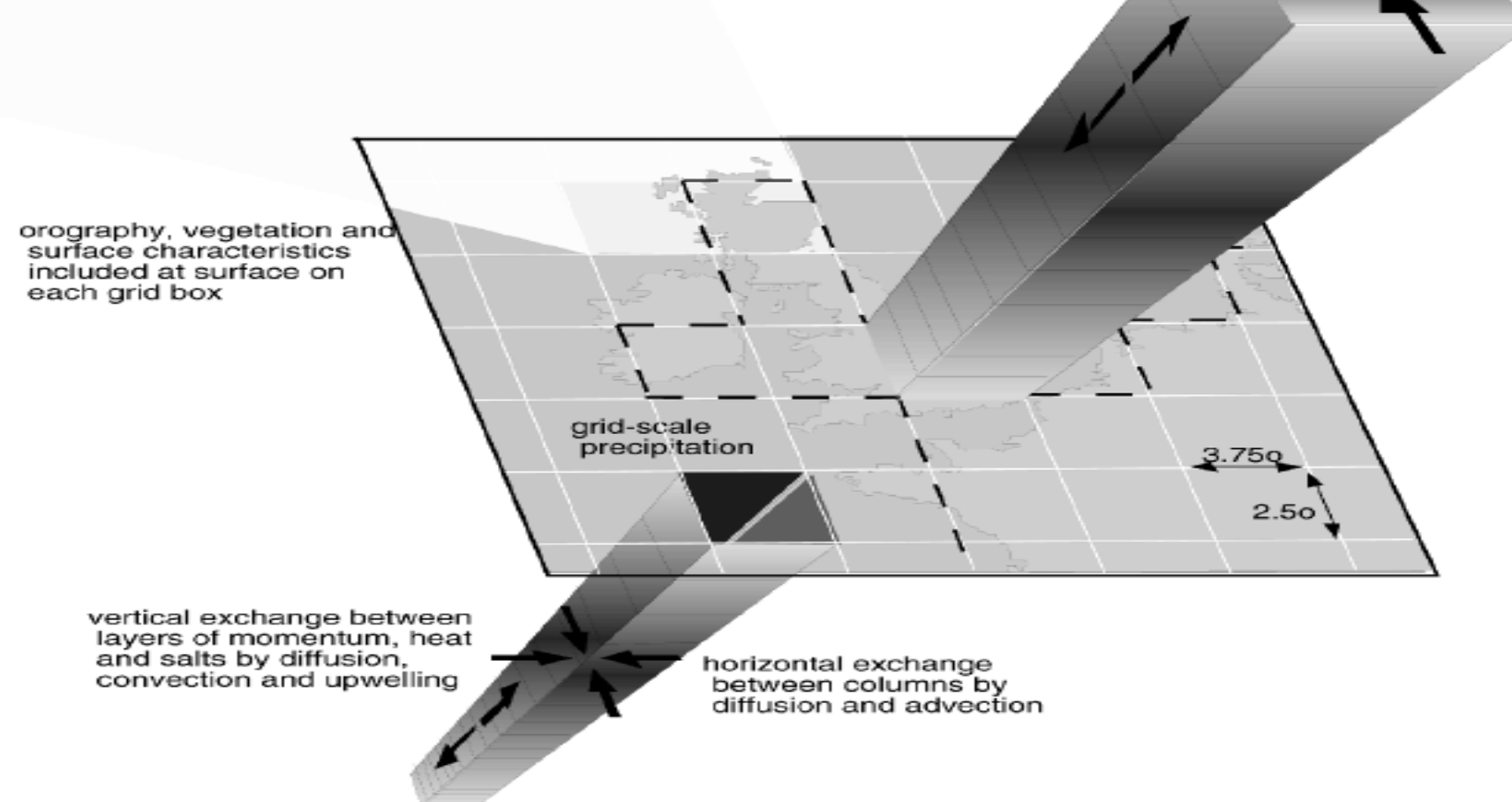

Fig. Conceptual structure of Coupled-Ocean-Atmospheric GCM 


\section{The climate system}

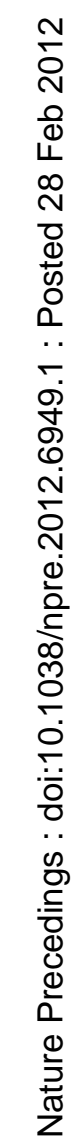

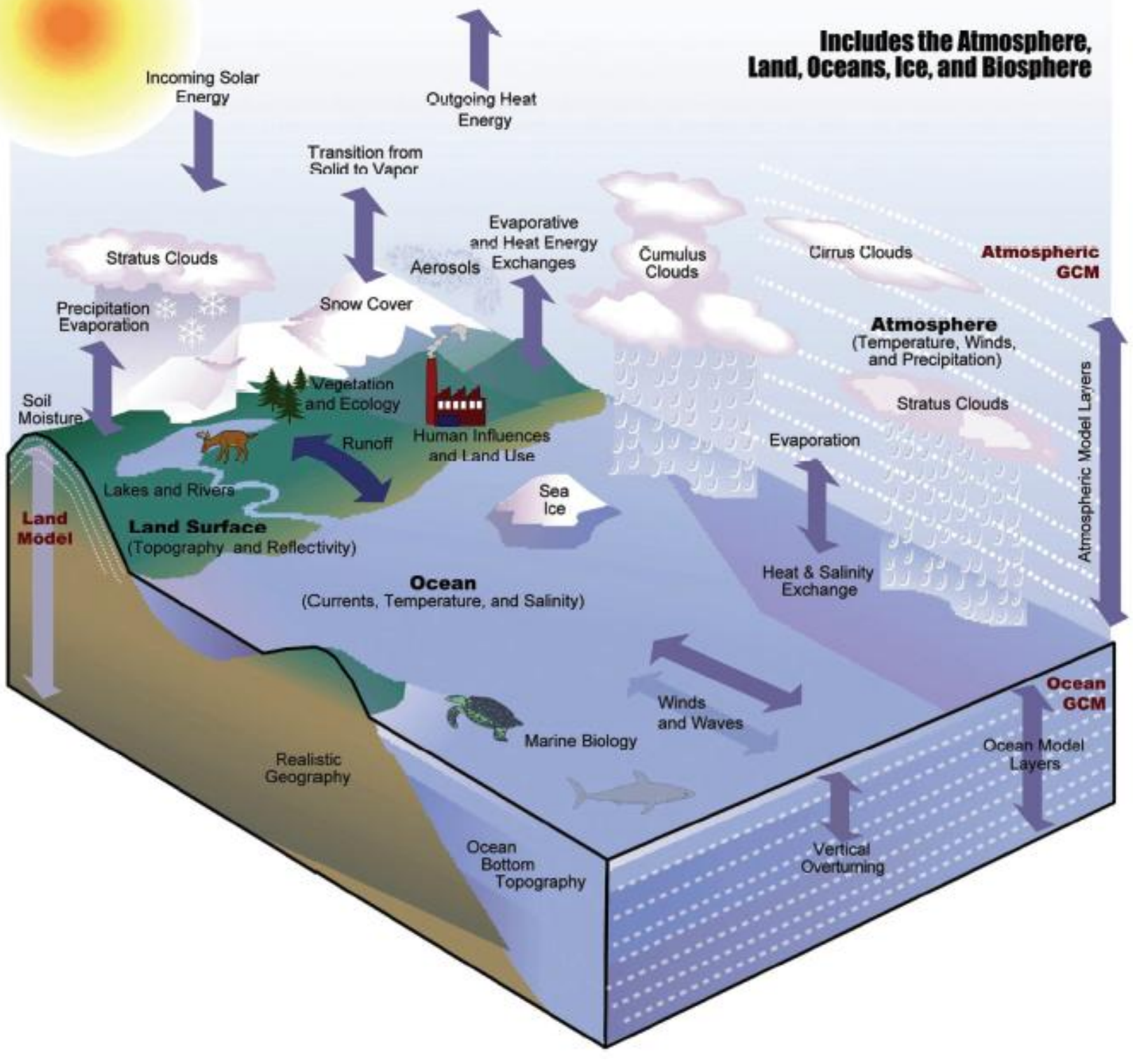




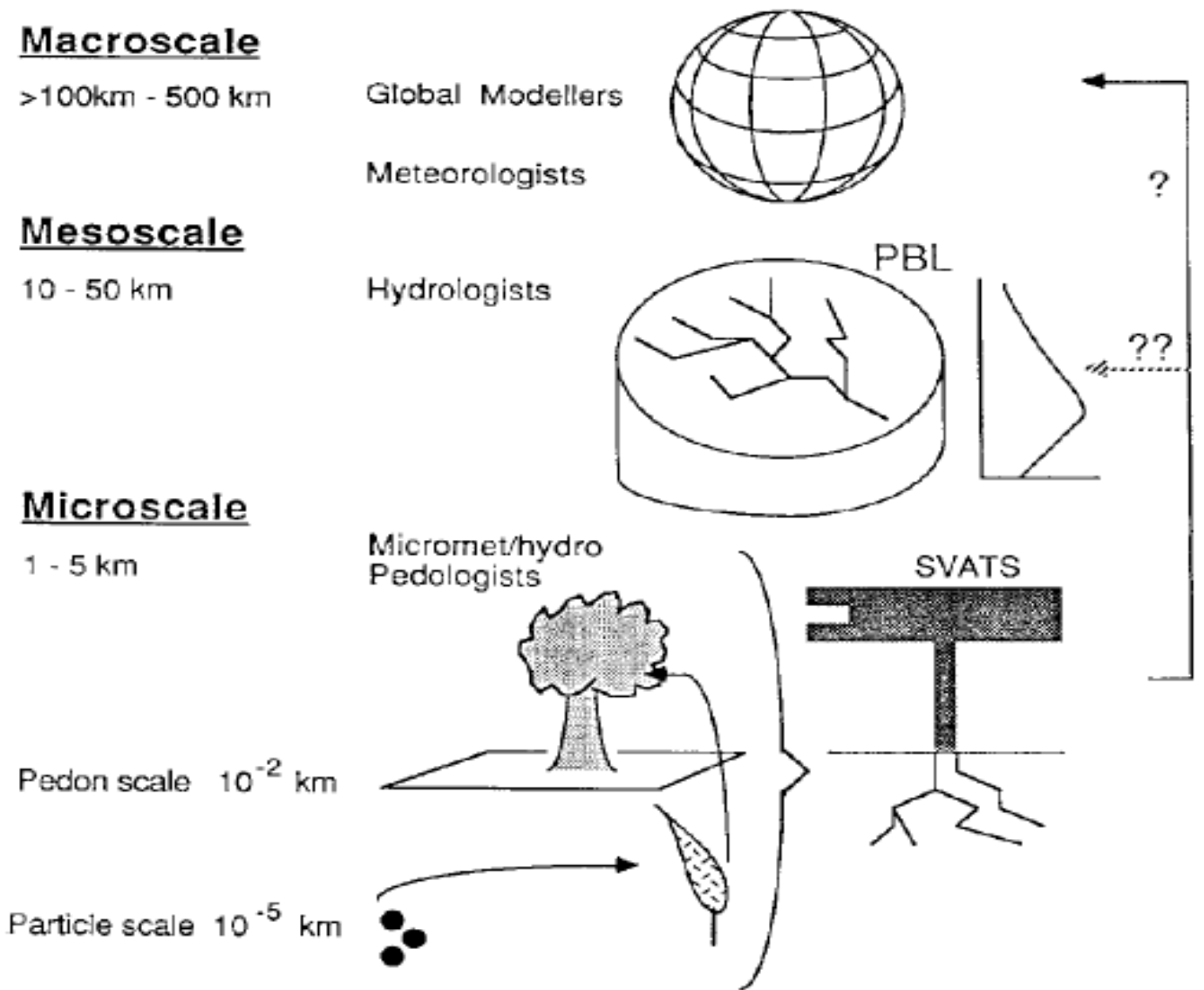

Figure 1. Global climate modellers freely utilise microhydrological and micrometeorological concepts and parameterizations in their coarse resolution models. This exploitation is based on the assumption that scaling of hydrological and other properties is reasonable. Note: SVATS means Soil-Vegetation-Atmosphere-Transfer-Scheme and PBL is the Planetary Boundary Layer (after Henderson-Sellers et a1., 1995). 


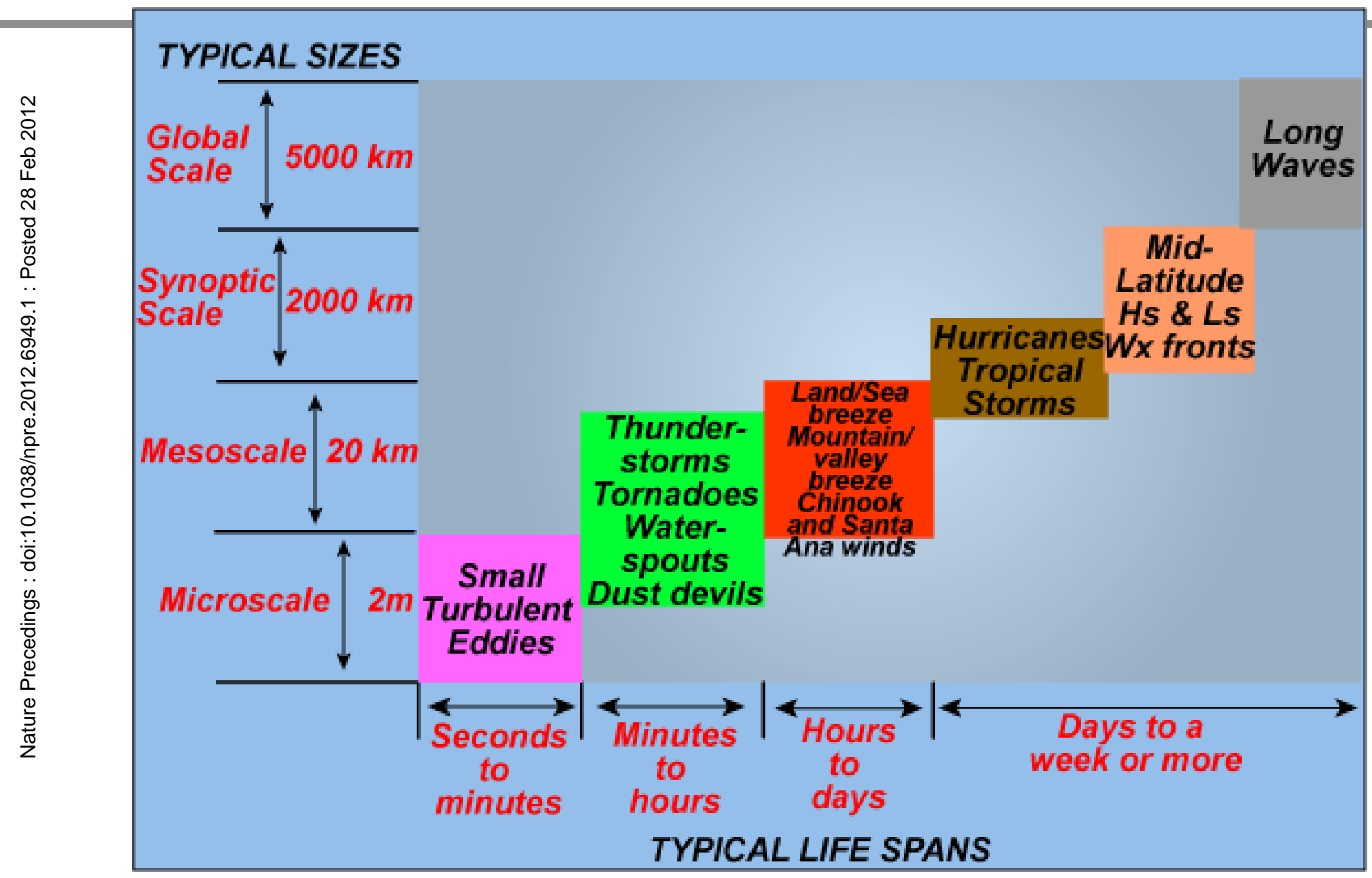




\section{Given}

- Three equations of motion $(u, v, w)$

- Continuity equation ( $\rho)$

- The ideal gas law (p)

- Thermodynamic energy equation $(T)$

- 6 equations, 6 unknowns $u, v, w, p, \rho, T$

- (Also: moisture, salinity etc. conservation)

- Too complicated to solve in practice - need to simplify / and turn to computational fluid dynamics!

The Primitive equation

- Explain the basic (large-scale) dynamics of the atmosphere

- In principle: possible to solve (\#unknowns = \#equations).

- In practice: analytical solutions not possible (e.g. nonlinearity)

(Various filtered forms of the equations of motion...) 


\section{Overview of Weather and Climate Models and the Required Observations}

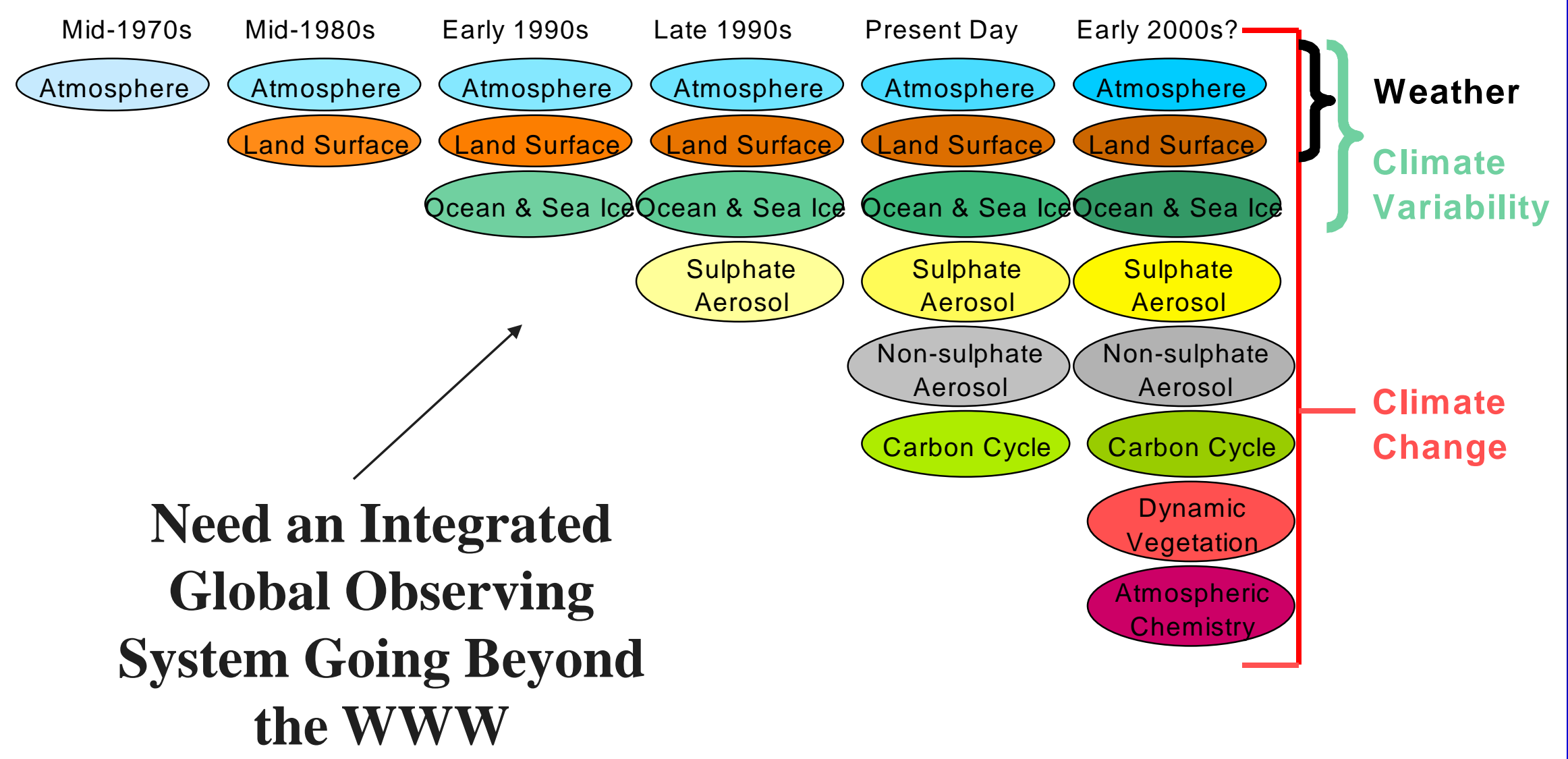

Ants Leetma, GFDL,NOAA,2007 


\section{Part Three}

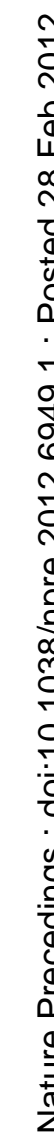

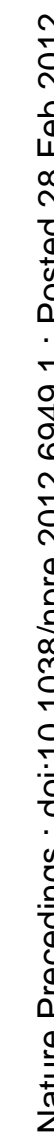

\section{Introductory Description} of

Regional

Climate Models 


\section{Model Details}

- Model used for study is ICTP Regional Climate Model Version 3 (RegCM3 )

- RegCM is a 3-dimensional, sigma-coordinate, primitive equation regional climate model

- RegCM3 is maintained \& supported by the Physics of Weather \& Climate Group at the Abdus Salam International Centre for Theoretical Physics in Trieste, Italy

- Model developed in Fortran code alongwith Makefile configuration 


\section{Computational Requirements}

- Successfully run in Parallel processing machines or High performance workstation (Sun, IBM, DEC, SGl etc)

- Portability also proved for PC-Linux, Fedora at PC with limited experimental option and Makefile compatibility

- Makefile compatible for

$>$ AMD64

$>\mathrm{IBM}$

$>\mathrm{DEC}$

$>$ IFC7

$>$ IFC8

$>$ IFC8-64

$>\mathrm{PGI} 3$

$>\mathrm{PGI} 5$

$>$ SUN

$>\mathrm{SGI}$

- RAM requirement 2GB ( Minimum)

- Harddisk 80 GB (Minimum)

- Operating System required UNIX or Linux

- Knowledge of Fortran and Graphics program (GrADS, Ferret, NCL, Matlab etc) 


\section{Model Grid configuration}

- Finite differenced model

- Arakawa-b staggered horizontal grid

- Temperature, moisture and pressure fields are defined on the cross points.

- The horizontal winds are defined on the dot points.

- Sigma vertical coordinate

$$
\sigma=\frac{P-P_{t}}{P_{s}-P_{t}}
$$

$p=$ pressure of a layer

$\mathbf{p}_{\mathrm{s}}=$ surface pressure

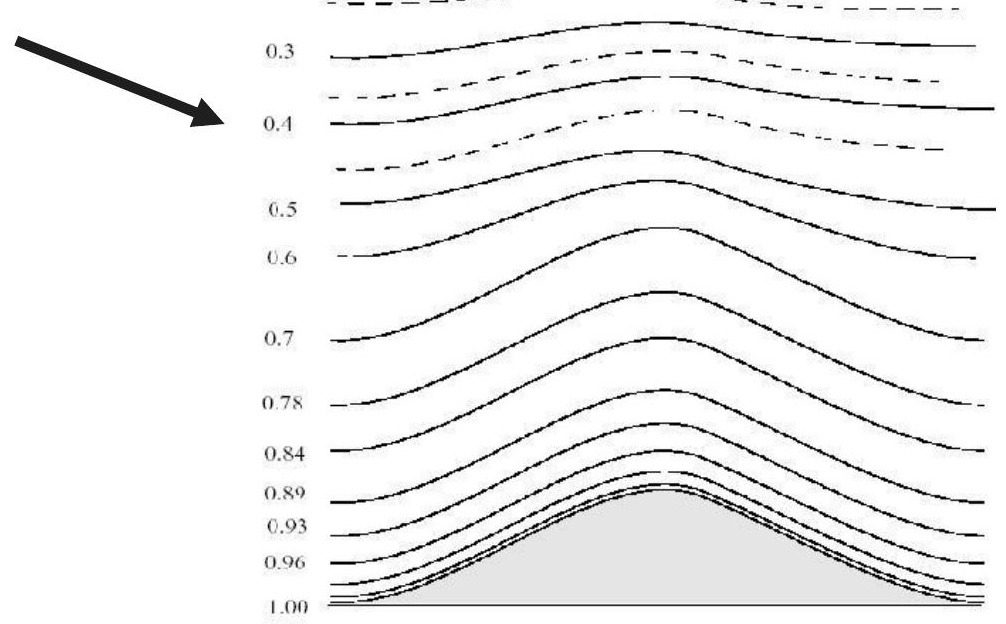




\section{The equations of a climate model}

$$
\frac{\partial \bar{V}}{\partial t}+\bar{V} \cdot \nabla \bar{V}=-\frac{\nabla p}{\rho}-2 \bar{\Omega} \times \bar{V}+\bar{g}+\bar{F} \bar{V}
$$

Conservation

of momentum

$$
C_{p}\left(\frac{\partial T}{\partial t}+\bar{V} \cdot \nabla T\right)=\frac{1}{\rho} \frac{d p}{d t}+Q+F_{T}
$$

Conservation

of energy

$$
\frac{\partial \rho}{\partial t}+\bar{V} \cdot \nabla \rho=-\rho \nabla \cdot \bar{V}
$$

Conservation

$$
\text { of mass }
$$

$$
\frac{\partial q}{\partial t}+\bar{V} \cdot \nabla q=\frac{S_{q}}{\rho}+F_{q}
$$

\section{Conservation of water}

$$
p=\rho R T
$$




\section{Model physics}

- BATS1E Land Surface Model (Dickinson, 1993)

- CCM3 Radiation Scheme

- Planetary Boundary Layer scheme (Holstag,1990)

- SUBEX large-scale precipitation (Pal, 2000)

- Convective precipitation schemes

- Grell

- Kuo

- Betts-Miller

- Ocean flux parameterizations

- BATS

- Zeng (1998) 


\section{RegCM3 Input Data Requirements}

- Surface data (Time-invariant)

> Topography (GTOPO30 elevation data of USGS)

$>$ Landuse Landcover data (GLCC landuse datset of USGS)

- Gridded analysis or GCM forcing data

$>3 \mathrm{D}$ field( $\mathrm{u}, \mathrm{v}, \mathrm{w}$ of wind components, $\mathrm{RH}$, Geopotential height, Temperature)

$>$ 2D field (Surface Pressure \& Surface Temperature)

$>$ GCMs (NNRP1, NNRP2, ERA40, ECWCRP, FVGCM) data resolution is $\left(2.5^{0} \times 2.5^{0} \times L 17\right)$

- Sea Surface Temperature Data (GISST or OISST) 


\section{Overview of Model Structure}

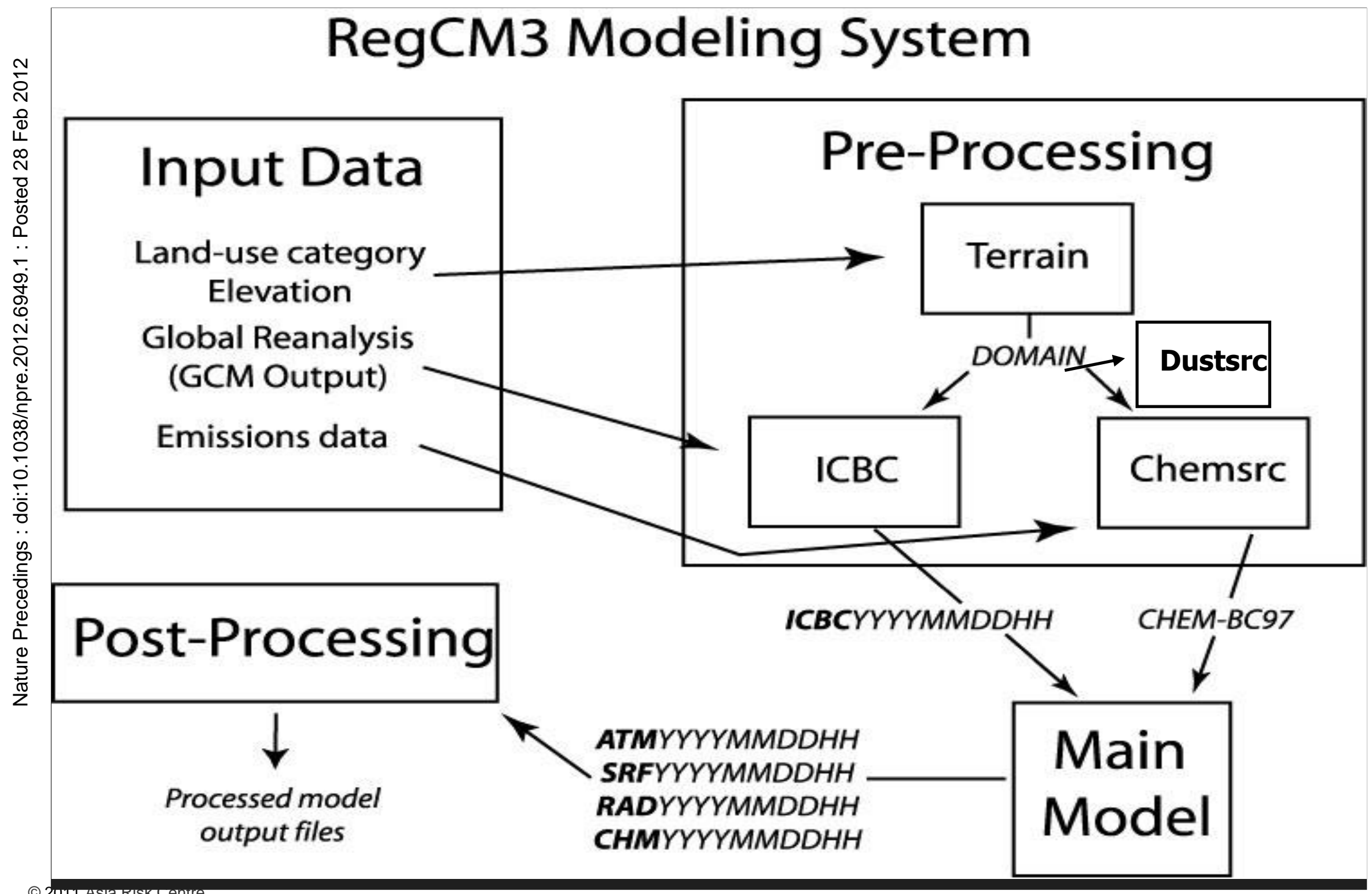




\section{Preparing the data \& run the model}

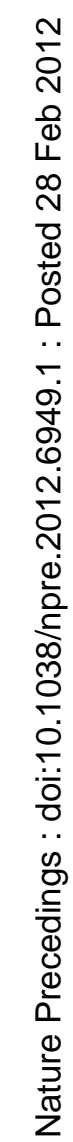

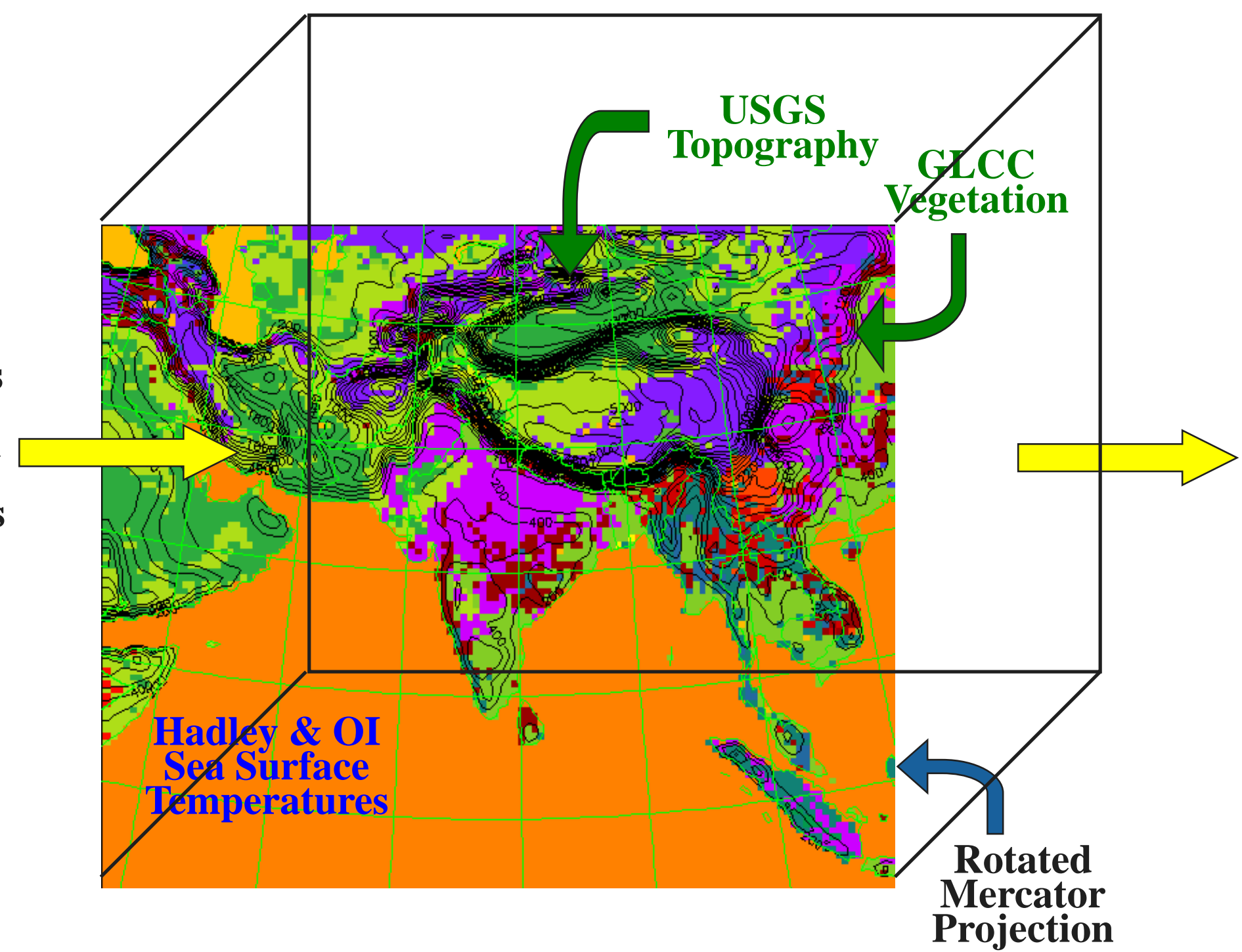
\& GCM Initial and Boundary Conditions

Hadley \& OI Sea Surface Temperatures 


\section{RegCM3 Output Files}

ATMYYYYMMDDHH (Table 8)

\begin{tabular}{|c|c|}
\hline Variables & Description \\
\hline บ & Zonal wind $\left(\mathrm{m} \mathrm{s}^{\mathrm{J}}\right.$ ) \\
\hline $\mathbf{v}$ & Maridional wind (m s ' \\
\hline the & Thamparalura (K) \\
\hline ad & Mixing ralio (g kg ? \\
\hline gc & Cloud mixing ratio (o kg ${ }^{3}$ ) \\
\hline pa & Surfaca pressura (I'a) \\
\hline rt & Tolal precipilalion (mm) \\
\hline $\operatorname{tg} x d$ & Geopolan Lial haight (gpm) \\
\hline smint & Tholal soil walar (mm) \\
\hline $\mathbf{r b}$ & HAga Dow (mom day-1) \\
\hline
\end{tabular}

RADYYYYMMDDHH(Table 10)

\begin{tabular}{|c|c|}
\hline Variables & Description \\
\hline fic & Cloud fraction (fraction) \\
\hline clvp & Cld liquid $\mathrm{H}_{2} \mathrm{O}$ palh $\left(\mathrm{g} \mathrm{m}^{2}\right.$ ) \\
\hline qra & Solar haAling rala (K a J) \\
\hline qr1 & LW oooling rata (Ka J) \\
\hline forw & Surlaca als solar ( $W \mathrm{~m}^{2}$ ) \\
\hline $\mathbf{f l} \mathbf{w}$ & LW cooling of surfaca $\left(W \mathrm{~m}^{2}\right)$ \\
\hline clrgt & Clarr alcy end atsa sol (W $\mathrm{m}^{2}$ ) \\
\hline clrga & Clear aky sur[ata sol (W m \\
\hline clrit & Claar aky nal up lux (W m ') \\
\hline clrls & Clear aky LW surf cool $(\mathrm{W} \mathrm{m}$ ' \\
\hline golln & Inglaml ineid solar ( $\mathrm{W} \mathrm{m} \mathrm{m}^{2}$ ) \\
\hline gabtp & Column alse solar ( $\mathrm{W} \mathrm{m}{ }^{2}$ ) \\
\hline firtp & 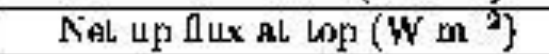 \\
\hline
\end{tabular}

\section{SRFYYYYMMDDHH (Table}

\begin{tabular}{|c|c|}
\hline Varia & Description \\
\hline un & Anamomalar sonal winds ( $\mathrm{m} \mathrm{s}^{\mathrm{J}}$ ) \\
\hline va & Anamomalar maridional winds ( $\mathrm{m} \mathrm{s}^{\mathrm{j}}$ ) \\
\hline dras & Surfaca draig alrasa \\
\hline tg & Ground lampiaralura (K) \\
\hline tff & Foliaga lamparaluta (K) \\
\hline ta & Anamomalar lamparalura (K) \\
\hline q̨a & Anamomalar spaeille humidi $\mathrm{ly}_{\mathrm{kg}} \mathrm{kg}$ \\
\hline smu & Top layar goil moishura (mm) \\
\hline SIrms & lzool layar soil moistura (mm) \\
\hline rt & Thlal pracipilalion (mun day ${ }^{j}$ ) \\
\hline et & Evapolrangpiralion (mm day ${ }^{j}$ ) \\
\hline mós & Surlaca runo[ (mm day ${ }^{\top}$ ) \\
\hline $\sin 0 \pi$ & Show walar aquiralanl (mm) \\
\hline sh & Sangibla haRl ( $\left.W \mathrm{~m}^{2}\right)$ \\
\hline 1Fn & Nial longwava (W m ${ }^{5}$ ) \\
\hline swn & Fal solar alsorbad ( $W \mathrm{~m}^{2}$ ) \\
\hline 1Find & Downward longwava ( $W \mathrm{~m}^{2}$ ) \\
\hline STw & Solar incidanl ( $W \mathrm{~m}^{2}$ ) \\
\hline TC & Convecliva pracipi lalion (mm day ' \\
\hline parf & 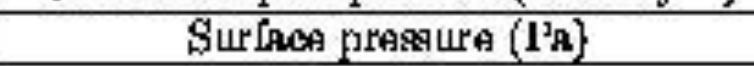 \\
\hline ephl & I'BL haight (m) \\
\hline
\end{tabular}




\section{RegCm3 Model Capability}

,

Input data resolution

$$
\left(2.5^{0} \times 2.5^{0}\right)
$$

Single Time as Initial condition

(8 GCM variables)

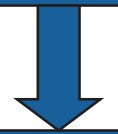

RegCM3 Model

Any Mode of Experiment $\&$

Sensitivity Studies including Conventional weather and climate Related studies
Output data Resolution ( horizontal spatial $10 \mathrm{~km}$ to $100 \mathrm{~km}$ Temporal resolution 1 hour to Month) Total 44 variables (in built) 


\section{Part Four}

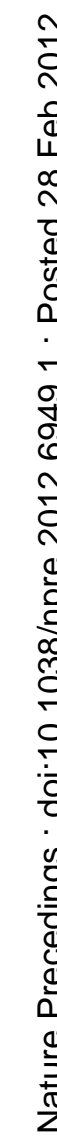

\section{Diseases}

Simulations

1. Mango Powdery Mildew 2. Pandemic Dengue 


\section{Forecasting Mango Powdery Mildew Diseasese} with

\section{High Performance Regional Climate Model}

P. Sinha, Division of Plant Pathology, I.A.R.I. New Delhi 12

S. Jha \& R. C. Raghava, Centre for Atmospheric Sciences (CAS), I.I.T. Delhi, New Delhi 16

Institute of Technology Delhi in collaboration with Indian Agricultural Research Institute, New Delhi. Few of the left analysis has been completed during my present tenure in Asia Risk Centre, RMS Risk Management Solutions India, Noida, India 


\section{Back Ground: Mango Powdery Mildew Disease}

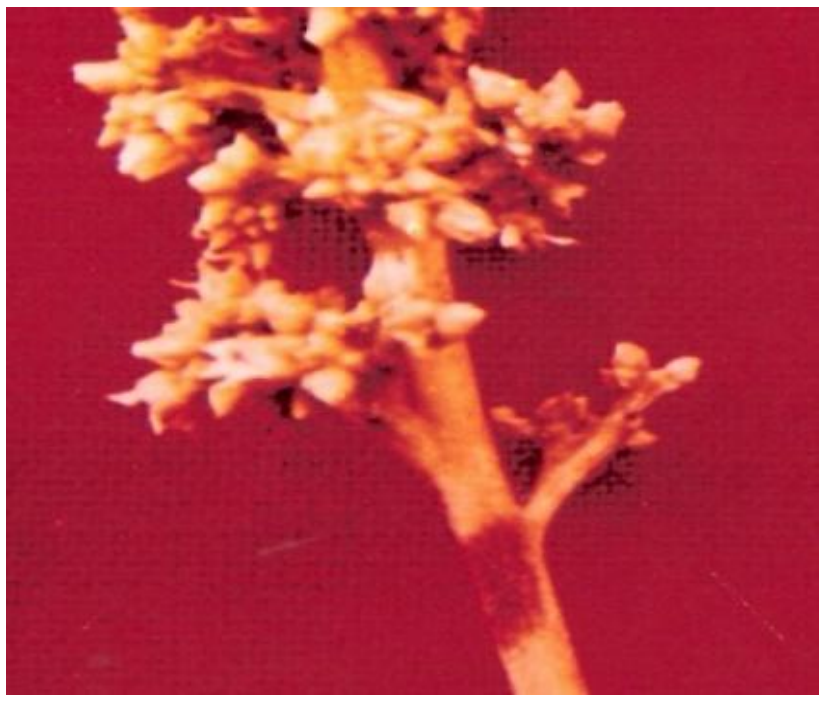

Visible Brown Patch on Panicle

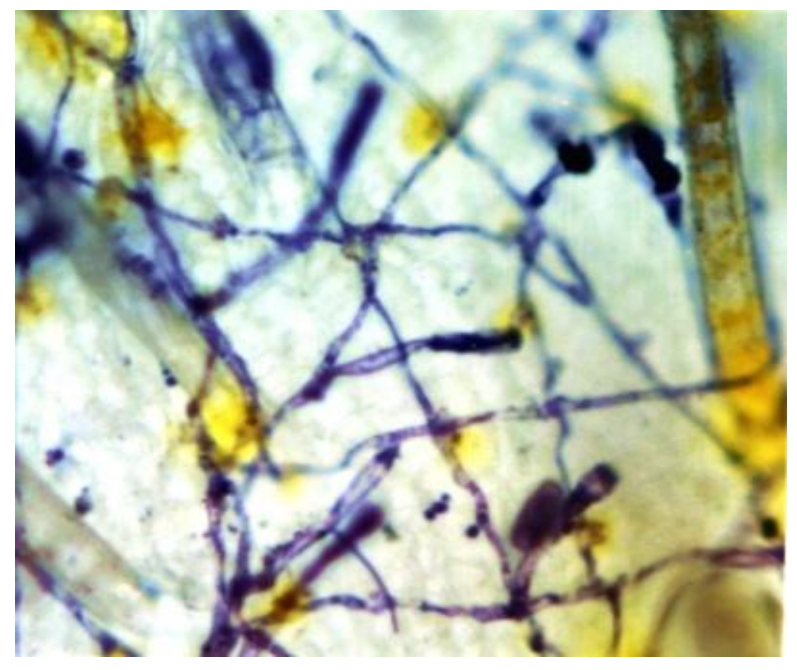

Initial Fungal Development

Kingdom: Fungi Phylum: Ascomycota Class:

Leotiomycetes Subclass: Leotiomycetidae

Order: Erysiphales Family: Erysiphaceae Genus:

Oidium Species: $\boldsymbol{O}$. mangiferae 


\section{Statistical Disease Model Study done by Dr. P.Sinha}

- Climate Variables $\rightarrow$ Hourly Temperature \& RH data from December to February for 1994-1995 and 1997 were used by AWS data of I.A.R.I, New Delhi

- Disease Data $\rightarrow$ Observed Mango Powdery Mildew disease infestation (brown patches etc) in Mango orchard, I.A.R.I., New Delhi 


\section{Infection Probability based on Temperature (Disease Function)}

Infection probability based on temperature index For predicting the probability of infection based on temperature the following model (Yin et al. 1995) has been used,

$$
f(T)=\left\{\begin{array}{c}
\left(\frac{T_{\max }-T}{T_{\max }-T_{\text {opt }}}\right)\left(\frac{T-T_{\min }}{T_{\text {opt }}-T_{\min }}\right)^{\left(T_{\text {ovi }}-T_{\max }\right) /\left(I_{\min }-T_{\text {wit }}\right)} \text { if } T_{\min } \leq T \leq T_{\max } \\
0, \text { otherwise }
\end{array}\right.
$$

Parameters in the model are Tmin, Topt and Tmax, which denote the minimum, optimum and maximum temperature $\left({ }^{\circ} \mathrm{C}\right)$ for infection, respectively. The model describes a probability, it has values between 0 and 1 . So, $f(T)=0$ at $T$ $=T$ min and $T=T \max$ and $f(T)=1$ at $T=$ Topt.

In our case for estimate of $f(T)$ take the following values Tmin $=10^{\circ} \mathrm{C}$; $\operatorname{Tmax}=36^{\circ} \mathrm{C}$; $\mathrm{Topt}=26^{\circ} \mathrm{C}$ 


\section{Sporulation Rate based on Temperature}

Sporulation rate based on temperature

Secondary infection spread of the disease is calculated indirectly based on the effect of temperature on sporulation (Sinha, 2005). The model for sporulation rate (y)

$\mathrm{y}=(0.002574 \mathrm{~T}-0.010783)\{(1-\exp [0.22492(\mathrm{~T}-36)]\}$.

Daily inoculums potential for spore formation was calculated by hourly accumulating the reciprocal of rate of sporulation

Rate of sporulation $(\mathrm{y})=(\mathrm{aT}-\mathrm{b})\{(1-\exp [\mathrm{c}(\mathrm{T}-36)])\} ;$ For hourly data model parameters $\mathrm{a}=0, \mathrm{~b}=0.002, \mathrm{c}=0.225 \& \mathrm{~T}=$ temperature ${ }^{\circ} \mathrm{C}$ 


\section{Disease Index: based on Temperature \& RH}

Disease favourable period

Powdery mildew forecast model simulates primary infection event by the pathogen based on air temperature and high RH hours and estimates hourly risk values on a scale either 0 or 1 basis to correspond unfavouarble or favourable for infection (Sinha, 1999). Consecutive occurrence of favourable values (1) for 3-5 days is considered for infection with assumption that sufficient inoculum is being present in the orchards

To find out Powdery mildew favourable weather period w.r.t. temperature (T) and high $\mathrm{RH}(\geq 80 \%)$. It is done finding out $\mathrm{O}$ and 1 with condition $T \geq 10^{\circ} \mathrm{C}$ and $\mathrm{RH} \geq 80 \%$.

Powdery mildew favourable weather period When $\mathrm{T} \geq 10^{\circ} \mathrm{C}$ and $\mathrm{RH} \geq 80 \%$ 


\section{${ }^{* *}$ New Disease Index: based on Mixing Ratio}

Disease favourable period based on water mixing ratio

Powdery mildew favourable weather period

Mixing Ratio $\geq 6.227$ (which is equivalent to $\mathrm{T} \geq 10^{\circ} \mathrm{C}$ and $\mathrm{RH} \geq \mathbf{8 0} \%$ )

Mixing Ratio is function of Temperature, RH \& Pressure

** This new approach has been developed by Dr. P. Sinha \& Somnath Jha 


\section{Experimental Design}

- Model Used : ICTP-RegCM3

- LSP Scheme selected : BATS

- PBL Scheme used : Holstag

- Model domain: $50.5^{\circ} \mathrm{N}$ to $30.5^{\circ} \mathrm{S}$ and $10^{\circ} \mathrm{E}$ to $140^{\circ} \mathrm{E}$

- Horizontal resolution: $20 \mathrm{Km}$ Grid spacing

- SST data: Optimum Interpolation of Sea surface data (Reynolds et al., 2002 from NCEP_NCAR dataset)

- GCM data forced : NNRP1 of NCAR centre GCM output for surface fields

- Model Integration : $1^{\text {st }}$ November, 00 hour Preceding Year through $31^{\text {st }}$ March 18 hour for next year with initial condition of $1^{\text {st }}$ November, 00 hour

- High Performance computing interface used : Sun cluster,(28 processor)

- Run node: Parallel Operating Environment (POE)

- Experimentation year selection: 1994, 1995, 1996 \& 1997

- New Fortran code coupled into ICTP-RegCM3 model code to derive Disease Index (based on Temperature \& $\mathrm{RH}$ ), Disease sporulation rate, disease function and New Disease Index (based on Mixing Ratio) 


\section{Fortran Code contd.}

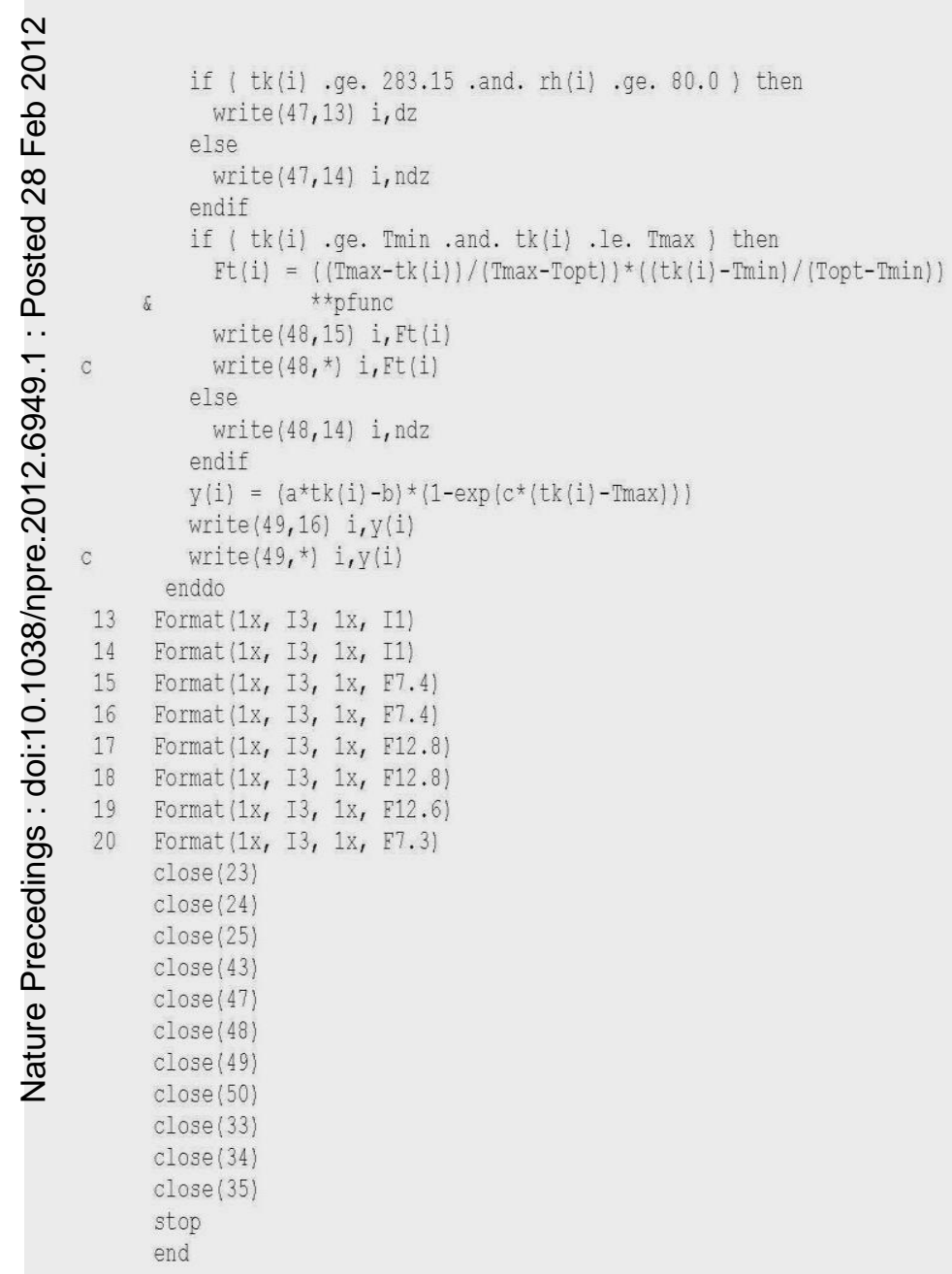

Programme to compute Mixing Ratio

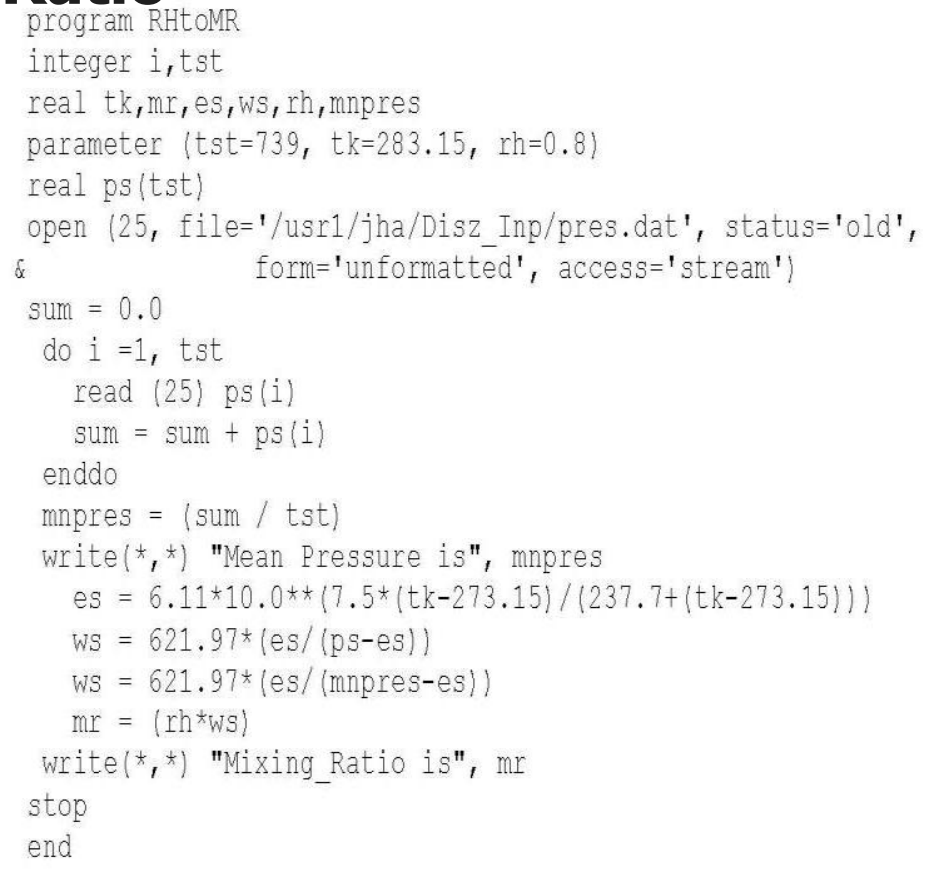

Mixing Ration is function of Temperature, Relative Humidity and Mean Pressure of a particular location 


\section{Domain of Experimental Setup}

定

BATS vegetation Classes

1. Crop/mixed farming

2. Short grass

3. Evergreen needleleaf tree

4. Deciduous needleleaf tree

5. Deciduous broadleaf tree

6. Evergreen broadleaf tree

7. Tall grass

8. Desert

9. Tundra

10. Irrigated Crop

11. Semi-desert

12. Ice cap/glacier

13. Bog or marsh

14. Inland water

15. Ocean

16. Evergreen shrub

17. Deciduous shrub

18. Mixed Woodland

19. Forest/Field mosaic

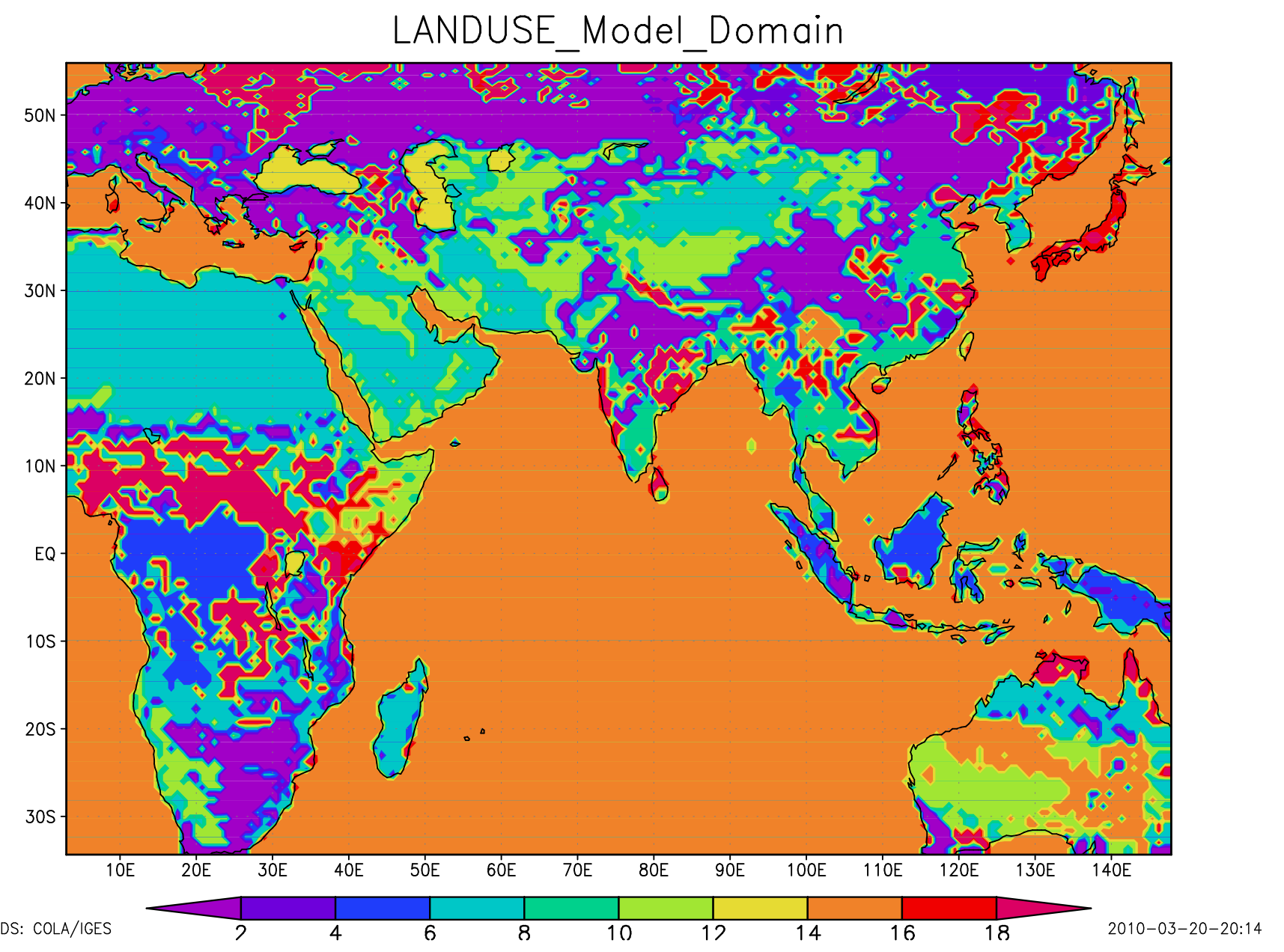

-201. ANateferand Land mixture 


\section{Fine Model Grids of Indian domain}

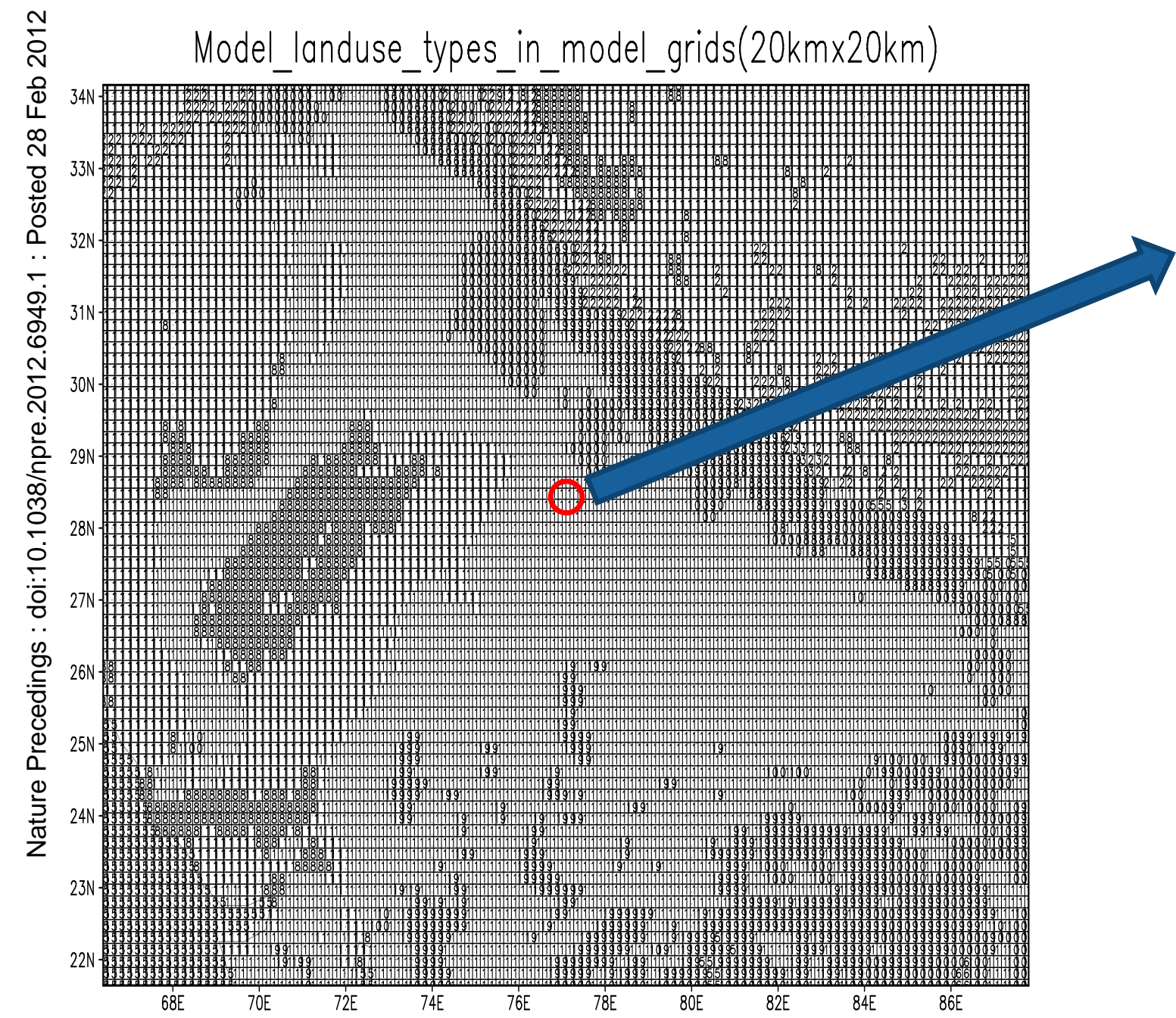

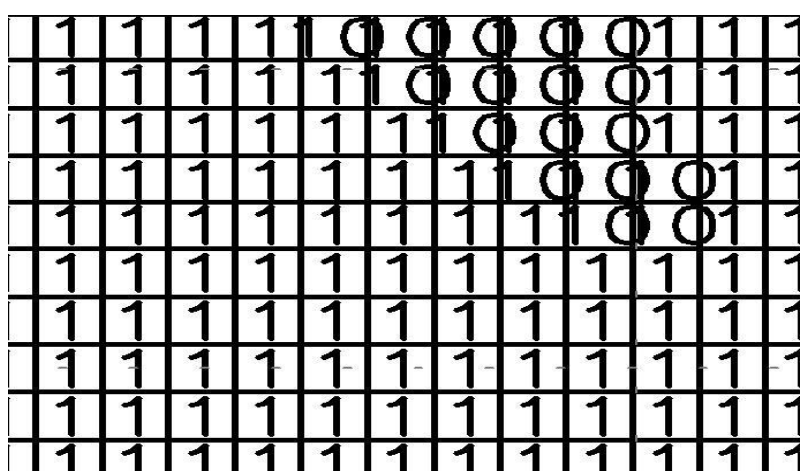

1: crop/mixed farming [1] 2: short grass [2] 3: Evergreen needleleaf tree [3] 4: Deciduous needleleaf tree [4] tree [5]

6: Evergreen Broadleaf tree [6] 7:Tall grass [7] 8: Desert [8]

9: Tundra [9] A:Irrigated crop [10] B: Semi-desert [11] C: Ice cap/Glacier [12] D: Bog/marsh [13] E:Inland water [14] F: Ocean [15] G:Evergreen shrub [16] H: Deciduous shrub [17] I:Mixed woodland [18] J:Forest or forest mosaic [19]

K: water and land mixture [20] 


\section{Biophysical Parameters of BATS Vegetation Class}

Thbla 2 BAIS wantation land-eorer

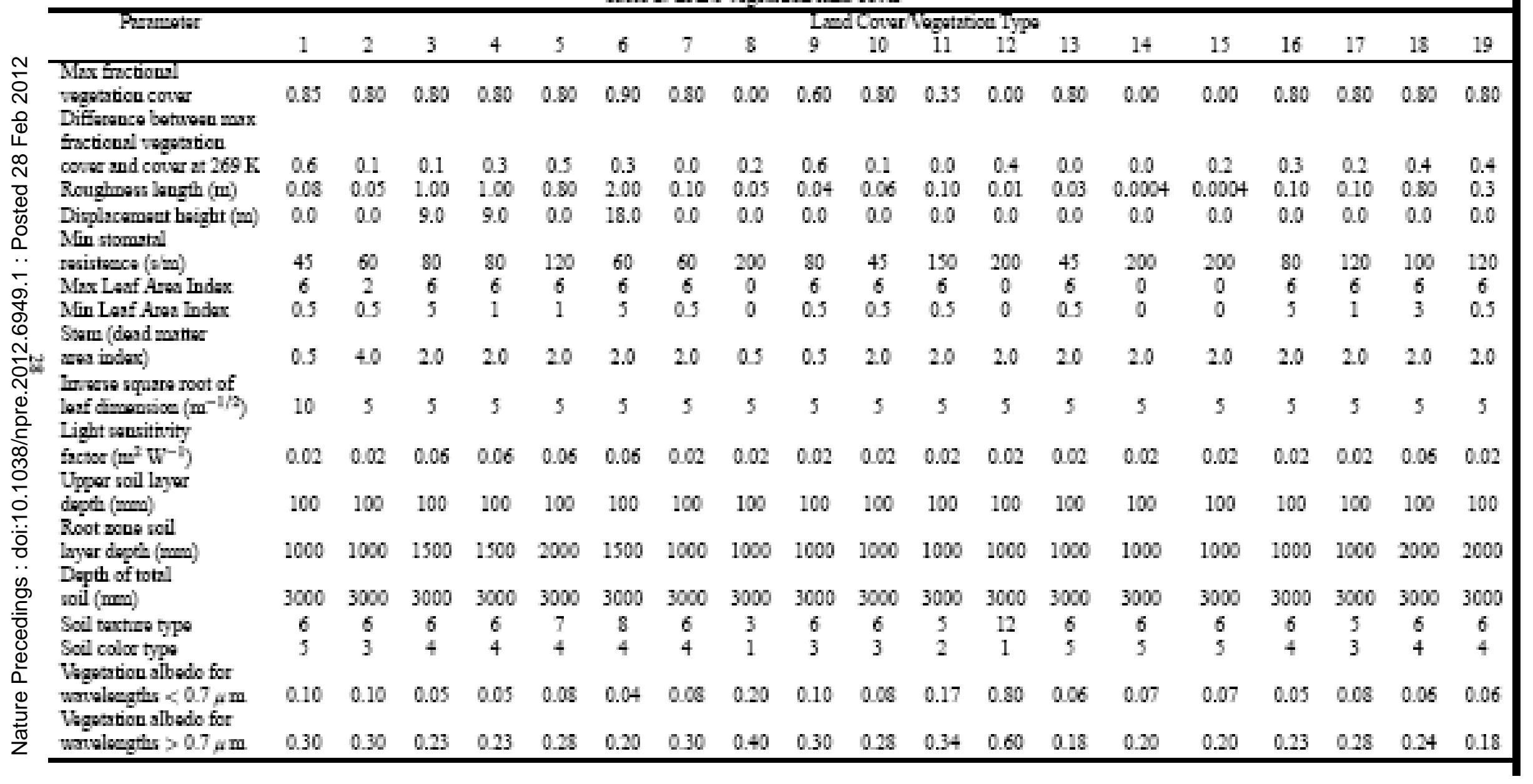




\section{Terrain variability of the Domain}
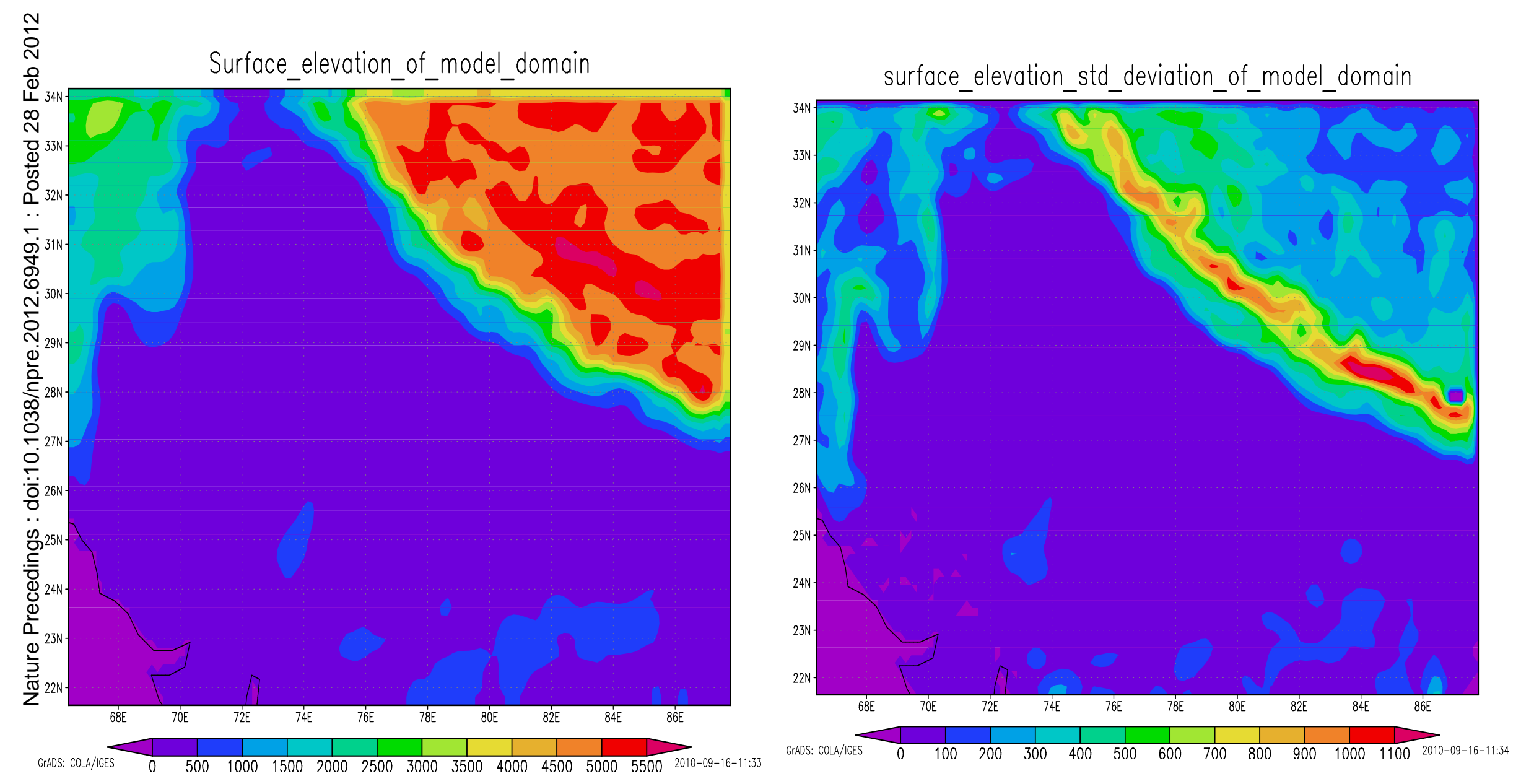


\section{Disease Code Coupled RegCM3 Model Output}

- Model output extracted for Delhi regions (grids)

- Model downscaled output climate variables were validated against the I.A.R.I. AWS weather data

- Disease Index (based on Temp. \& RH) and New Disease Index (based on Mixing Ratio) are compared and forecast skill of both the approaches has been analysed

- Diseases of the two seasons are described further as Disease Cycle 1 (for the Disease of period Dec, 1994 to Feb 1995) \&

Disease Cycle 2 (for the Disease of period Jan., 1997Feb.1997) 


\section{Disease Function and Sporulation Rate}

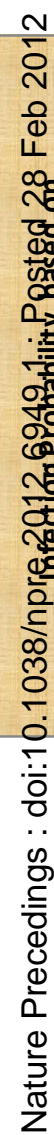

\begin{tabular}{|c|c|}
\hline Cumulative Hour Count & Week No. \\
\hline 0 & 0 \\
\hline 168 & 1 \\
\hline 336 & 2 \\
\hline 504 & 3 \\
\hline 672 & 4 \\
\hline 840 & 5 \\
\hline 1008 & 6 \\
\hline 1176 & 7 \\
\hline 1344 & 8 \\
\hline 1512 & 9 \\
\hline 1680 & 10 \\
\hline 1814 & 11 \\
\hline
\end{tabular}

Cumulative Hour Count Since Dec1, 1994: 00 Hour to Feb15,1995:23 hour

\section{Disease Cycle1(Dec1,1994-Feb15,1995)}

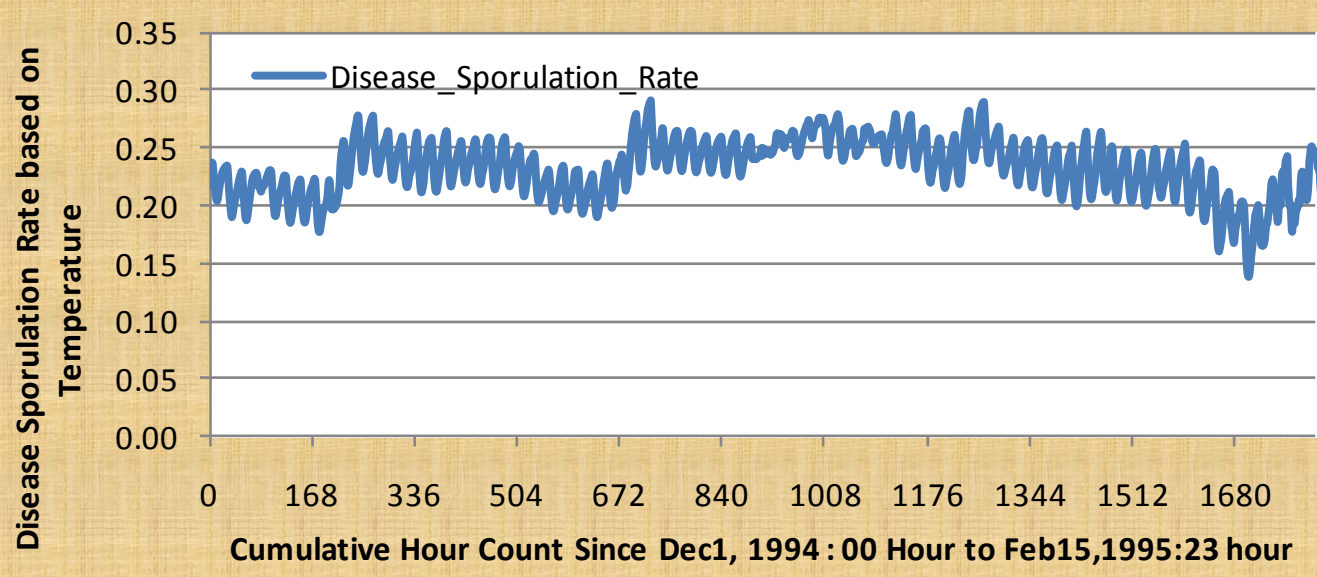




\section{Forecast of Disease Index based on Temp \& RH as well as on Mixing Ratio for Disease Cycle 1}

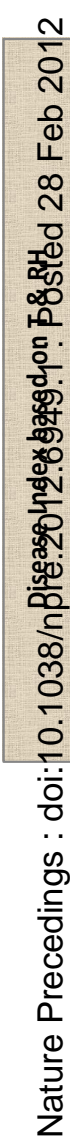

\section{Disease Cycle1(Dec1,1994-Feb15,1995)}

Disease Index (based on T and RH)

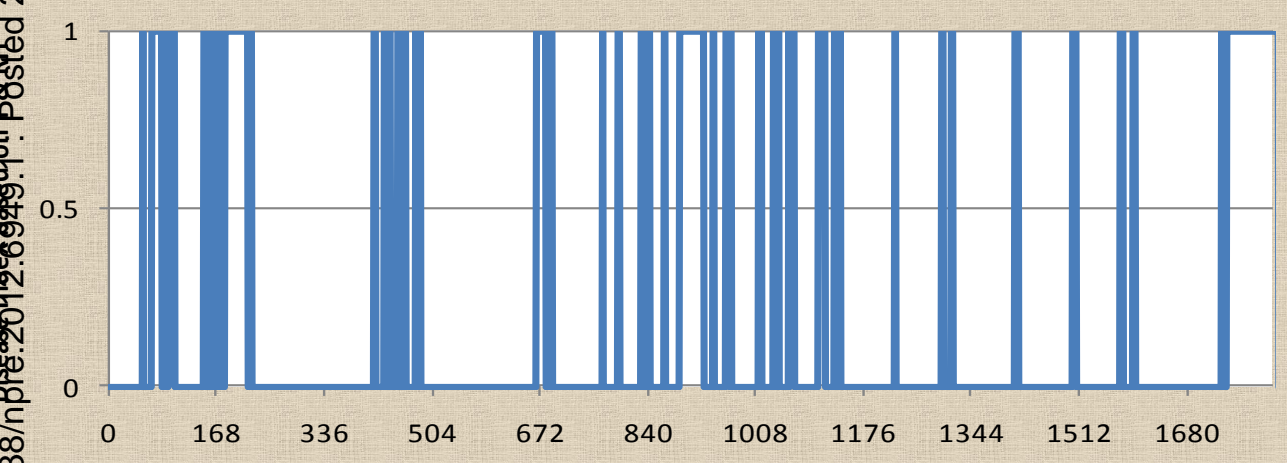

Cumulative Hour Count Since Dec1, 1994 : 00 Hour to Feb15,1995:23 hour

\begin{tabular}{|c|c|}
\hline Cumulative Hour Count & Week No. \\
\hline 0 & 0 \\
\hline 168 & 1 \\
\hline 336 & 2 \\
\hline 504 & 3 \\
\hline 672 & 4 \\
\hline 840 & 5 \\
\hline 1008 & 6 \\
\hline 1176 & 7 \\
\hline 1344 & 8 \\
\hline 1512 & 9 \\
\hline 1680 & 10 \\
\hline 1814 & 11 \\
\hline
\end{tabular}

Disease Cycle1(Dec1,1994-Feb15,1995)

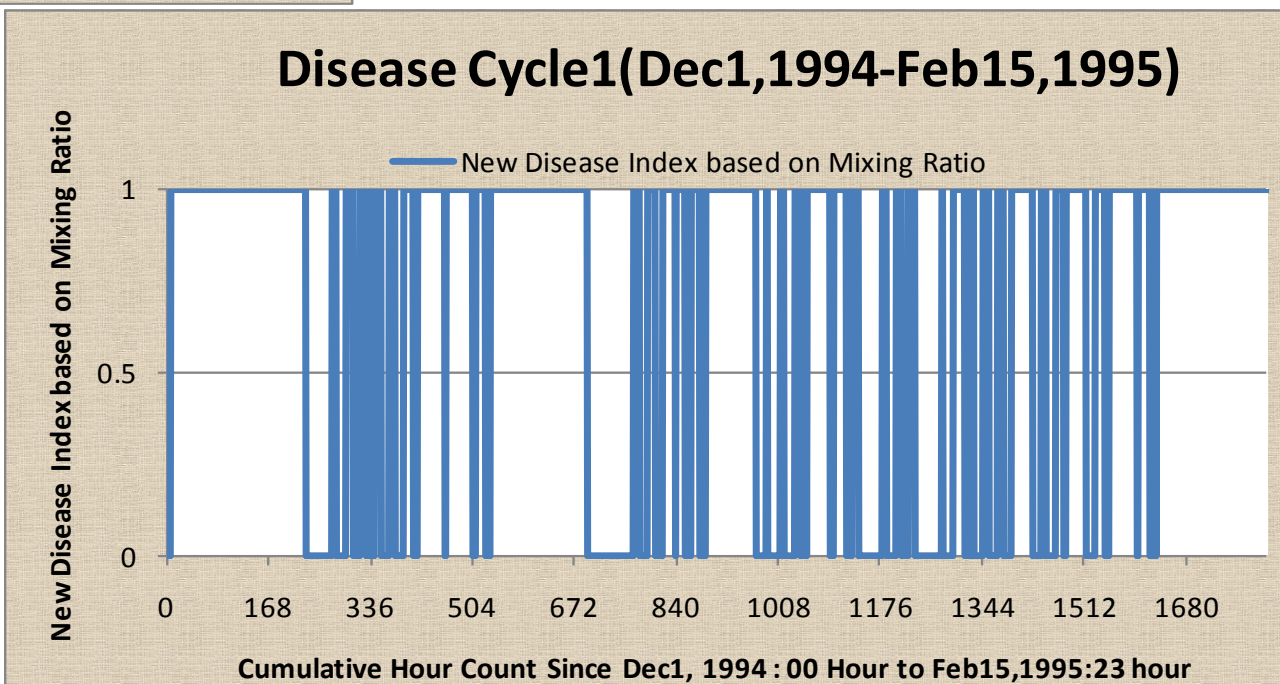




\section{Disease Cycle 1}
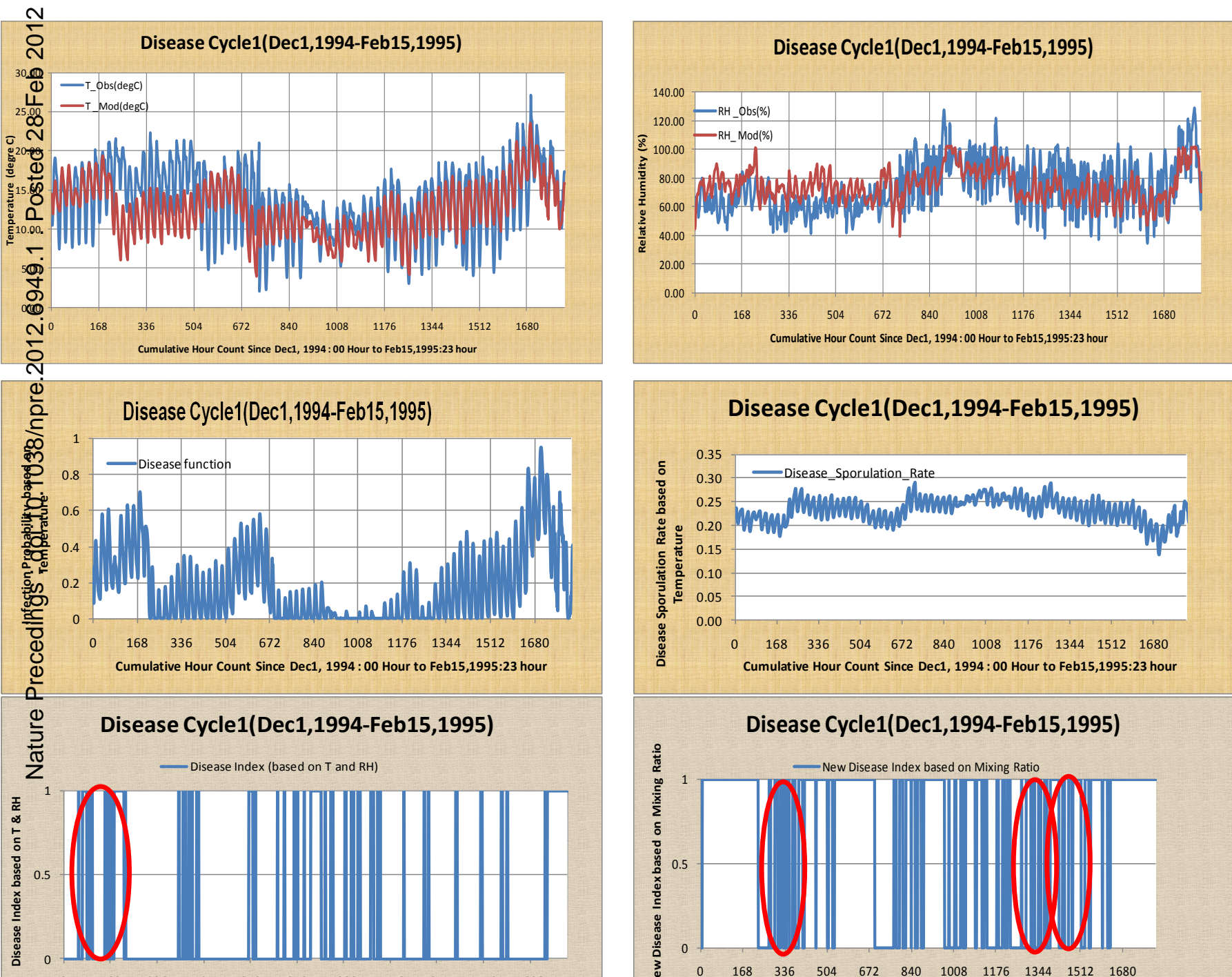

\begin{tabular}{|c|c|}
\hline Cumulative Hour Count & Week No. \\
\hline 0 & 0 \\
\hline 168 & 1 \\
\hline 336 & 2 \\
\hline 504 & 3 \\
\hline 672 & 4 \\
\hline 840 & 5 \\
\hline 1008 & 6 \\
\hline 1176 & 7 \\
\hline 1344 & 8 \\
\hline 1512 & 9 \\
\hline 1680 & 10 \\
\hline 1814 & 11 \\
\hline
\end{tabular}

\section{Disease Cycle1(Dec1,1994-Feb15,1995)}

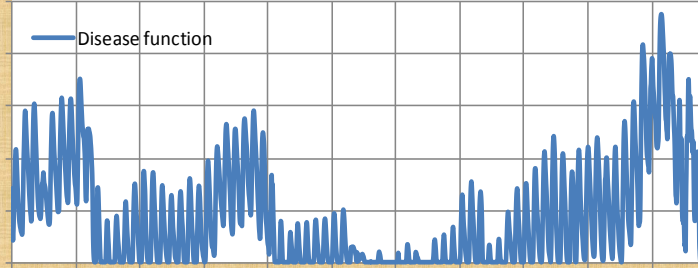

$\begin{array}{lllllllllll}0 & 168 & 336 & 504 & 672 & 840 & 1008 & 1176 & 1344 & 1512 & 1680\end{array}$ Cumulative Hour Count Since Dec1, 1994 : 00 Hour to Feb15,1995:23 hour

\section{Disease Cycle1(Dec1,1994-Feb15,1995)}

- Disease Index (based on $T$ and $R H$ )

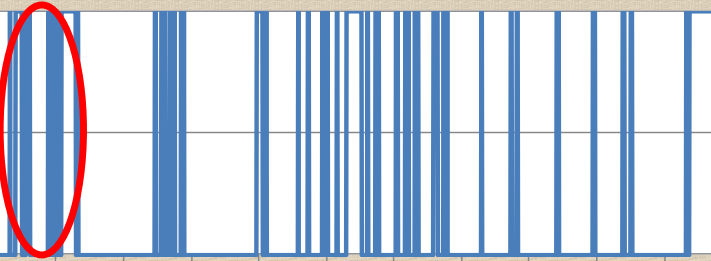

$\begin{array}{lllllllllll}0 & 168 & 336 & 504 & 672 & 840 & 1008 & 1176 & 1344 & 1512 & 1680\end{array}$ Cumulative Hour Count Since Dec1, 1994 : 00 Hour to Feb15,1995:23 hour

\section{Disease Cycle1(Dec1,1994-Feb15,1995)}

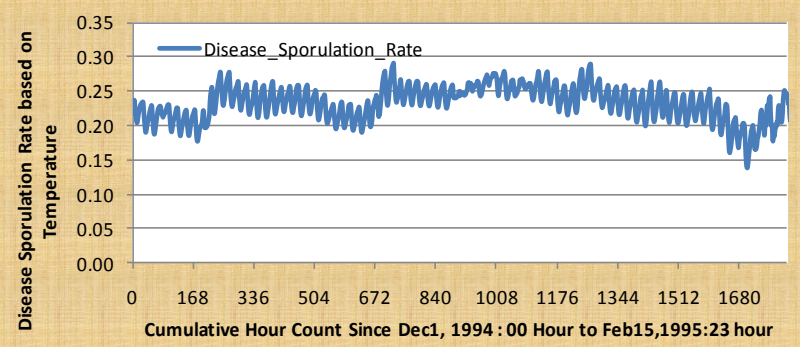

Disease Cycle1(Dec1,1994-Feb15,1995)

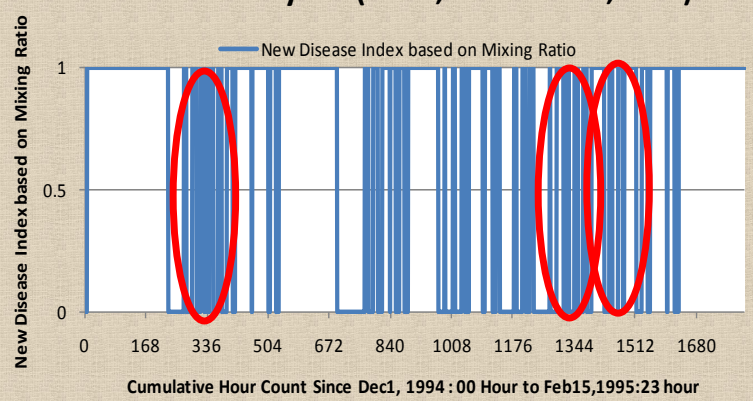




\section{Disease Cycle 2}

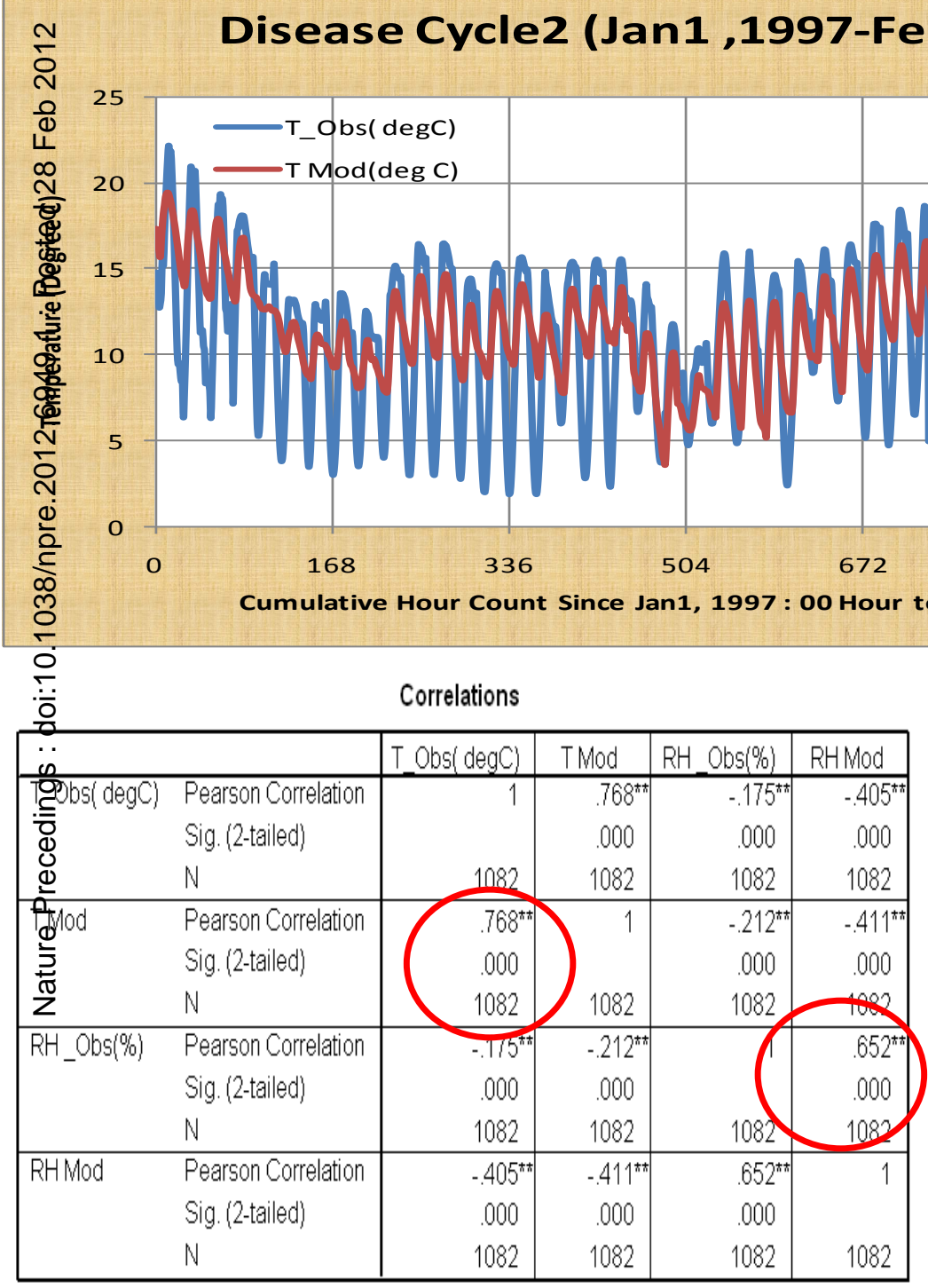

${ }^{\text {*t. }}$. Correlation is significant at the 0.01 level (2-tailed).

\begin{tabular}{|c|c|}
\hline Cumulative Hour Count & Week No. \\
\hline 0 & 0 \\
\hline 168 & 1 \\
\hline 336 & 2 \\
\hline 504 & 3 \\
\hline 672 & 4 \\
\hline 840 & 5 \\
\hline 1008 & 6 \\
\hline
\end{tabular}

$$
840 \quad 1008
$$

Disease Cycle2 (Jan1 ,1997-Feb15,1997)

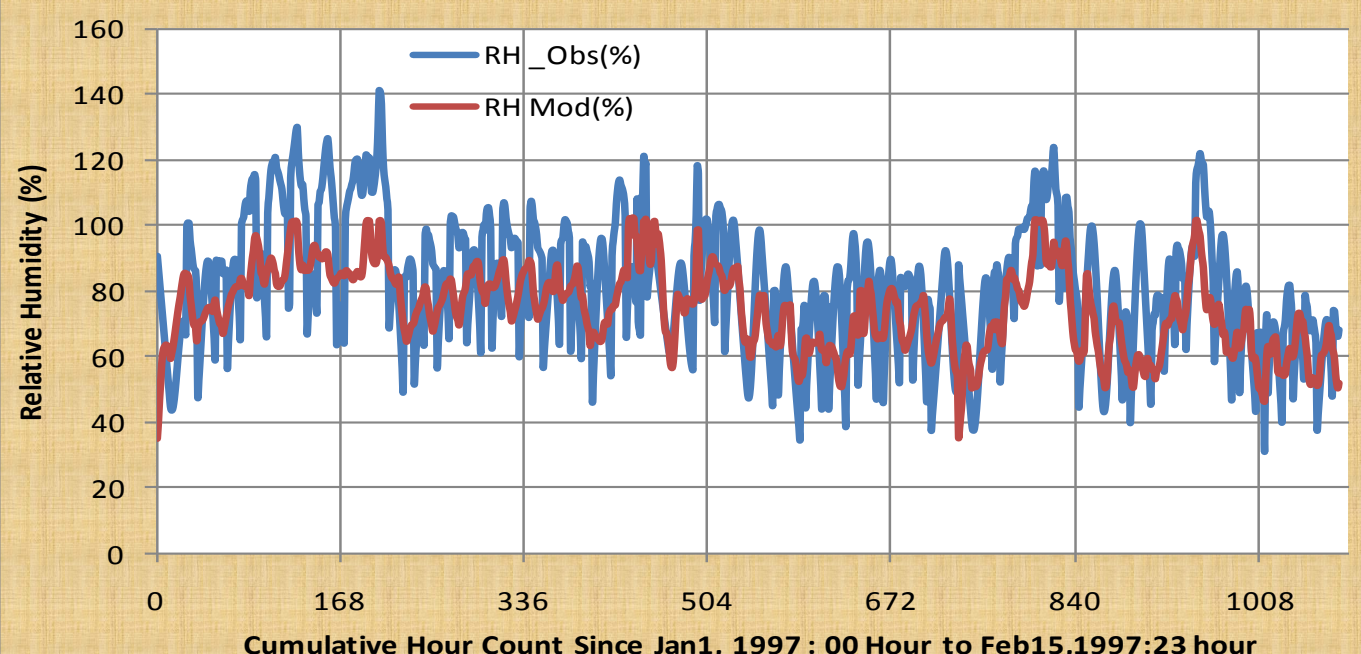

Cumulative Hour Count Since Jan1, 1997 : 00 Hour to Feb15,1997:23 hour 


\section{Disease function \& Sporulation Rate}

(1)

Disease Cycle2 (Jan1 ,1997-Feb15,1997)

1 Disease_function

0.8

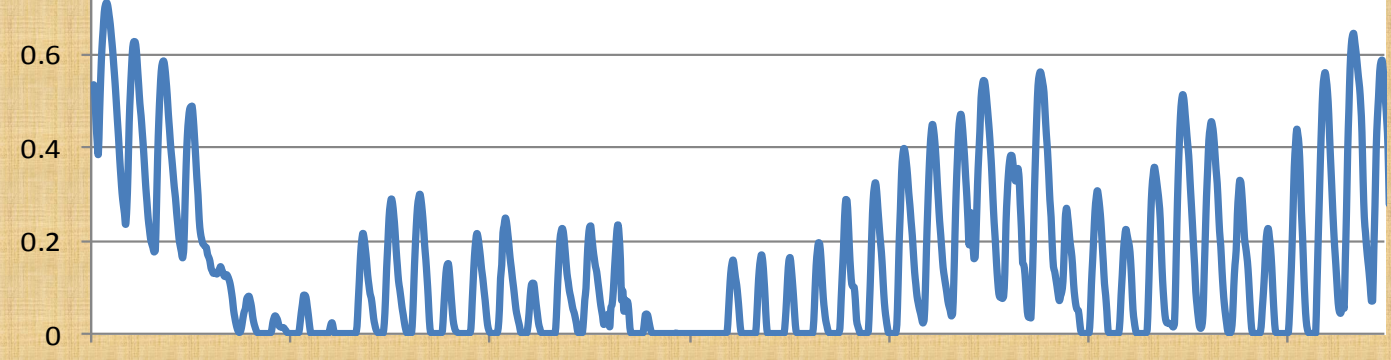

0

336

504

672

840

1008

Cumulative Hour Count Since Jan1, 1997: 00 Hour to Feb15,1997:23 hour

\section{Disease Cycle2 (Jan1 ,1997-Feb15,1997)}

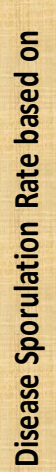

Disease_Sporulation_Rate

0.3

0.25

0.2 manm

\begin{tabular}{|c|c|}
\hline Cumulative Hour Count & Week No. \\
\hline 0 & 0 \\
\hline 168 & 1 \\
\hline 336 & 2 \\
\hline 504 & 3 \\
\hline 672 & 4 \\
\hline 840 & 5 \\
\hline 1008 & 6 \\
\hline
\end{tabular}




\section{Disease Cycle 2}

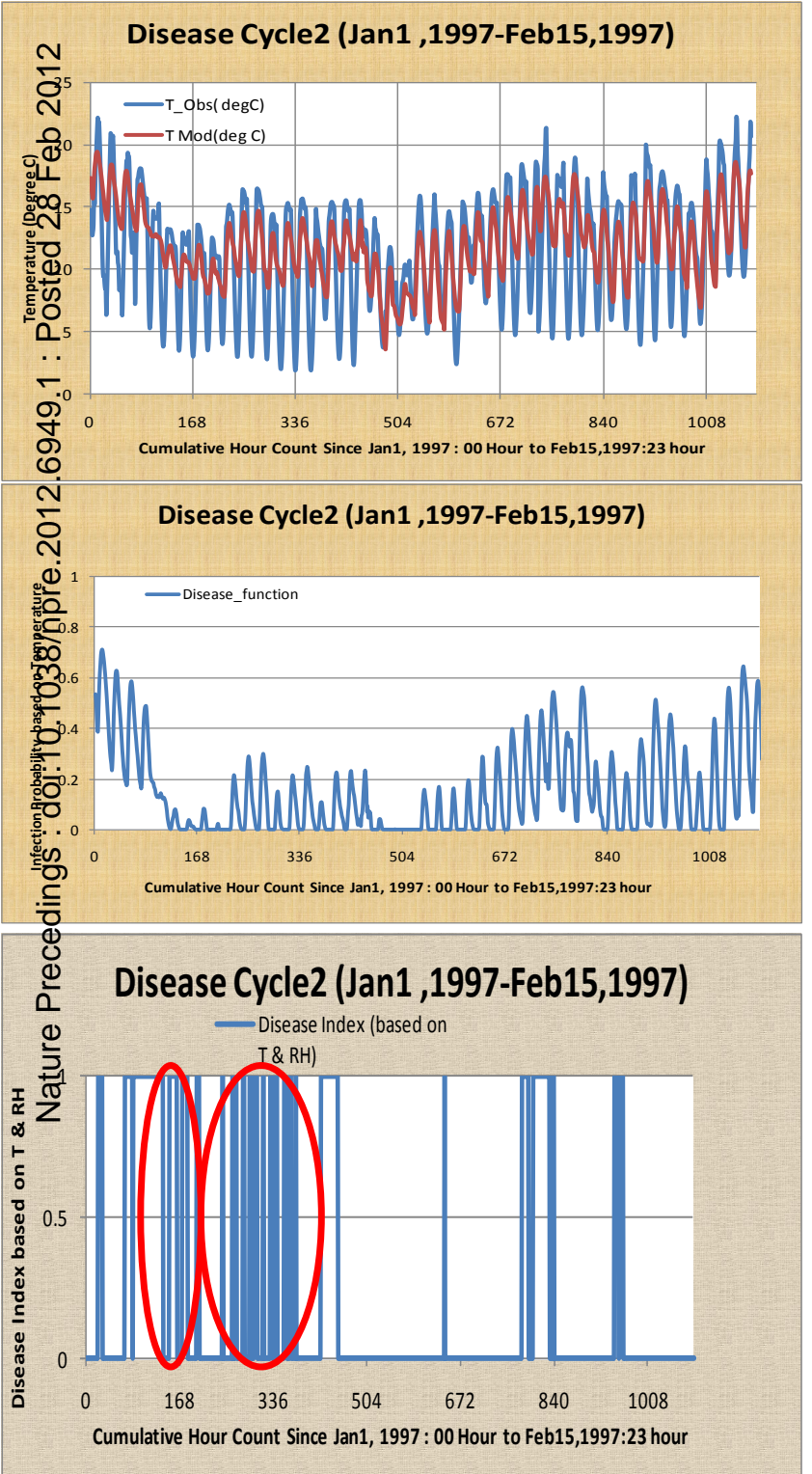

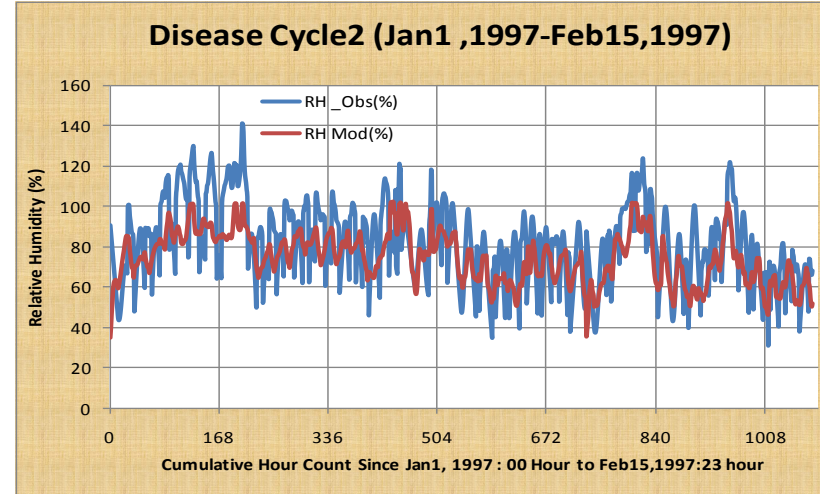

\section{Disease Cycle2 (Jan1 ,1997-Feb15,1997)}

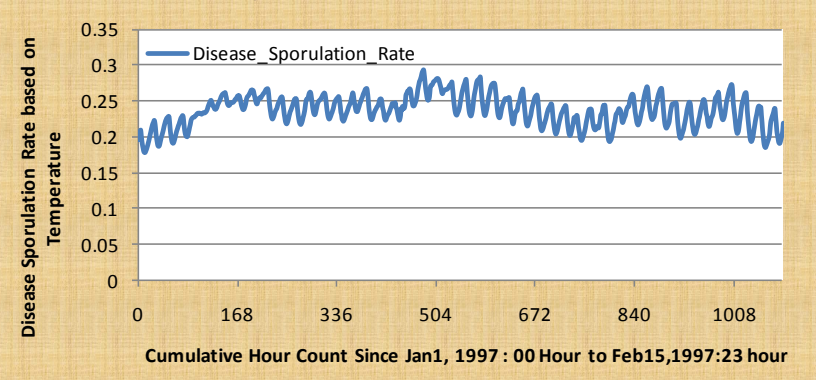

Disease Cycle2 (Jan1 ,1997-Feb15,1997)

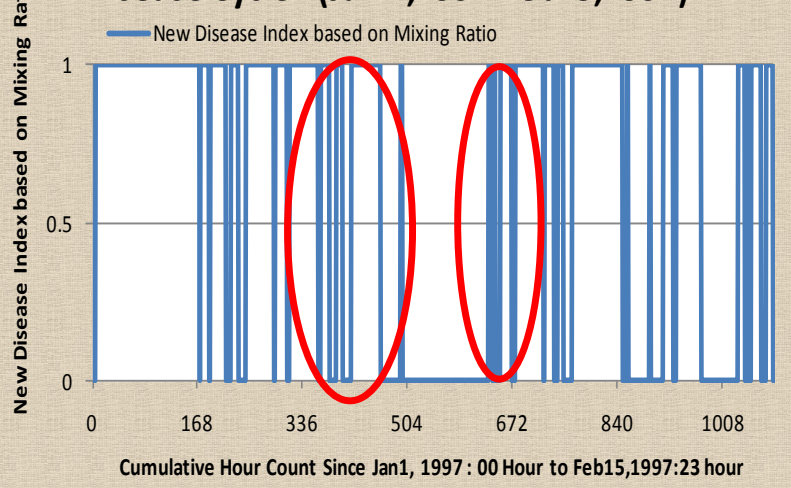

\section{Cumulative Hour Count Week No.}

\begin{tabular}{|c|c|}
\hline 0 & 0 \\
\hline 168 & 1 \\
\hline 336 & 2 \\
\hline 504 & 3 \\
\hline 672 & 4 \\
\hline 840 & 5 \\
\hline 1008 & 6 \\
\hline
\end{tabular}




\section{Forecast Skill Statistics for Disease Cycle 2}

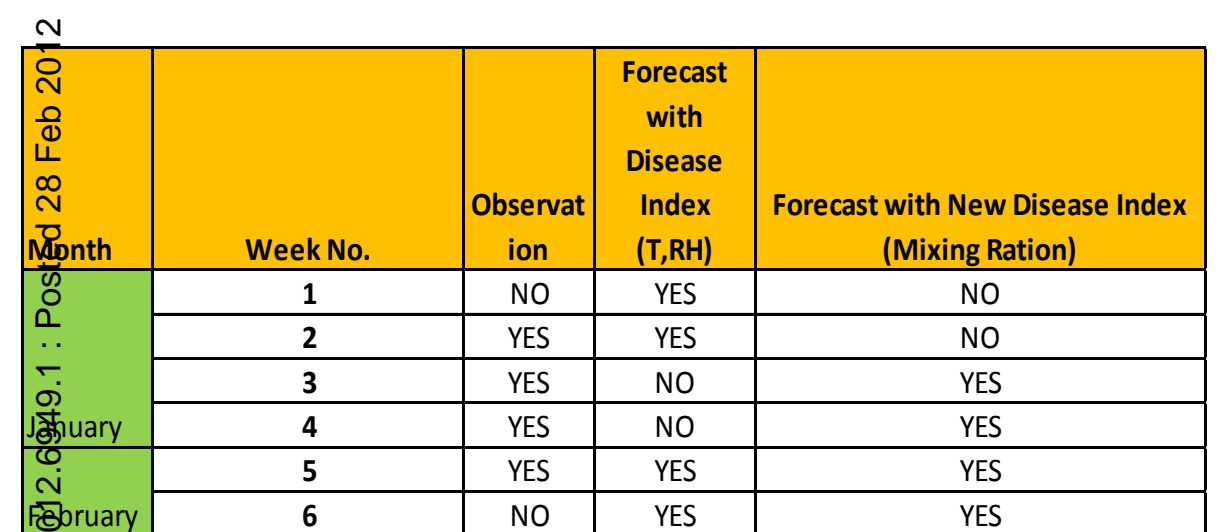

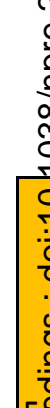

\section{息}

$$
\begin{array}{|c}
\frac{0}{2} \\
\hline \text { Dis } \\
\text { Dis }
\end{array}
$$

T्Forecast with New
Disease Index (Mixin

\begin{tabular}{|c|c|c|c|c|c|c|}
\hline Hit & Miss & $\begin{array}{l}\text { False } \\
\text { Alarm }\end{array}$ & $\begin{array}{l}\text { Correct } \\
\text { Rejection }\end{array}$ & $\begin{array}{l}\text { Corrected } \\
\text { Event }\end{array}$ & $\begin{array}{l}\text { Expected } \\
\text { Correct } \\
\text { Event } \\
\end{array}$ & $\begin{array}{l}\text { Total } \\
\text { Event }\end{array}$ \\
\hline 2 & 2 & 2 & 0 & 2 & 2 & 6 \\
\hline 3 & 1 & 1 & 1 & 4 & 2 & 6 \\
\hline
\end{tabular}

Ration)

\begin{tabular}{|c|c|c|c|c|}
\hline \multirow{7}{*}{ Month } & Week No. & $\begin{array}{c}\text { Forecast } \\
\text { with } \\
\text { Disease } \\
\text { Index } \\
\text { Observat } \\
\text { ion }\end{array}$ & $\begin{array}{c}\text { (T,RH) } \\
\text { Forecast with New Disease Index } \\
\text { (Mixing Ration) }\end{array}$ \\
\hline \multirow{4}{*}{ January } & $\mathbf{1}$ & NO & False Alarm & Correct Rejection \\
\cline { 2 - 5 } & $\mathbf{2}$ & YES & Hit & Miss \\
\cline { 2 - 5 } & $\mathbf{3}$ & YES & Miss & Hit \\
\cline { 2 - 5 } & $\mathbf{3}$ & YES & Miss & Hit \\
\cline { 2 - 5 } & $\mathbf{5}$ & YES & Hit & Hit \\
\hline
\end{tabular}




\section{Conclusions}

- Mango Powdery Mildew coupled RegCM3 output can be used as a satisfactory forecast products

- Numerical models, Regional Climate Model (RCMs) and Weather Forecast Models can be used to study the teleconnecting pattern of crop diseases

- RCMs and Weather forecast models after proper validation can well be used as a good substitute for costly AWS installation

- Mixing Ratio has a better estimation of absolute moisture content and its disease forecasting capability than the combined system of temperature \& $\mathrm{RH}$

- Threshold Mixing Ratio of 6.227 is proven to be a good exiterion for Mango Powdery Mildew disease triggering 


\section{Contd. Conclusions}

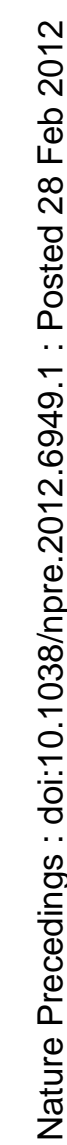

- New Approach with Mixing Ratio has proven to be a much better and novel approach as developed by us (Somnath Jha \& P. Sinha, 2011: this work is under review in a peer reviewed international journal with minor revision). 


\section{Climate Model \&} Pandemic Disease Simulation

\section{under \\ Climate Change Scenario (Chinate Hazard Sensitivity)}

Acknowledgement: The following work on Pandemic Dengue has been single handedly done as a pilot project during my tenure of employment at RMSI Pvt. Ltd, Noida, India in coordination with Pushpendra Johari, Vice President, Risk \& Indurance Unit in RMSI Pvt Ltd, Noida, India. Therefore, this part of the presentation is being done on request of RMSI Pvt Ltd and in presence of Dr. Indu Jain (representative from RMSI Pvt Ltd) for your review with the limitation that the model code will not be displayed or answered 


\section{Pandemic Dengue Disease Simulation for Doubling of Carbon Dioxide IPCC Future Scenario across the Globe}




\section{Contents}

Introduction

舟

- Review

- Component of Ideal Pandemic Dengue Model Physics

- Selection of IPCC Future Scenario

- Pandemic Dengue Algorithm (prototype) \& Validation

- Results

1.Pandemic Dengue under Future Scenario across the globe

2. Limitation of the global distribution of the Pandemic Dengue Disease

- Conclusions

- Limitation of the present algorithm 


\section{Introduction: Why to Model Pandemic Dengue?}

\section{- Pandemic Dengue Disease}

$>$ Dengue (Dengue Fever, Dengue Haemorrhagic Fever, Dengue Shock Syndrome)

$>$ Causal Vector Mosquito (Aedes aegypti) which has a survival limit in northern hemisphere till the Jan $10^{\circ} \mathrm{C}$ isotherm \& in southern hemisphere till the Jul $10^{\circ} \mathrm{C}$ isotherm

$>$ Tropical distribution

$>$ No vaccine available

$>$ Least explored complex disease dynamics due to tropical distribution

$>$ Four closely related DENV virus serotypes available

$>$ Special feature of ADE (Antibody-dependent enhancement) due to no cross protection against serotypes 


\section{anomalies of various climatic variables}

- Linear correlation coefficient between larval anomaly \& temperature anomaly is high \& positive for west Africa, Brazil, Argentina, central America, SE Asia, India \& East Asia whereas the same is low \& negative (value being in the range of $-\mathbf{0 . 3}$ to $-\mathbf{0 . 1}$ )

- Linear correlation coefficient between larval anomaly \& precipitation anomaly is high \& positive $(0.5$ to 0.7$)$ for Australia, west \& peninsular India, western \& southern region of Africa whereas the same for east Asia is negative \& low $(-0.3$ to -0.1$)$

- Linear correlation coefficient between larval anomaly $\&$ relative humidity anomaly is positive $\&$ low $(0.1$ to 0.3$)$ for Australia, SE Asia, India \& west Africa while the same is the highest value (0.7 to 1) for S. America

- Linear correlation coefficient between larval anomaly \& cloud cover anomaly is positive \& low (0.1 to 0.3) for Australia, India \& west \& south America

Source: Hopp, M.J. \& Foley, J.A. (2003): Worldwide fluctuations in dengue fever cases related to climate variability. Climate Research, 25, 85-94

- The mean development period (from egg to adult) is reduced by 2.1 days as the temperature is increased by 5 degree $\mathrm{C}$ from 20 to 25 degree $C$ while the same is reduced by 3.7 days as the temperature increased by 5 degree from 25 to 30 degree $\mathrm{C}$ for Aedes aegypti

Source: Surtees, G., Hill, M.N., \& Broadfoot, J. (2683c). Survival \& development of a tropical mosquito, Aedes aegypti, in Southern England. From Arbovirus Epidemiology Unit, Microbiological Research Establishment, Porton Down, Salisbury, England 
- The Adult Female Index (A.F.I.) is one main driver for Dengue transmission. But the AFI has a typical global pattern of change in various seasons

- In January, maximum AFI is found in some portion of Brazil, SE Asia, Northern Australia while the minimum AFI is found in Central African Sahel region, Lower Gangetic plain region of India

- In April, the maximum AFI is the same as the trend or pattern during the January

- In July, the maximum AFI is found in the whole of central \& east India, east Asia, SE Asia, a portion of Brazil whereas the minimum AFI is found in Northern Australia

Source: Hopp, M.J. \& Foley, J.A. (2003): Worldwide fluctuations in dengue fever cases related to climate variability. Climate Research, 25, 85-94

- In October, the maximum AFI is found in India, especially eastern part of the country India including peninsular portion, SE Asia \& portion of Brazil whereas the minimum AFI is found along the Gulf coast of North America \& east China coast 
Review: Ideal Pandemic Dengue Model Physics have Three Components

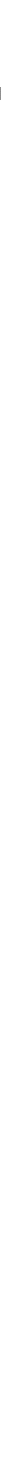



points on the map) from 1950 to 2010

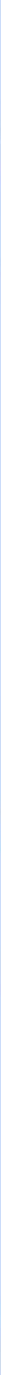


Socio-economic Component of Dengue Distribution: Population Density \& Urban

\section{Clusters}

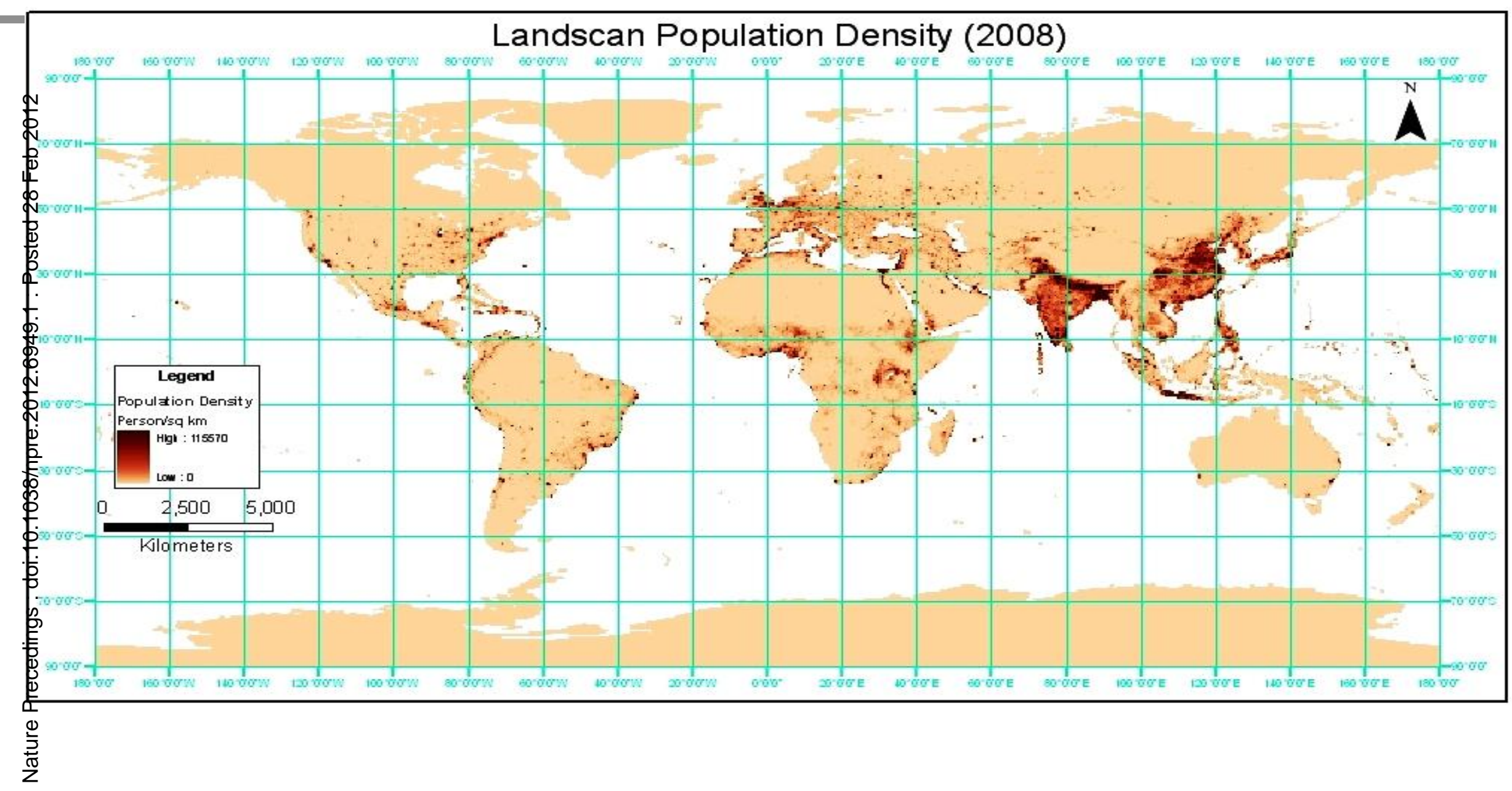




ẩ

בิ 


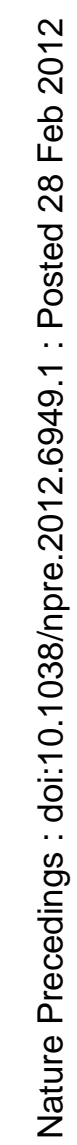

Why to chose the Doubling Of

Carbon Dioxide Scenario? 


\section{IPCC Scenario Dataset Selection}

- Scenario Data selected 1PTO2X (30b) for Thirty year averages

- Short term (2010-2039)

- Mid term (2040-2069)

- Long term (2070-2099)

- Non-SRES Scenario: 1PTO2X (1\% to double)

- Experiments run with greenhouse gasses increasing from pre-industrial levels at a rate of $1 \%$ per year until the concentration has doubled and held constant thereafter

- Model Name: ECHAM5/MPI-OM (max Plank Institute of Germany)

- Variables taken as input to Pandemic Dengue algorithm

- Precipitation flux

- Surface air temperature

- GDD computed from the air temperature 


\section{Future Scenario as par 1PTO2X for Short, Mid \& Long term}
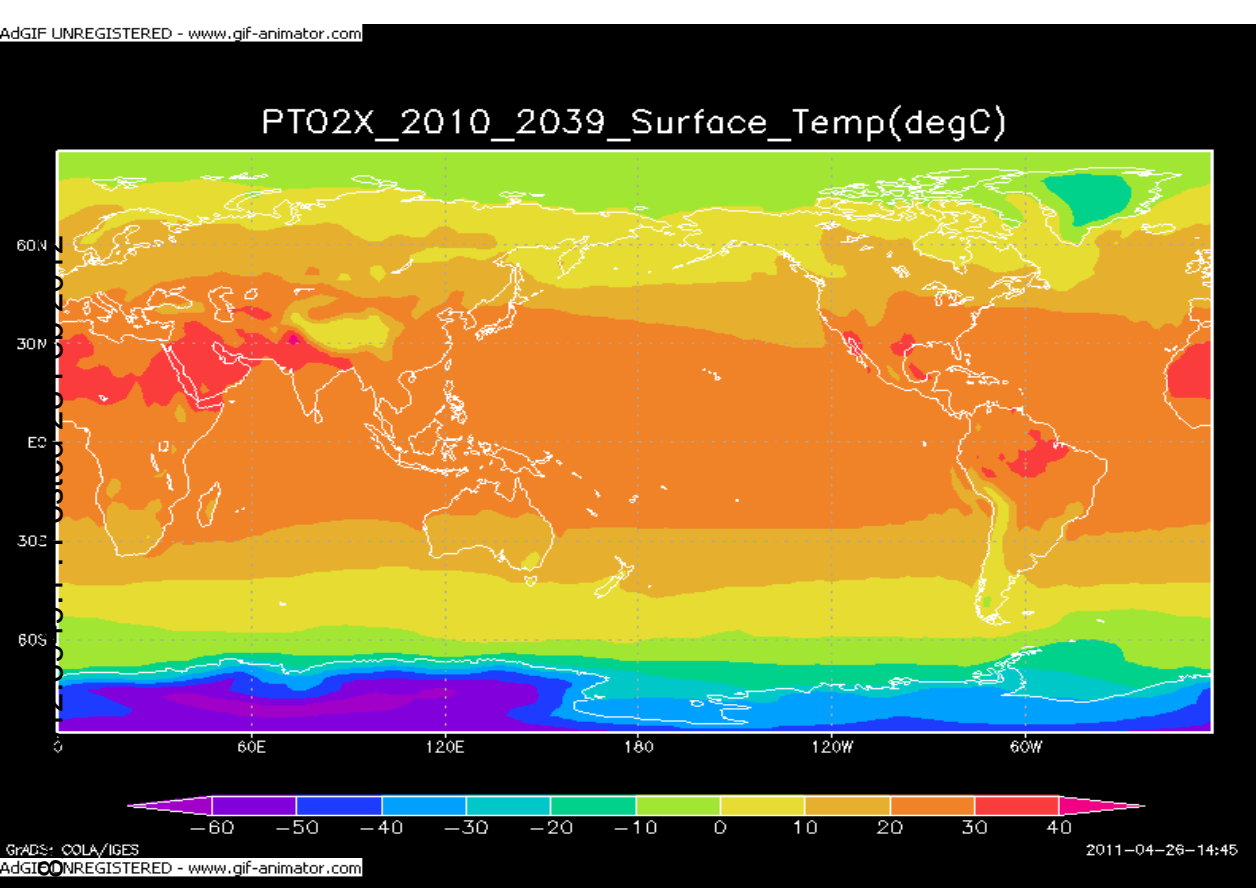

FTOO2X_2010_2039_Surface_Downwelling_Shortwave_Flux(W/sq.m)
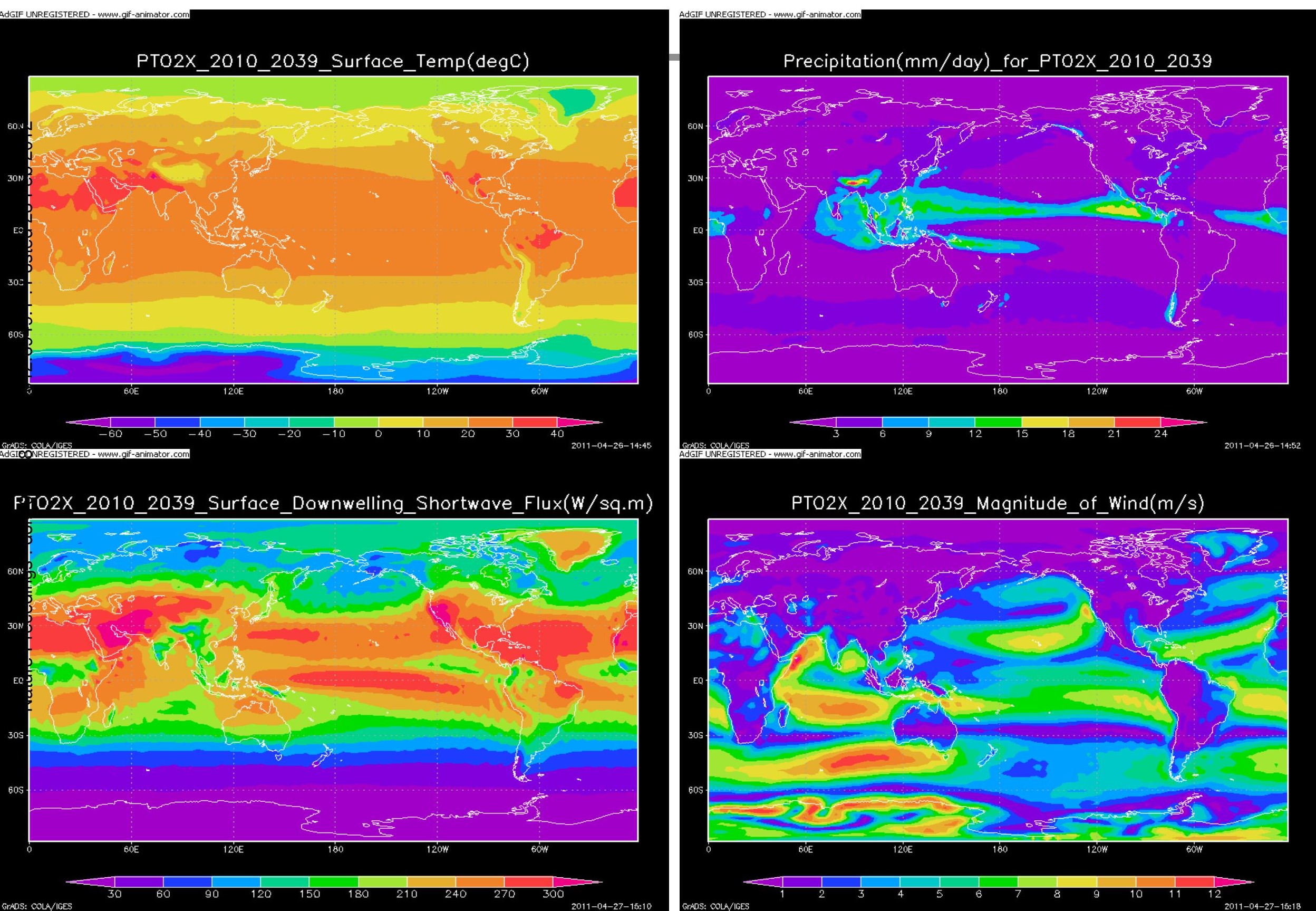


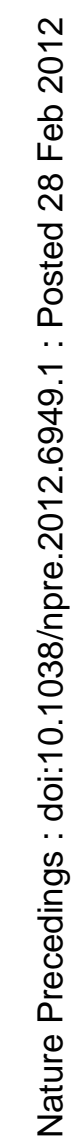

\section{Pandemic Dengue \\ Algorithm (Prototype)}




\section{Pandemic Dengue Algorithm (prototype)}

- The Pandemic dengue algorithm (prototype) is based on the Decision-hierarchy rules

- It is primarily based on the climatic variables embedded on the decision tree of the pandemic dengue disease causal vector Aedes aegypti

- The climate \& the vector interaction flow is an important factor for generating favourable disease condition

- The favourable climate for the continuation of the life-cycle of dengue causal vector Aedes aegypti has been analyzed through the decision tree

- Thus the output of the algorithm depicts the potential dengue favouring climatic condition \& the maximum likelihood of the potential disease spread in presence of the vector 


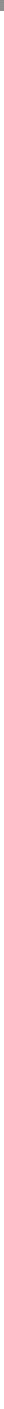




\section{Pandemic Dengue Algorithm (prototype)}

- Important Three phases of Dengue Mosquito Lifecycle

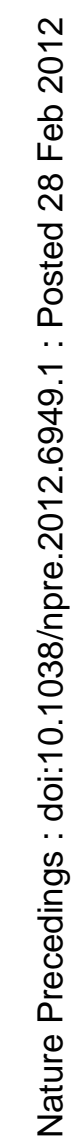

> Emergence (Adult or Gonotrophic)

> Oviposition (Egg Laying)

$>$ Hatching (Larva phase)

- Inputs to Pandemic Dengue Algorithm are

$>$ Temperature

$>$ Growing degree day

$>$ Precipitation 
Dataset used in Pandemic Dengue Algorithm:

- CRU Ts 3.0 dataset for

- Daily Mean Temperature

- Precipitation

- Growing degree day calculated from the daily mean temperature \& base temperature of phases of life cycle of Aedes aegypti

Phases of Lifecycle wise Pandemic Dengue Simulation

$>$ Emergence or Adult $(E)$

$>$ Oviposition or Egg Laying $(O)$

$>$ Hatching or Larva phase $(H)$

Algorithm made in GrADS script programming and run in OpenGrADS 


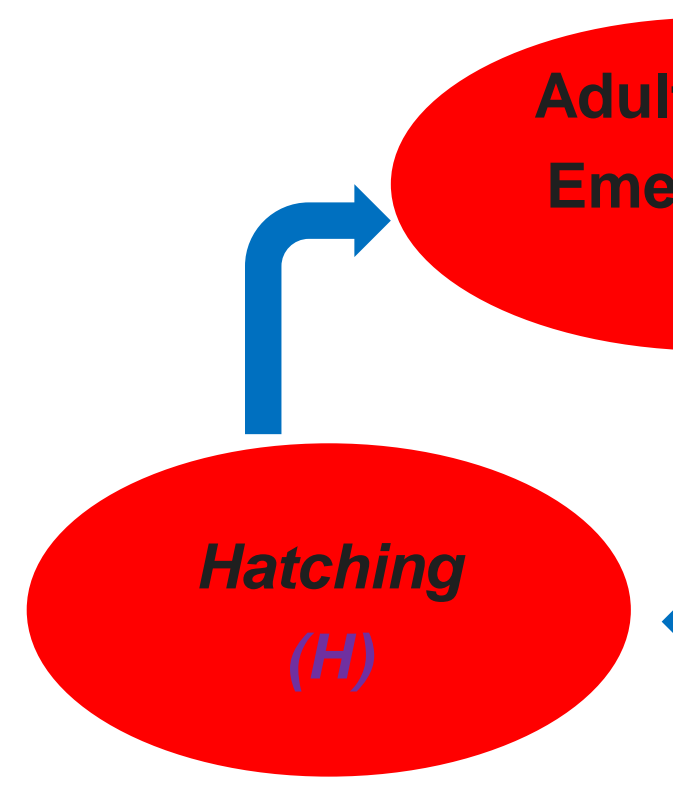

$\{\mathrm{H}+\mathrm{E}\}$

$\{\mathrm{E}+\mathrm{O}+\mathrm{H}\}$

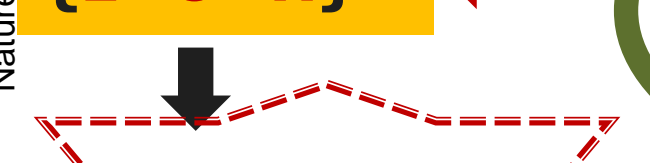

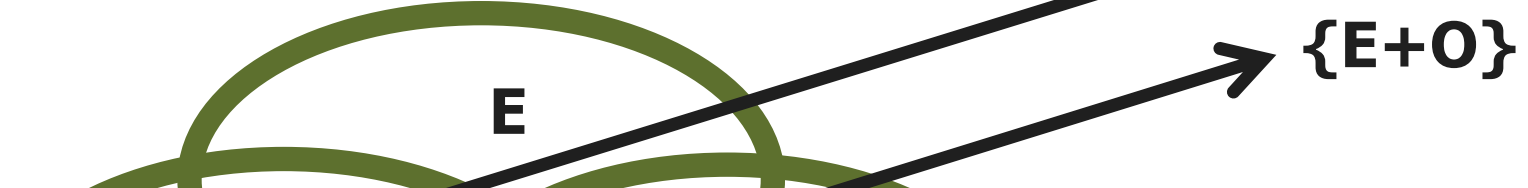

$==-$ Maximum Risk $y==0$ 
Matrix of Interaction between Climate \& Phases of Life-Cycle of Aedes aegypti as depicted in the algorithm

\begin{tabular}{|c|c|c|}
\hline Diagram & $\begin{array}{c}\text { Phases of } \\
\text { Aedes Life } \\
\text { Cycle }\end{array}$ & Status \\
\hline 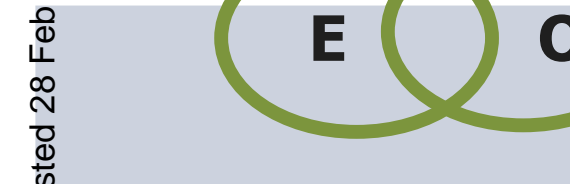 & $\begin{array}{l}\{\mathrm{E}+\mathrm{O}\}=\text { both } \\
\text { YES }\end{array}$ & $\begin{array}{l}\text { Favourable for Adult Emergence \& } \\
\text { Oviposition }\end{array}$ \\
\hline$\frac{0}{1}$ & $\{\mathrm{E}=\mathrm{Yes}, \mathrm{O}=\mathrm{No}\}$ & $\begin{array}{l}\text { Favourable for Adult Emergence but } \\
\text { not congenial for Oviposition }\end{array}$ \\
\hline 竞 & $\begin{array}{l}\{\mathrm{O}+\mathrm{H}\}=\text { both } \\
\text { YES }\end{array}$ & Favourable for Oviposition \& Hatching \\
\hline 离 & $\{\mathrm{O}=$ Yes, $\mathrm{H}=\mathrm{No}\}$ & $\begin{array}{l}\text { Favourable for Oviposition but not } \\
\text { congenial for Hatching }\end{array}$ \\
\hline 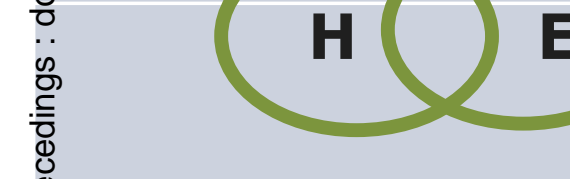 & $\begin{array}{l}\{\mathrm{H}+\mathrm{E}\}=\text { both } \\
\text { YES }\end{array}$ & $\begin{array}{l}\text { Favourable for Hatching \& Adult } \\
\text { Emergence }\end{array}$ \\
\hline 党 & $\{\mathrm{H}=\mathrm{Yes}, \mathrm{E}=\mathrm{No}\}$ & $\begin{array}{l}\text { Favourable for Hatching but not } \\
\text { congenial for Emergence }\end{array}$ \\
\hline & $\begin{array}{l}\{\mathrm{E}+\mathrm{O}+\mathrm{H}\}=\text { all } \\
\mathrm{YES}\end{array}$ & $\begin{array}{l}\text { Favourable for the whole lifecycle of } \\
\text { Aedes (Emergence, Oviposition \& } \\
\text { Hatching). These are the regions with } \\
\text { maximum risk }\end{array}$ \\
\hline
\end{tabular}


Validation: Pandemic Dengue Algorithm output Vs Observed Dengue Incidence for

\section{7}

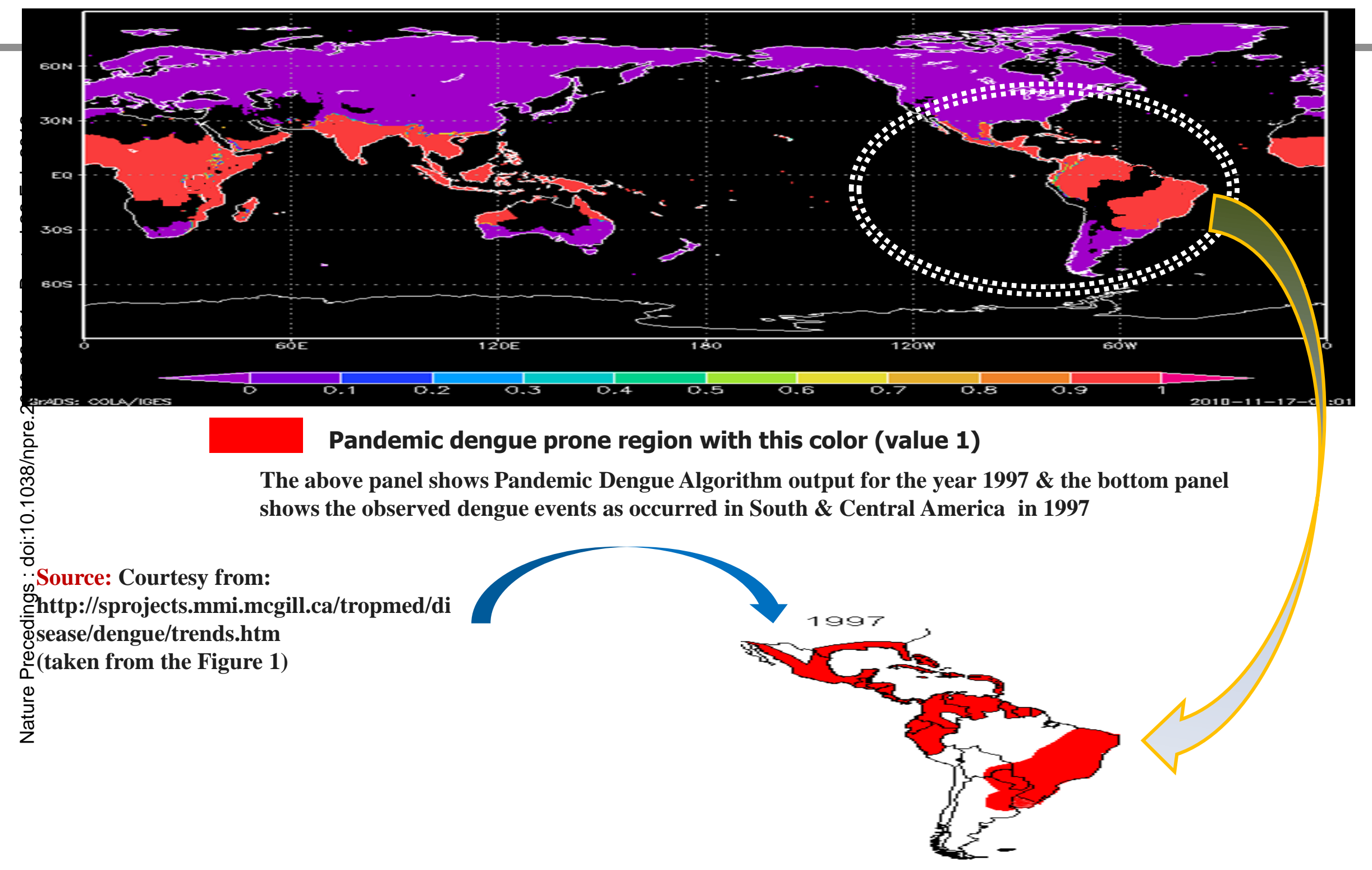




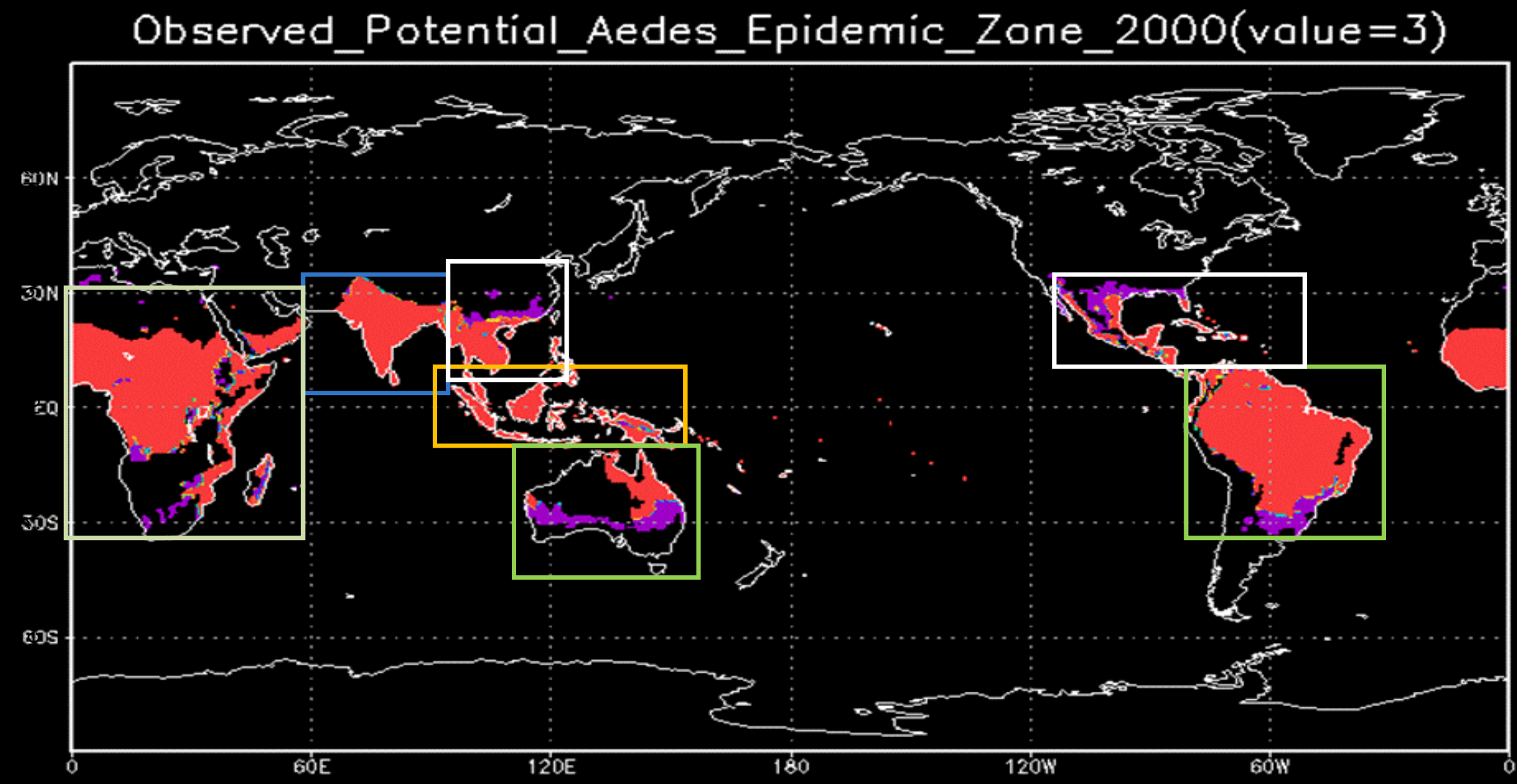

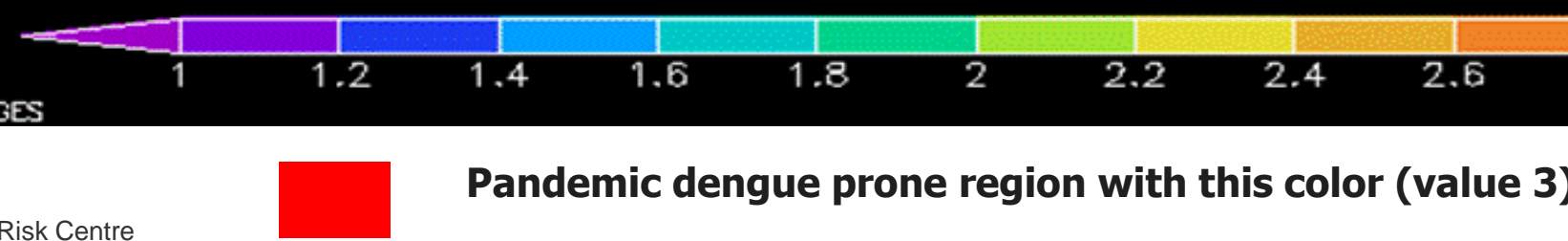


Validation: Pandemic dengue algorithm (prototype) Output (Favouring

\section{Climate), Aedes aegypti distribution \& Population Density}

Observed_Potential_Aedes_Epidemic_Zone_2000(value=3)

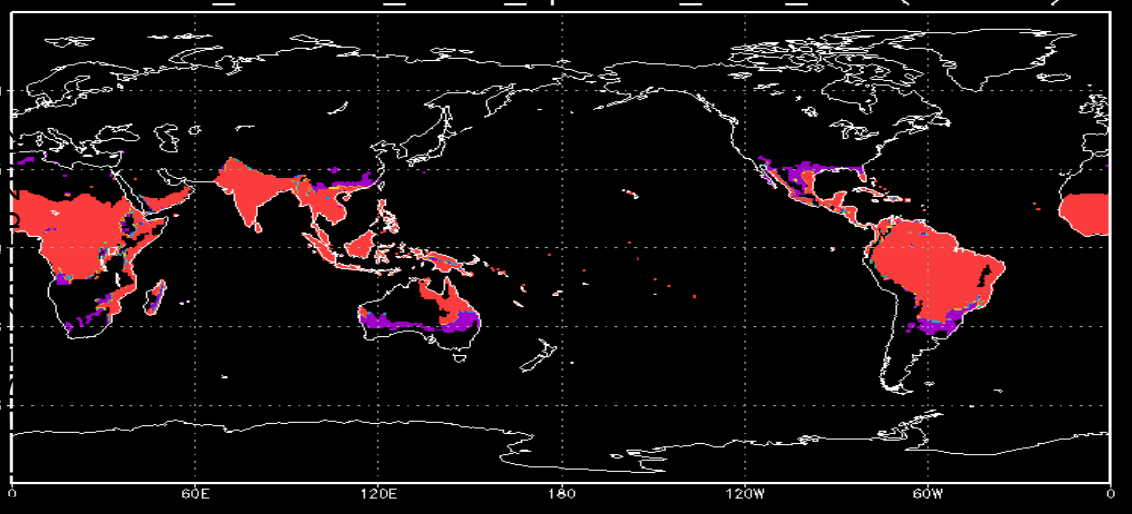

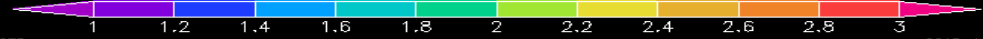

Potential_Aedes_Epidemic_Zone_2002(value=3)

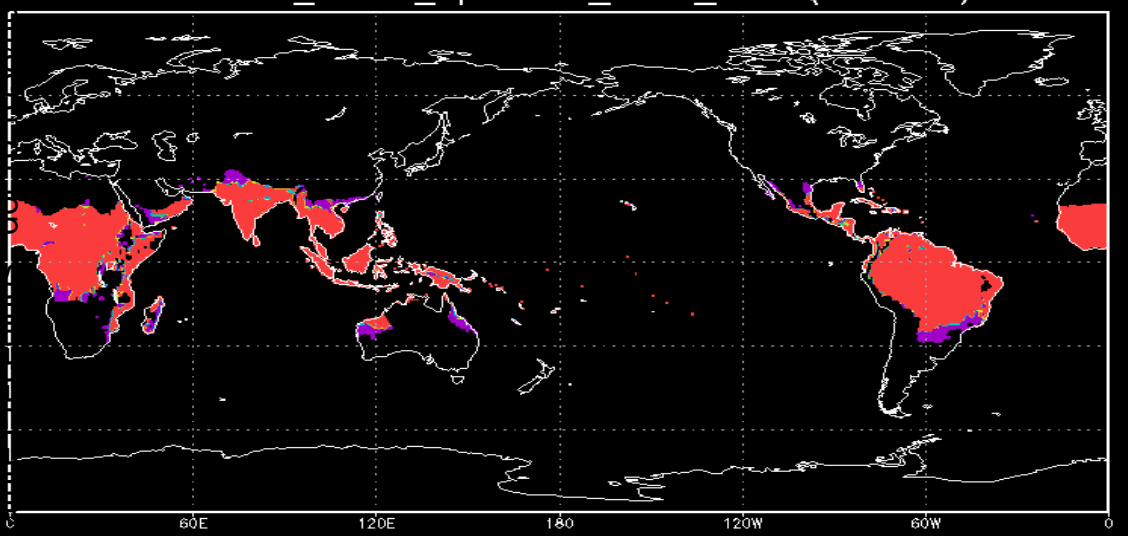

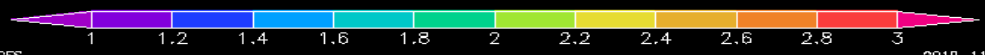

Pandemic dengue prone region with this color (value 3)
Potential_Aedes_Epidemic_Zone_2001(value=3)

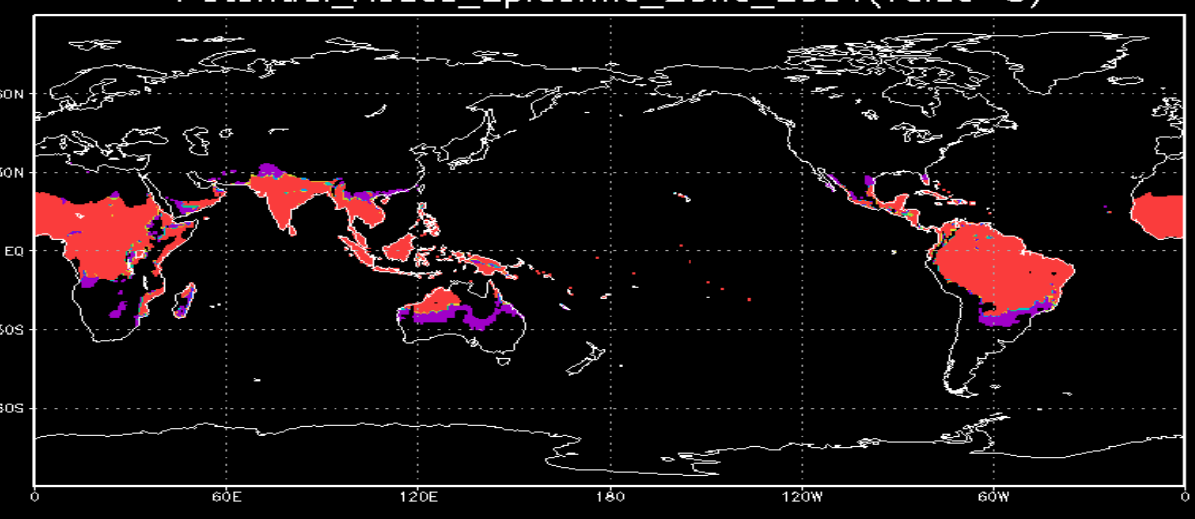

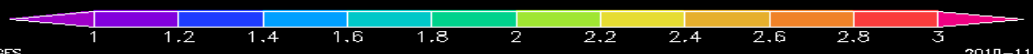

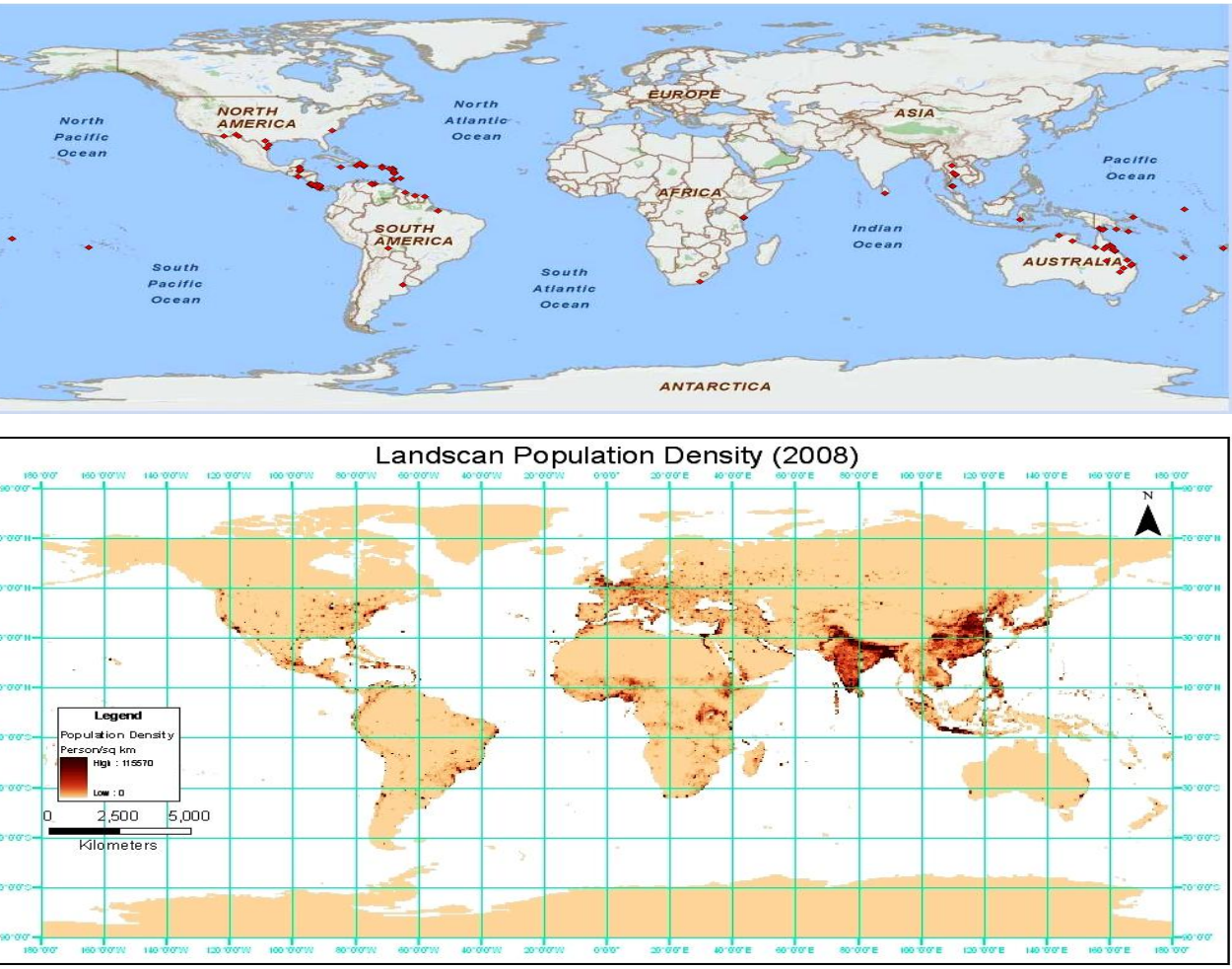




\section{Validation: Observed Dengue Epidemics}

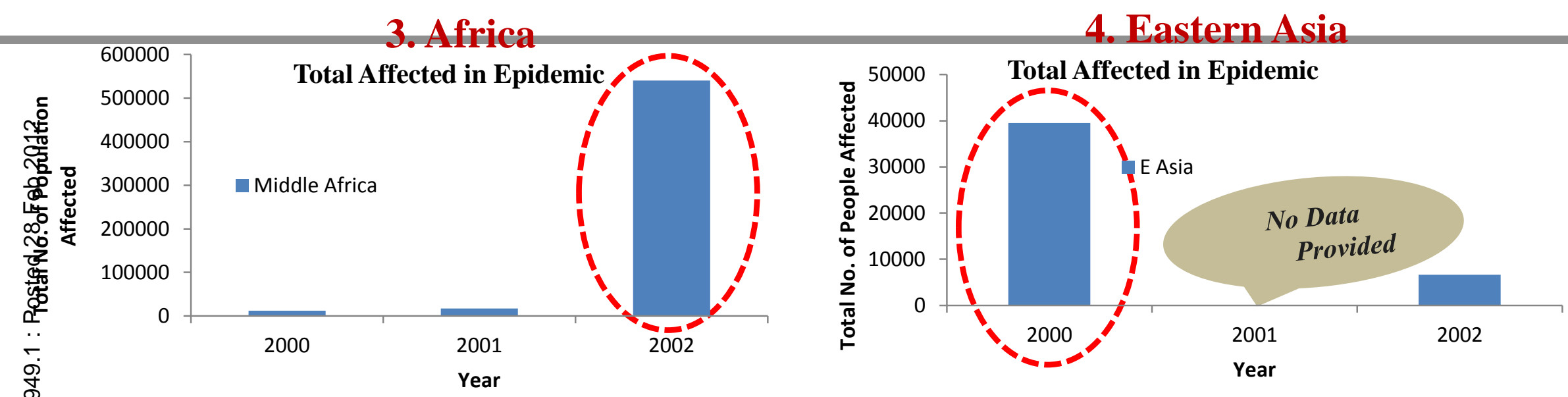

Source for 3. Africa \& 4. Eastern Asia: "EM-DAT: The OFDA/CRED

International Disaster Database

www.emdat.be - Université Catholique de Louvain - Brussels - Belgium"

* EM-DAT provides the estimate of total affected by Epidemics as a whole, not as a categorical Epidemics

Pandemic Dengue Algorithm outputs capture well the global dengue outbreak at macroscale for the year 1997, 2000, 2001, 2002. The algorithm outputs signify the prevalence of dengue favouring climatic condition whereas the observed dengue data are the result of complex interaction among Climate X Vector X Man. The similar trend of both the results also signify the impact of climate on pandemic dengue outbreak 


\section{Results: Pandemic dengue Simulation for Future Scenario}

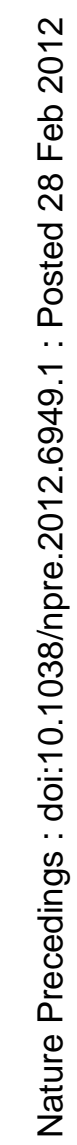

\section{Pandemic Dengue}

in

Future Scenario 


\section{Aedes_Adult_Emergence_PTO2X_2010_2039}

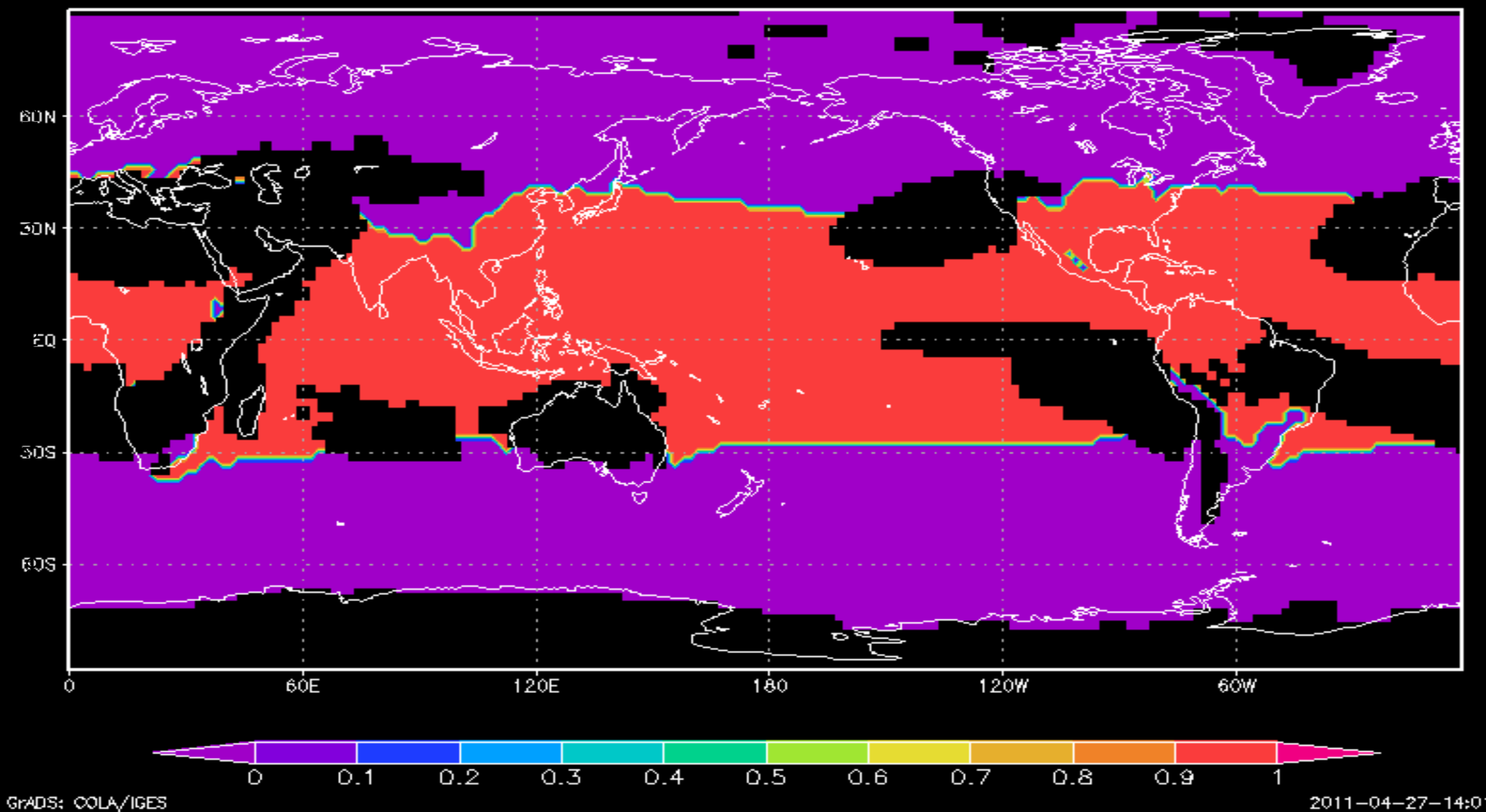




\section{Potential Dengue Outbreak in Future Scenario}

AdGIF UNREGISTERED - www.gif-animator.com

\section{Aedes_Outbreak_PTO2X_2010_2039}

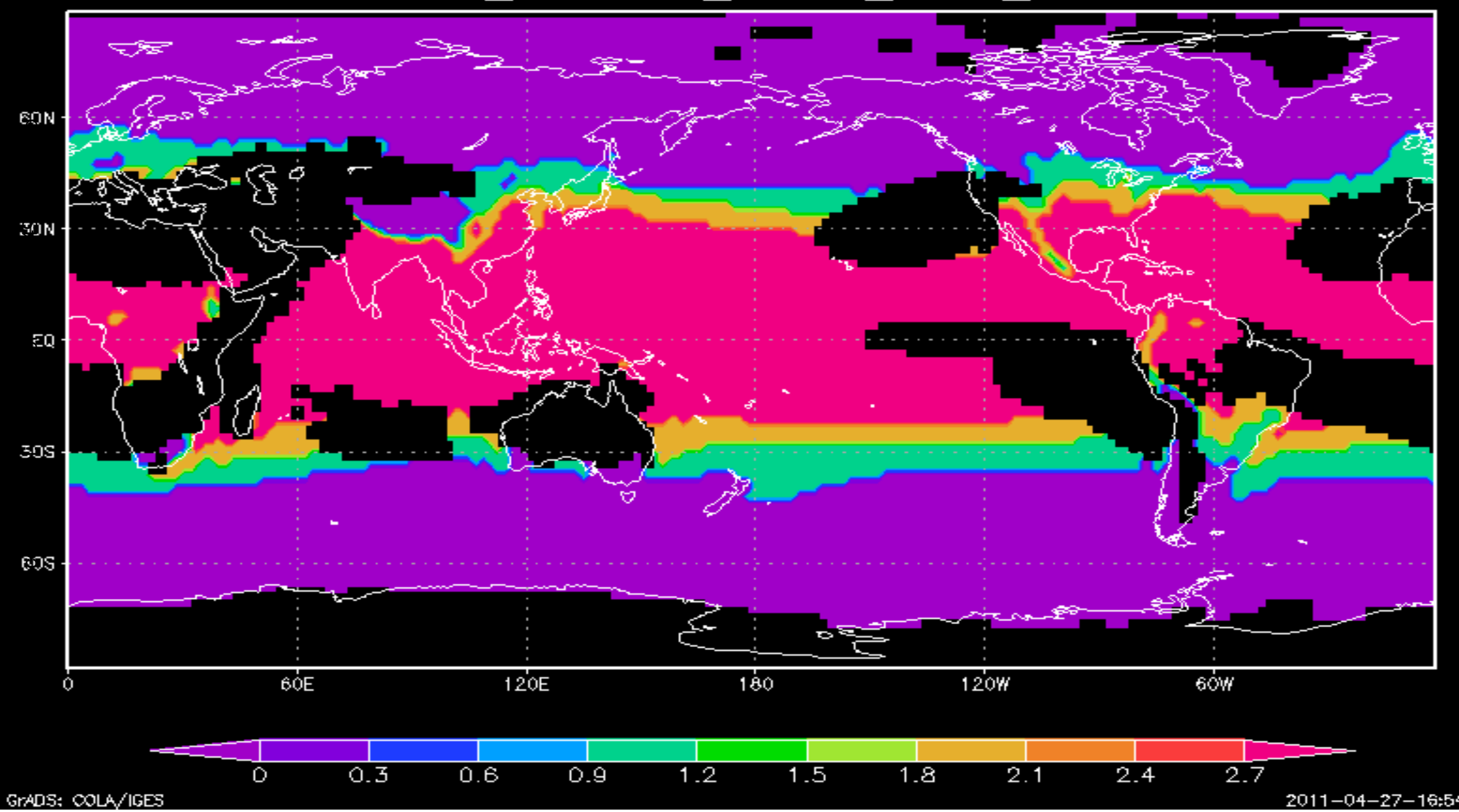




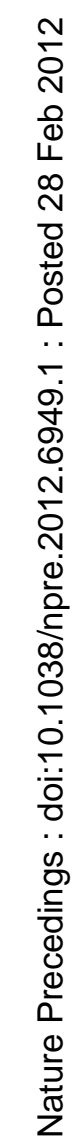

\section{Some}

Challenges Ahead! 
Problems: Lack of presence of uniform Entomological Indices \& its relation with climatic variables

Seasonal variation of Entomological Indices in Dengue affected villages in Vellore district of Tamil Nadu

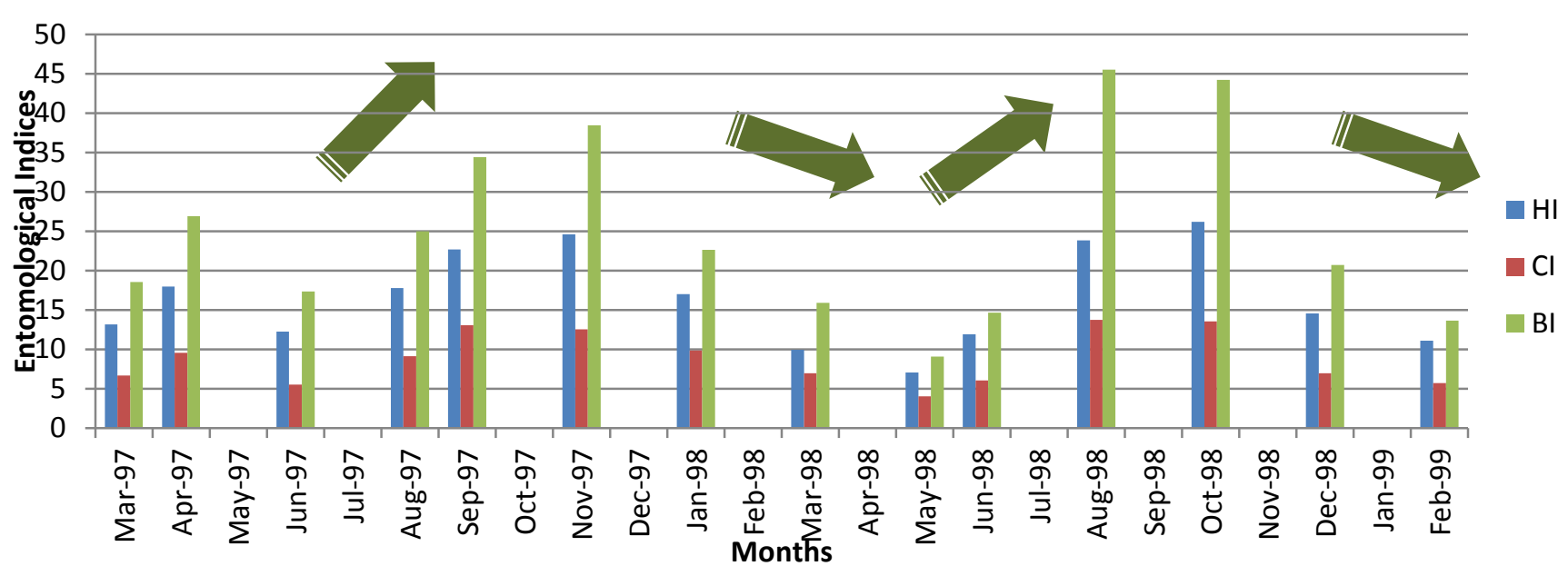

Source: Tewari et al., 2004 (http://onlinelibrary.wiley.com/doi/10.1111/j.13653156.2004.01103.x/full\#t1)

$>$ Yotopranoto et al., 2010: HI, CI, BI has a trend for Surabaya city, Indonesia follows January > March > May

HI: House Index

CI: Container Index

BI: Breteau Index 


\section{Interactions}

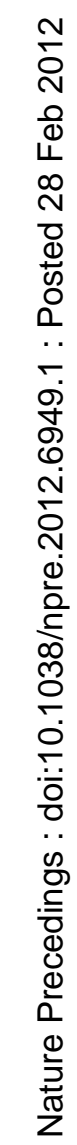

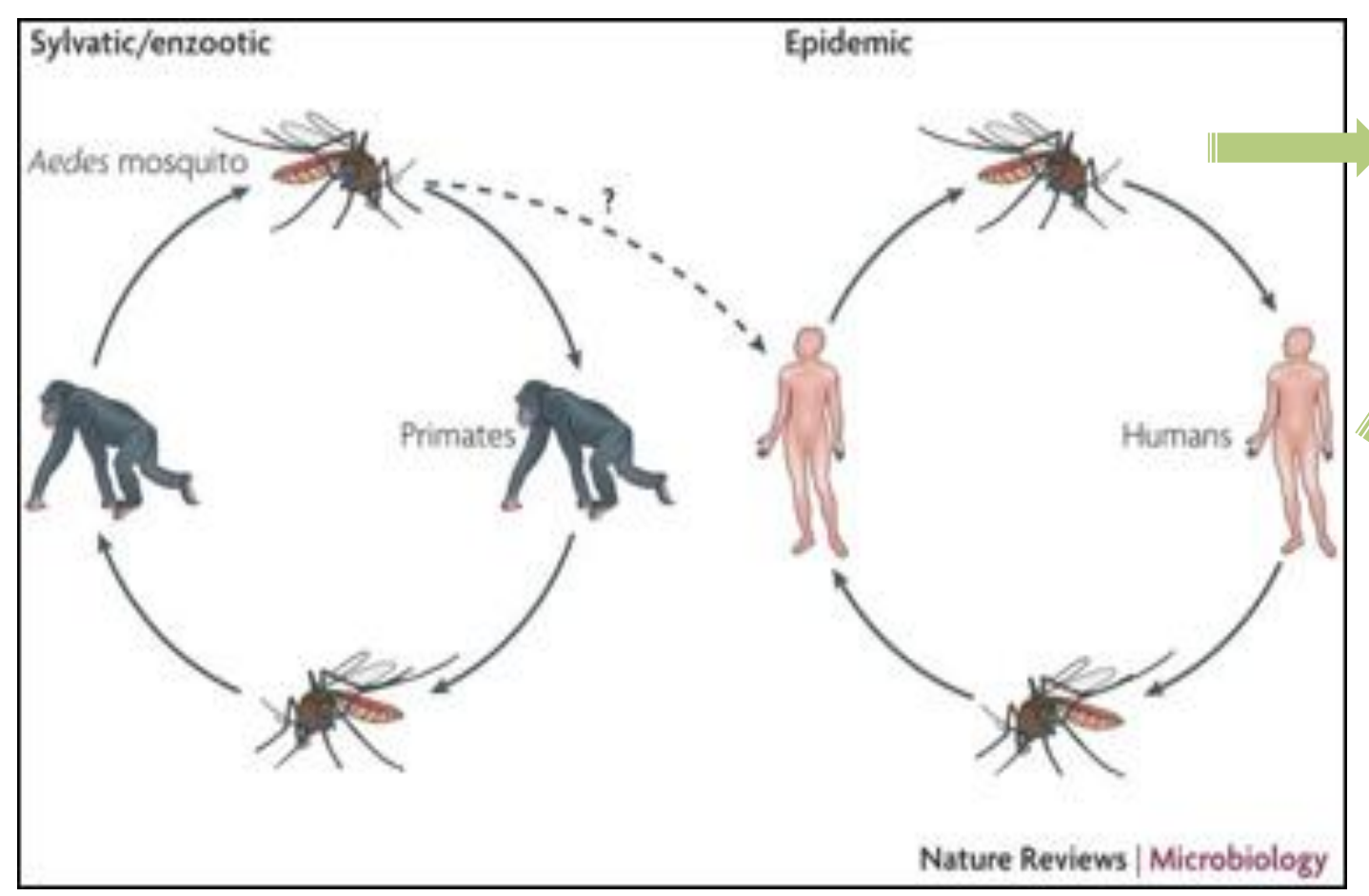

Source:

http://www.stanford.edu/group/parasites/ParaSites2008/Nkem_Cristina\%20Valdo inos/ugonabon_valdovinosc_dengueproposal.htm 
$>$ Lack of proper epidemiological dynamics of Dengue

$>$ Endemic Steady state

$$
R O X S=1 \quad \text { (where, } R 0=\text { basic reproduction }
$$
number of the infection, $S=$ Susceptible population)

If $R O<1 \rightarrow$ disease will die out $R O>1 \rightarrow$ disease will spread in population

$>$ If RO value increases much high it becomes Epidemic (local or regional) or Pandemic (global)

$>$ Possibility of development of Syndemic or Comorbid disease due to pandemic dengue \& other diseases (Yellow Fever Virus, Japanese Encephalitis) by the same vector in future 


\section{Looking towards Future}

- Understanding \& solving the puzzle of Macro to Micro Spatio-temporal integration of climate signal and its impact on local weather

- Macro to Micro integrated approach: May lead to decrease the uncertainty in climate prediction

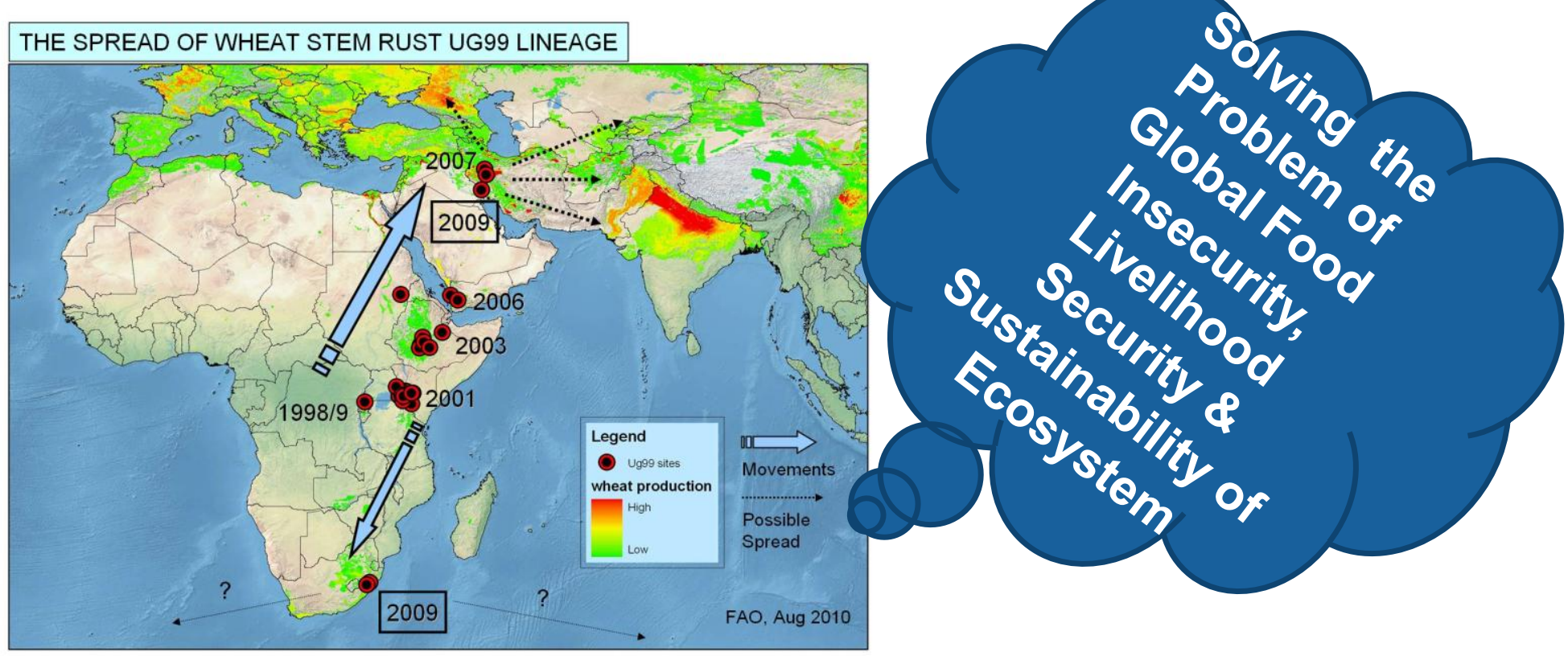




$$
\text { Itend }
$$

